\title{
Exogenous interferons for the prevention of respiratory viral infections: evaluation of different aspects in vitro
}

Citation for published version (APA):

Gulraiz, F. (2014). Exogenous interferons for the prevention of respiratory viral infections: evaluation of different aspects in vitro. [Doctoral Thesis, Maastricht University]. Maastricht University. https://doi.org/10.26481/dis.20140522fg

Document status and date:

Published: 01/01/2014

DOI:

$10.26481 /$ dis.20140522fg

Document Version:

Publisher's PDF, also known as Version of record

Please check the document version of this publication:

- A submitted manuscript is the version of the article upon submission and before peer-review. There can be important differences between the submitted version and the official published version of record.

People interested in the research are advised to contact the author for the final version of the publication, or visit the DOI to the publisher's website.

- The final author version and the galley proof are versions of the publication after peer review.

- The final published version features the final layout of the paper including the volume, issue and page numbers.

Link to publication

\footnotetext{
General rights rights.

- You may freely distribute the URL identifying the publication in the public portal. please follow below link for the End User Agreement:

www.umlib.nl/taverne-license

Take down policy

If you believe that this document breaches copyright please contact us at:

repository@maastrichtuniversity.nl

providing details and we will investigate your claim.
}

Copyright and moral rights for the publications made accessible in the public portal are retained by the authors and/or other copyright owners and it is a condition of accessing publications that users recognise and abide by the legal requirements associated with these

- Users may download and print one copy of any publication from the public portal for the purpose of private study or research.

- You may not further distribute the material or use it for any profit-making activity or commercial gain

If the publication is distributed under the terms of Article $25 \mathrm{fa}$ of the Dutch Copyright Act, indicated by the "Taverne" license above, 


\section{Exogenous interferons for the prevention of respiratory viral infections: Evaluation of different aspects in vitro}

Fahad Gulraiz 
(c) All rights reserved

ISBN nr: 978-90-817958-9-0

Cover design: Mayk Lucchesi

Printed by: Graphic Services, Facility Company azM

Financial support by Long Fonds for the printing of this thesis is gratefully acknowledged. 


\title{
Exogenous interferons for the prevention of respiratory viral infections: Evaluation of different aspects in vitro
}

\author{
DISSERTATION \\ to obtain the degree of Doctor at \\ Maastricht University, \\ on the authority of the Rector Magnificus, \\ Prof. dr. L.L.G. Soete \\ in accordance with the decision of the Board of Deans, \\ on Thursday 22 May 2014, at 14:00 hours \\ by
}

Fahad Gulraiz 


\section{Supervisor}

Prof. dr. C.A. Bruggeman

\section{Co-supervisor}

Dr. F.R.M Stassen

Assessment Committee

Prof. Dr. E.F.M Wouters (Chairman)

Prof. Dr. A. Bast

Dr. G.H. Koek

Dr. A.D. Kraneveld, Universiteit Utrecht

Prof. Dr. J. Neyts, Katholieke Universiteit Leuven 
Dedicated to my family 



\section{Contents}

Chapter 1 General Introduction and outline of the thesis

Chapter 2 Efficacy of IFN- $\lambda 1$ to Protect Human Airway Epithelial Cells against Human Rhinovirus $1 B$ Infection

Chapter 3 Effect of exogenous interferons on the inflammatory

63 and antiviral response of macrophages and A549 cells in mono and co-cultures

Chapter $4 \quad$ Exogenous interferon- $\beta$ provides protection against rhinovirus infection even in cigarette smoke extractexposed airway epithelial cells

Chapter 5 Haemophilus influenzae increases the susceptibility and 105 inflammatory response of airway epithelial cells to viral infections

Chapter 6 General Discussion \& Summary

Acknowledgements 



\section{CHAPTER 1}

General Introduction and outline of the thesis 


\section{General introduction}

\section{Preface}

The human lung has the largest epithelial surface in the body. This large surface is predominantly required to perform its basic function, which is the exchange of gases [1]. In order to perform this function, the adult human lung inhales about 11,000 liters of air every day. Besides normal air, contaminants and different microbes (e.g. viruses, bacteria, fungi, parasites and protozoa) may also be aspirated into lungs [2]. Luckily, in most cases the innate immune system of lung has the ability to clear the inhaled pathogens and noxious particles, and as such protects the lungs against diseases and maintains its respiratory function. However, when this defense system becomes impaired or even dysfunctional, pulmonary diseases may develop [1,3]. These pulmonary diseases can range from acute transient to chronic irreversible conditions.

Although the adoption of hygienic measures and the development of new drugs and vaccines have reduced the prevalence, respiratory infections caused by different microbes still impose a huge burden on the society in terms of disability, mortality and health care services. A significant proportion of these respiratory infections are caused by viruses. Usually these infections are benign in nature, but in patients with chronic respiratory conditions with a concomitant impaired (local) immune system they could become life threatening. For example, asthma and chronic obstructive pulmonary disease (COPD) are the two chronic respiratory conditions where viral infections are the most important cause of exacerbations, acute worsening of the symptoms, which could even lead to mortality. Thus, prevention of these respiratory infections in asthma and COPD is the need of the hour.

\subsection{Acute respiratory tract infections}

Acute respiratory tract infections (ARIs) are the most frequently encountered clinical syndrome for people to present for medical care and are still a matter of concern even in developed countries [2]. Among all classes of microorganisms which can infect the respiratory tract, bacteria and viruses are the most common infectious agents to cause ARIs. Conventionally, and depending on the anatomical region involved, ARIs are divided into two groups: acute upper respiratory tract infections (URTIs) and acute lower respiratory tract infections (LRTIS) [4]. 


\subsection{Upper Respiratory Tract Infections}

The upper respiratory tract includes the nose, sinuses, larynx and pharynx which are collectively called upper airways [5]. Infections associated with this part are common cold, rhinitis, influenza, laryngitis, sinusitis, pharyngitis, tonsillitis and otitis media. These infections are caused by different viruses and bacteria and are the major cause of illness, especially in children and older people [6-8]. Among ARIs, acute URTIs are the predominant reason to seek medical care. In United States alone, uncomplicated acute URTIs are responsible for 25 million visits to family physicians and about 20 million days of absence from work or school each year [9]. Fortunately, most URTIs are generally not life threatening [10]. They are usually mild, mainly caused by viruses and their symptoms resolve within three to ten days. A typical example of such an infection is a common cold, a very common benign and self-limiting disease $[9,10]$. Despite the fact that more than 200 different types of viruses and some bacteria can cause a common cold, human rhinovirus (HRV) are responsible for the majority of these cases [9,11-14]. Other viruses frequently implicated are coronaviruses, para-influenza virus (PIVs), respiratory syncytial virus (RSV) and adenoviruses [9,15]. Another highly contagious infection of the upper respiratory tract is seasonal influenza. Type-A, $-B$ and $-C$ influenza viruses are the causative agents and it can lead to significant morbidity and mortality, in particular among children less than two years of age or in people older than 65. Otherwise, usually patients recover within a week (World Health Organization. Influenza Seasonal 2009, http://www.who.int/mediacentre/ factsheets/fs211/en/index.html) [16,17]. Sinusitis and otitis media are two other important acute URTIs, which are caused by both viruses and bacteria. Also for these diseases, like common cold, rhinoviruses are mainly involved in the induction of these infections and the bacteria which are commonly implicated are Streptococcus pneumonia (S. pneumonia), Haemophilus influenza (H. influenzae) and Moraxella catarrhalis (M. catarrhalis) [18-22].

\subsection{Lower Respiratory Tract Infections}

The lower respiratory tract extends from the trachea through the branching bronchi to the terminal alveoli [23]. Acute infections, which encompass this part, are mainly responsible for acute bronchitis, acute exacerbations of chronic bronchitis and pneumonia. In outpatient settings, these are the most frequently diagnosed infections [24]. In contrast to URTIs, which are mainly responsible for morbidity, LRTIs are also associated with significant mortality and are the third 
leading cause of death all over the world (WHO 2008 updated 2011 http://www.who.int/mediacentre/factsheets/fs310/en/index.html). Although bacterial agents can also cause these LRTI, the majority of the cases are attributed to respiratory viruses, and in particular to influenza viruses [25]. Among these LRTIs, acute bronchitis is usually mild and self-limiting $[26,27]$. On the other hand, pneumonia is the most frequent reason of death of children in developing countries and of elderly in developed countries [28]. It is estimated that every year 1.2 million children under the age of five die due to pneumonia. The first and second most common causes of pneumonia in children are $S$. pneumoniae and $H$. influenza respectively. Among viruses, RSV is the major cause. (WHO 2012, http://www.who.int/mediacentre/factsheets/fs331/en/). S. pneumoniae and $H$. influenza are also the major cause of community acquired pneumonia (CAP) in adults. Other important bacteria associated with CAP are Legionella species and Chlamydia pneumonia (C. pneumonia)[29,30]. Among viruses, influenza viruses are the major cause of CAP in adults [31]. Other viruses which are frequently detected during lower ARIs in children and CAP in adults are PIVs, adenovirus and HRV $[28,32]$.

\subsection{Pulmonary immune systems}

Because of its anatomical nature, the epithelial surface of the lungs is permanently exposed to a variety of inhaled substances like environmental pollutants, cigarette smoke, pathogens or airborne allergens. In order to protect the lungs from these noxious agents and to maintain its proper functioning, complex defense systems have evolved over time. These defense mechanisms can be divided into the innate immune system, which provides immediate protection in a nonspecific manner, and the adaptive or acquired immune system, which provides late protection in a more specific manner. Nevertheless, both systems work in close concert to preserve proper functioning of the lungs. Both systems will be discussed in detail in the next paragraphs and a schematic overview is presented in figure 1.

\subsection{Innate/Nonspecific defense system}

As part of the non-specific defense system, immediate protection is provided by physical barriers. Among these, first are the anatomical barriers. Depending on the size of the inhaled particles, these barriers block their penetration into the lungs at different locations. Particles of more than $30 \mu \mathrm{m}$ are filtered by nasal hair 
(vibrissae). Those with a size between 10-30 $\mu \mathrm{m}$ are mostly captured in the nasal airways, turbinates and nasal septum [3,33]. Further downstream, where the large airways start branching, airflow is reduced and here most of the particles, having sizes of more than $2 \mu \mathrm{m}$, sediment due to gravity [34,35]. Thus, the particles which reach the alveoli are mostly less than $2 \mu \mathrm{m}$ of size.

The next barrier is the airway epithelium. Epithelial cells are attached to their neighbors by intercellular tight junctions, adherins junctions, gap junctions and desmosomes. As a result cells are separated into a basolateral and luminal side and thereby provide an impermeable barrier for microbes [36,37]. Apart from its function as a barrier, from trachea down to the bronchioles the airway epithelium is lined with airway surface liquid (ASL). ASL is composed of the outer mucous blanket and the inner low viscosity periciliary sol. About $90 \%$ of the particles and microbes which enter and precipitate into the airways are entrapped in the mucous blanket $[38,39]$. Then, due to coordinated movements of cilia present on epithelial cells, mucous is propelled towards the oral cavity, where it is either expectorated or swallowed $[3,33]$. Other reflexes like sneezing and coughing also help to remove mucous along with unwanted substances [34]. ASL not only helps to entrap and remove the foreign particles, it also contains different antimicrobial molecules. Examples of these molecules include lactoferrins, lysozyme, secretory leukocytes protease inhibitor, defensins and cathelicidins [40]. Altogether these molecules collaborate to inhibit microbial growth and ultimately kill the microbes.

However, if pathogens evade these defense systems, they finally encounter host cell membranes. Host immune cells recognize these pathogens by pattern recognition receptors (PRRs). PRRs have the ability to detect conserved molecular patterns; the so-called pathogen associated molecular patterns (PAMPs) present on the microorganisms [3]. Toll-like receptors (TLRs), type I transmembrane receptors, constitute the major family of PRRs. Until today, 10 functional TLRs in human and 12 in mouse have been identified [41]. TLR1, 2, 4, 5 and 6 are localized on the cell surface and largely recognize microbial membrane components [41,42]. Alternatively, other TLRs (TLR3, 7, 8 and 9) are expressed in the intracellular vesicles and are responsible for the detection of nucleic acids, mainly viral nucleic acids $[41,43]$. TLR3 recognize double stranded RNA (dsRNA), TLR 7 and 8 recognize single stranded RNA (ssRNA) and TLR9 recognize CpG DNA [44].

Upon recognition of ligands (PAMPs) by PRRs intracellular signaling starts which leads to a change in the expression of many different genes. This ultimately 
leads to the production of different cytokines and chemokines, which regulate the inflammatory and immune responses [34]. Besides leukocytes, epithelial cells, which also express most of the TLRs, play an important role in this context. They also express intracellular virus recognition receptors like retinoic acid-inducible gene 1 (RIG-1) and melanoma differentiation associated gene 5 (MDA-5). Similar to TLR3, 7, 8 and 9, RIG-1 and MDA-5 are the important sensors of viral RNA and play central role in the detection of viral infections [44]. Thus after activation of these receptors, cells start producing different cytokines, chemokines and other immune mediators which not only activate and recruit other immune cells to the site of infection, but also kill the pathogens $[3,36,39]$. Among these cytokines, interferons (IFNs), produced in direct response to viral infection, are central to the cellular defense against viral infections. Their role will be discussed in detail in the section "2.3 Antiviral defense".

Among the pulmonary innate immune cells, alveolar macrophages are the most prominent ones. They constitute about $95 \%$ of the airspace leukocytes. Lymphocytes comprise $\sim 1-4 \%$ of the total immune cell population and only about $1 \%$ are neutrophils [45]. Resident tissue macrophages are the most important phagocytic cells. In response to infection or injury, they ingest all the inhaled pathogens and other particulate matter or debris. They also produce different cytokines and chemokines which recruit other immune cells $[45,46]$.

Also present in the lungs are dendritic cells. As compared to macrophages, which are poor antigen presenting cells, dendritic cells (DCs) are specialized for this job. After ingestion, DCs process the antigen and present it to the lymphocytes and thus initiate the adaptive immune response.

Although under normal conditions only present in low amounts, following infection neutrophils are massively recruited to the lungs in response to IL- 8 and CXC chemokines, produced by macrophages and epithelial cells. Their main function is to phagocytose and kill the invading pathogen [46-48]. Mast cells are yet another important cell type which play an important role in the respiratory immune system. Along with the expression of different TLRs, they also express the receptor for IgE. Activation of mast cells upon binding of ligands to their receptors result in the production of different molecules that stimulate inflammation and can also polarize T-cells [46]. 


\subsection{Acquired/specific defense system}

The next line of defense after the non-specific/innate system is the adaptive/acquired defense system, which is directed against specific pathogens or molecules. For the initiation of this system, dendritic cells (DCs) play a central role. Two phenotypes of pulmonary DCs have been identified: conventional DCs (cDCs)/myeloid DCs (mDCs) and plasmacytoid DCs (pDCs) [49]. In lungs, immature cDCs are found in close contact with the epithelium starting from the nose down to the alveoli [50-52]. They form a tight network throughout the mucosa and in the alveoli and send their extended dendritic projections through the epithelial tight junctions into the airway lumen. Here they detect and take up the foreign antigens $[53,54]$. For this cDCs are equipped with a number of different receptors including TLRs [55]. With the help of these receptors they recognize and capture the antigens followed by a maturation process. During this process the expression of various chemokine receptors (CCR1, 2, 5 and 6) is down-regulated while the expression of CCR7 is up-regulated which drives migration of DCs to lymph nodes [56,57]. In the lymph nodes, DCs further mature into antigen presenting cells. Antigens are processed by two different pathways. In the endocytic pathway, antigens obtained from extracellular space are processed into small peptides. These peptides are then loaded on major histocompatibility complex ( $\mathrm{MHC}$ ) class II molecules. Alternatively, in the endogenous or classical pathway, intracellular antigenic peptides are processed and loaded onto MHC class I molecules. These antigen loaded MHC class I and II molecules are then recognized by $\mathrm{CD} 8^{+}$and $\mathrm{CD} 4^{+} \mathrm{T}$-cells, respectively, which along with other co-stimulatory molecules leads to $T$ cell stimulation, proliferation and activation. As a result of this, naive T-cells are activated and polarized into antigen specific T-effector phenotype [58-61]. Polarized and activated subsets of $\mathrm{CD}^{+}{ }^{+}$T-cells are T-helper 1 (Th1) and T-helper 2 (Th2) cells which constitute Th1 and Th2 responses respectively. Th1 response is characterized by the production of interferon gamma (IFN $\gamma$ ), interleukin-2 (IL-2), tumor necrosis factor alpha (TNF- $\alpha$ ) and granulocyte/macrophage colony-stimulating factor (GMCF) by Th1 cells. This response activates the alveolar macrophages to kill the intracellular pathogens. Also in the presence of Th1 cytokines, the interaction between DCs, Th1 cells and $\mathrm{CD}^{+}$T cells leads to the development of cytotoxic T-lymphocytes (CTL). These CTLs not only activate the macrophages but they also kill the infected cells themselves. On the other hand, production of IL-4, IL-5, IL-10 and IL-13 characterizes the Th2 response. These cytokines have anti-inflammatory properties and play an important role in tissue eosinophilia and antibody production [62,63]. 
Another type of T-cells is the regulatory $T$-cell $\left(T_{\text {reg }}\right) . T_{\text {reg }}$ cells express transcription factor forkhead box P3 (Foxp3) and most of them are CD4 ${ }^{+} \mathrm{T}$ cells which also express IL-2 receptor- $\alpha$ chain (CD25). They naturally develop in the thymus but can also be induced in peripheral tissues. These cells control the immune responses by suppressing the effector function of different immune cells. Moreover, they suppress their activation and proliferation $\left(\mathrm{CD} 4^{+}, \mathrm{CD} 8^{+} \mathrm{T}\right.$ cells, antigen presenting cells, B cells etc.) thereby dampening the immune response which prevents tissue damage because of an exaggerated inflammatory reaction [64]. In contrast to cDCs, pDCs are poor antigen presenting cells. Also cDCs and pDC differ in their expression of TLRs. TLR7 and TLR9 are strongly expressed by pDCs while TLR2/3/4/5 are not expressed by pDCs. Due to this differential expression of TLRs, cDCs recognize bacterial products more efficiently while pDCs are predominantly equipped for the recognition of viral RNA/DNA and methylated DNA (CpG motifs). Upon viral infection pDCs produce large amounts of type-1 interferons, which induce a strong antiviral response and limit the viral replication. Also they migrate to lymph nodes where they promote the Th1 response by secreting Type- 1 interferons $[55,65]$.

\subsection{Antiviral defense}

As discussed above, a large proportion of upper and lower respiratory tract infections are caused by viruses. To fight against viral infections, cells are equipped with different PRRs which immediately detect viral PAMPs and activate antiviral defense mechanisms. Detection of viral PAMPs via different PRRs results in the activation of different antiviral signaling pathways which culminate in the downstream activation of common transcription factors like interferon regulatory factor 3 (IRF3), nuclear factor kappa B (NFkB) and activator protein 1 (AP1) [66]. Activated transcription factors are then translocated to the nucleus where they start the transcription of IFN genes, which finally leads to the production and release of IFNs by cells $[66,67]$. Three different types of IFNs have been identified so far: type-I IFNs (IFN $\alpha / \beta)$, type-II IFN (IFN- $\gamma$ ) and type-III IFNs (IFN- $\lambda 1,-\lambda 2$ and $\lambda 3)$. Although all three types have antiviral properties, type-I and type-III are the IFNs which are predominantly produced in direct response to viral infections $[68,69]$. Once released type-I and type-III IFNs then bind to their specific receptors in an auto- or paracrine fashion, thereby activating intracellular signaling pathways which leads to the transcriptional induction of interferon stimulated genes (ISGs) $[67,70]$. Proteins encoded by these ISGs finally exert the antiviral effects through 
different mechanisms including interference with translation, degradation of RNA and interference with virus assembly and release [67]. Intriguingly, and in contrast to the type I IFNs, not all cell types respond to type-III IFNs. The main reason for this difference is that expression of receptors for type-III IFNs is limited to few types of cells (predominantly epithelial cells)in contrast to the ubiquitous expression of receptors for type-I IFNs $[66,67,71]$. Because of this cell type specific expression, it has been suggested that type-III IFN might be better suited for treatment of viral infections e.g. of the respiratory tract. However, clinical data are lacking and experimental data are scarce.

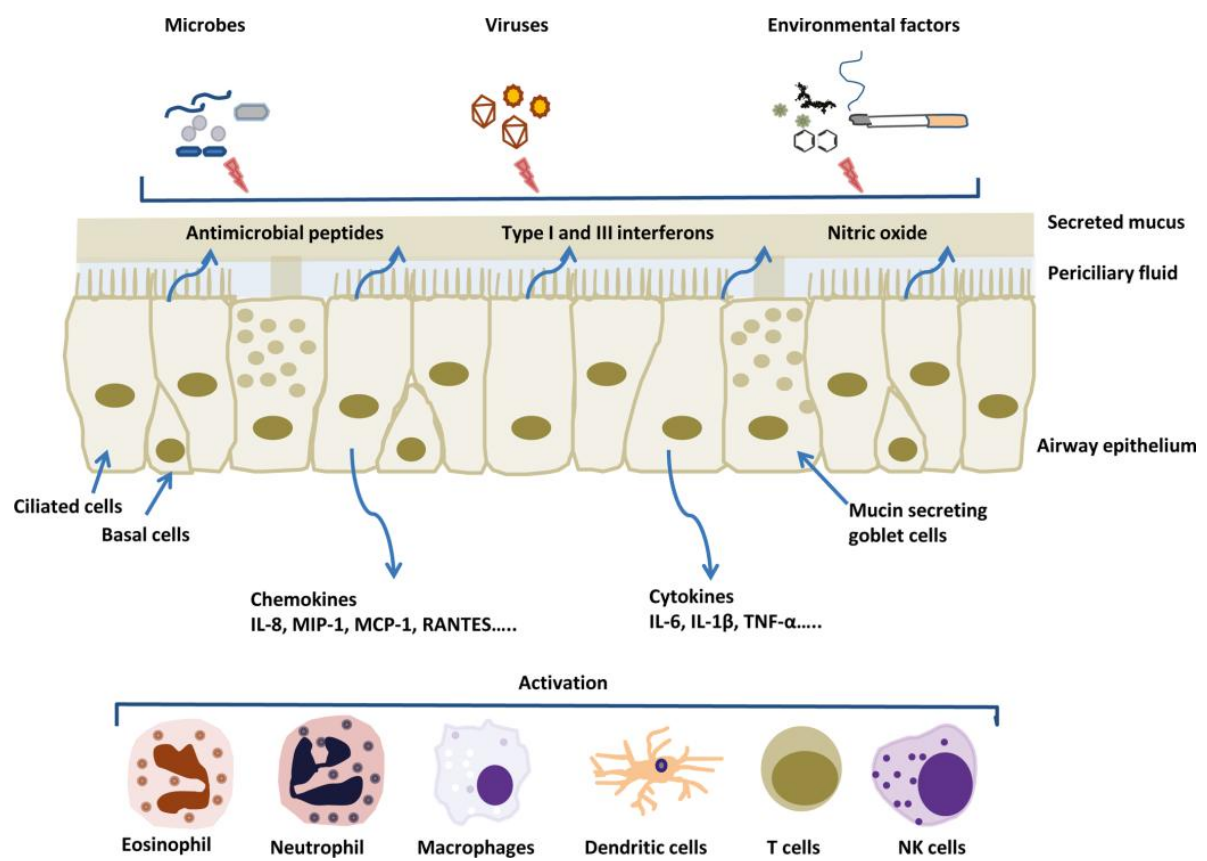

Figure-1. Schematic representation of defense system of healthy airways: Airway epithelium is the first line of defense against foreign insults. Layer of epithelial cells connected with tight junctions act as a barrier. Secreted mucus layer not only trap the foreign particles but also contain different antimicrobial peptides which kill the microorganisms. In response to foreign insults, epithelial cells produce cytokines, chemokines and other important immune mediators which not only produce direct lethal effects on microorgamisms but also recruit other immune cells and activate the adaptive immune system.

Along with their direct antiviral properties, both type-I and type-III IFNs also have immunodulating properties $[44,68,72]$. Although the immunoregulatory properties of type-III IFNs are less extensively studied as compared to type-I IFNs, overlap between the two has been observed. For example both type-I and type-III 
IFNs increase natural killer cells and T cell toxicity $[73,74]$, both promote Th1 responses [74,75], both upregulate the MHC class I molecules expression [76-78] and both mediate cell apoptosis [79-81]. On the other hand type-II IFN- $\gamma$ is produce mainly by mitogen activated natural killer, natural killer T cells and by Th1 cells [82] and plays important roles e.g. in innate immune response against intracellular infections and the regulation of adaptive immune response [83].

\subsection{Chronic respiratory diseases}

Among chronic diseases, those affecting the respiratory tract are the third leading cause of death [84]. Over one billion people suffer from chronic respiratory diseases (CRD) and more than half of them live in low and middle income countries [85]. Every year, more than 4 million people die from CRDs [86]. Among the most prevalent CRDs are chronic obstructive pulmonary disease (COPD) and asthma. Another important genetic disorder, in which chronic infections and ongoing inflammation are commonly seen, is cystic fibrosis (CF) [87].

Defense systems of healthy lungs usually resolve infections efficiently and preserve the normal lung functioning. However, in the presence of CRDs respiratory infections occur more with more severity. Apart from other mechanisms which can account for increased severity, it has also been demonstrated that respiratory defense systems in CRDs may not function properly [88-91]. Infections then can lead to an acute worsening of the symptoms called acute exacerbations (AE). Management of AEs is the major problem in CRDs. AEs not only accelerate the progression of the disease but are also the major cause of decline in lung function, morbidity and mortality in CRDs. Because of the enormous impact of exacerbations, not only on patients but on the community in general, prevention of exacerbations in above mentioned CRDs is a major goal of current scientific research. The role of respiratory infections and immune modulation in the induction of exacerbations will be discussed in the following sections.

\subsection{Chronic obstructive pulmonary disease}

COPD, which is characterized by irreversible airflow obstructions, is the most common chronic respiratory condition in adults [92]. Worldwide, more than 200 million people are affected. COPD is the fourth leading cause of death and its prevalence is expected to increase further [93-95]. Different mechanisms have been implicated in the development of disease. Among these, tobacco smoking is 
considered to be the primary underlying risk factor for the disease. Burning of biomass fuels, which is a major source of indoor pollution in developing countries, is also associated with the development of the disease [96]. Yet, susceptibility to the disease varies between individuals. Though it also depends on the amount and duration of smoking, not all smokers develop the disease. This suggests that genetic factors might also be involved. [97]. Genetic defects resulting in deficiency of $\alpha 1$-antitrypsin (inhibitor of neutrophil elastase) and ultimately the development of emphysema have also been identified as important causes of the disease. Also, oxidative stress and imbalance between proteinases and anti-proteinases results in increased airway inflammation [98-100]. Moreover, age-related changes and autoimmunity have been proposed in the progressive course of the disease $[101,102]$. Importantly, the central aspect within all these mechanisms is the exaggerated chronic inflammation mostly likely in combination with host genetic susceptibility.

In the management of COPD, AEs are the major problem and are associated with significant morbidity and mortality. It has been shown that AEs are a strong predictor of subsequent mortality in COPD patients, especially in patients who suffer from three to four exacerbations in a year with hospitalization $[103,104]$. In addition, AEs also significantly increase the economic burden due to extra healthcare visits, treatments and hospitalizations [105].

Although different factors are associated with the induction of AEs in COPD, respiratory infections caused by bacteria and viruses, are implicated in the majority of these AEs. $[106,107]$. About $50 \%$ of these AEs are attributed to bacterial infections and the most frequently isolated bacterial species is $H$. influenzae. Other commonly isolated species include $M$. catarrhalis, S. pneumoniae, and also Pseudomonas aeruginosa (P. aeruginosa) [108]. Moreover, the lower respiratory tract of COPD patients is frequently colonized by bacteria. An association between bacterial load and induction of $\mathrm{AEs}$ has been proposed, although there are significant discrepancies between reports [106,109-112]. On the other hand, acquisition of new bacterial strains has been strongly associated with the induction of AEs in COPD. However, along with the pathogenic ability of newly acquired strains, modulation of immune mechanisms also plays an important role in the pathogenesis of AEs [108,113,114].

The relative contribution of viruses in the induction of COPD AEs is still debated. Earlier, due to lack of sensitive diagnostic tools, only $10-20 \%$ of COPD AEs were associated with viral infections. Nevertheless, due to the development of 
more sensitive PCR-based diagnostic tools, rate of detection of viruses in COPD AEs has been increased significantly. As a result of this up to $60 \%$ of COPD AEs have been reported to be virus-induced [106-108,110,115]. In these virus-induced AEs human rhinoviruses (HRVs) are most commonly isolated. Other frequently isolated viruses are (para-)influenza viruses, respiratory syncytial virus (RSV), corona viruses, adenovirus and human metapneumovirus [116]. Apart from just the detection of viruses in COPD AEs, a direct correlation between viral infection and development of symptoms of AEs has also been shown. In an experimental HRV infection study in COPD patients, Mallia and colleagues observed the development of typical lower respiratory symptoms of $A E$. This strongly suggests that viral infections have a causative role in the induction of AEs [117].

Apart from the fact that both viral and bacterial agents can independently induce AEs, virus-bacterial co-infections have also been linked to the induction of COPD AEs [109]. Notably infection with either a virus or a bacterium can facilitate the subsequent infection with the other microbe $[118,119]$. These AEs induced by co-infections are usually more severe and often result in longer hospital stays $[106,109]$.

\subsection{Impairment of immune system in COPD}

In COPD, different abnormalities in the respiratory immune mechanisms have been reported which enhance the susceptibility to infections [92,108]. Cigarette smoking, which is the major risk factor for the development of disease, has deleterious effects on the defense system of lungs [120]. Smoking leads to excessive production and impaired clearance of mucus. This happens because of mucous cell hyperplasia, replacement of differentiated ciliated cells and secretory cells with squamous cells [121-123]. These effects are accompanied with loss of Clara cells, resulting in lower production of host defense factors like surfactant proteins [124]. Furthermore, cigarette smoke increases the permeability of epithelium and impairs the junction barrier formation through down-regulation of a broad transcriptional program and thereby impairing the antimicrobial defense in COPD smokers [125-127].

The function of important airway immune cells like alveolar macrophages (AM), DCs, neutrophils and natural killer cells seems impaired in COPD. In smokers and COPD patients the number of AM and neutrophils is augmented. Increased numbers of AMs is correlated with the airway obstruction and severity of disease [128]. Alternatively in COPD smokers, impaired functioning of AMs seems to play 
an important role in suppression of host defense. For example, reduced phagocytic activity, inactivation of $\mathrm{M} 1$ polarization and activation of subtypes of $\mathrm{M} 2$ polarization and suppression of innate immune genes like CXCL9, CXCL11, CCL5 have been observed in COPD $[89,129]$. Due to suppressed M1 polarization, The numbers of IFN- $\gamma$ producing $T$ cells are reduced whereas the amount of CD4+CD25+ regulatory $T$ cells is increased which could maintain the immunosuppressive environment [130,131]. Similarly, neutrophil-derived elastase could lead to emphysematous destruction of lung tissue [132]. Furthermore, although neutrophils from COPD patients migrate faster, their accuracy seems impaired suggesting that they may have become more harmful than beneficial [133]. On the other hand, the number of mature DCs is significantly reduced in COPD, while marked depression in activity of NK cells has been observed in smokers and COPD smokers [134-137].

Previously it has been suggested that cigarette smoking in particular enhances the susceptibility to viral infections of respiratory tract $[138,139]$. In vitro studies have shown that cigarette smoke not only impairs the production of IFNs but also affects intracellular signaling induced by IFNs [140,141]. Similarly, ex vivo rhinovirus infection of cells, derived by bronchoalveolar lavage from COPD patients, showed deficient induction of IFN- $\beta$, IFN- $\alpha$ and IFN- $\lambda$ [117]. Moreover, when COPD mice were infected with rhinovirus they also showed deficient production of IFN- $\alpha$, $-\beta$ and $-\gamma$ as compared to controls [142]. In contrast, infection of epithelial cells from COPD and controls with HRV showed no difference in interferon production. Yet, higher viral loads and increased production of inflammatory mediators was observed in cells from COPD patients than controls, indicating that antiviral defense in COPD patients is compromised [143].

\subsection{Asthma}

Asthma is a chronic respiratory condition of airways, which is characterized by airway hyper-responsiveness (AHR) and reversible airflow obstruction [144,145]. Worldwide, about 300 million people are estimated to have asthma and the incidence is expected to increase further in coming years. Every year, about 250,000 deaths are attributed to asthma. Also, it accounts for $1 \%$ of the total global disease burden (Global Initiative for asthma (GINA) Global strategy for asthma management and prevention (updated 2012, www.ginasthma.org). Asthma AEs, like in COPD, inflict a significant social and economic burden. Costs of treating asthma patients with AEs have been shown to be three and half times higher than 
treating patients without AEs [146]. Even for patients who do not require hospital admissions, significant costs are still incurred just because of visits to the hospital emergency departments [147].

Risk factors for the development of asthma involve complex interaction of host and heterogeneous environmental factors. Among the host factors, the most important ones are genetic factors. Asthma is a complex heritable disorder and many candidate genes have been identified which can influence the development of asthma $[148,149]$. Obesity and sex are the other host-related factors. Obesity increases the susceptibility for the development of asthma. Similarly, the prevalence of asthma is more in males than in females during childhood, while among adults females are at a higher risk than males. [150-153]. Different environmental factors can contribute to the development of asthma. Particularly, in children risk factors are persistent sensitization to allergens [154,155], viral infections [156,157], bacterial colonization [158], prenatal and post-natal smoking and exposure to other pollutants in early childhood $[159,160]$. Factors associated with inception of asthma in adults are less clear as compared to childhood-onset asthma. Yet, asthma related to irritant exposure in the work place, which is called occupational asthma, is more frequently observed in adults. Other factors could be cigarette smoking, upper airway diseases, paracetamol and aspirin intake and respiratory infections [161].

Similar to COPD, main triggers of AEs in asthma are respiratory infections. However, in contrast to COPD, where both bacterial and viral infections have more or less equal share in the induction of AEs, asthma AEs are mainly associated with viral infections. Along with a strong involvement of viruses in the development of asthma, they are also detected in approximately $80-85 \%$ of AEs in children and in more than $60 \%$ of AEs in adults [162-164]. Most commonly isolated viruses are rhinoviruses which account for about two-third of virus-induced asthma AEs. Seasonal patterns of occurrence of AEs, which peak during fall and spring especially in children, correspond to the pattern of HRVs isolation. This suggests a causal relationship between HRV infections and the induction of AEs [165-167]. Other viruses, which have been detected during asthma AEs, are RSV, (para-)influenza viruses, coronaviruses, human metapneumoviruses, adenoviruses and bocaviruses [168]. Yet, in children of 2-17 years of age, only HRVs were found to be significantly associated with asthma AEs [169]. Although different studies suggest a strong relationship between viral infection (in particular HRV) and induction of AEs, other studies also indicate the involvement of multiple factors [170,171]. Allergy and 
environmental pollution are the major other factors. Allergy, allergen exposure, pollutants and virus infection have been shown to synergistically increase the risk of induction of AEs both in children and in adults [172-174].

The role of bacterial infections in the induction of exacerbations in asthma is not clear. Possible relationship between the colonization of bacterial species like S. pneumoniae, $H$. influenzae, $M$. catarrhalis and development of asthma has been shown by Bisgaard and colleagues [158]. In another study, the same group has also shown an association between infections by these bacteria and acute wheezing in children [175]. Yet, these studies do not prove the causal role of these bacterial species in the induction of exacerbations. Similarly, infections with atypical bacterial species have also been suggested to play a role in the pathogenesis of asthma and in the induction of exacerbations: however, until now data are still inconclusive. Cunningham and colleagues reported increased levels of $C$. pneumoniae specific IgA antibodies in children who had four or more exacerbations as compared those who had just one [176]. In another study Wark and colleagues reported that among patients of AEs of asthma, $47 \%$ had antibodies against $C$. pneumoniae and $38 \%$ had increased levels C. pneumoniae antibodies [177]. Nonetheless, in both of these studies detection levels of viruses were also very high. For this reason infections with $C$. pneumoniae have been suggested to contribute to the virus-induced asthma exacerbations rather than being an independent inducer [178]. Still, another study showed significant improvement in AEs symptoms and lung function following treatment with telithromycin, an antibiotic specifically active against atypical bacteria, [179]. This indicates the possible involvement of atypical bacteria in the induction of asthma AEs. However further studies are required to explore the role of bacterial infections in the induction of asthma exacerbations.

\subsection{Impairment of immune system in asthma}

The immune system of asthmatics is perturbed at different levels and may as such contribute to disease progression. For example, the barrier function of the epithelium, which is the first point of contact with foreign particles, is intrinsically defective in asthmatics. [180]. As a result, penetration of inhaled pathogens into the airway tissue is facilitated. This barrier is also disrupted by other insults, which are implicated in the pathogenesis of asthma, like proteolytic allergens, viruses and air pollutants (for instance, environmental particulates and tobacco smoke) $[181,182]$. Infection of epithelial cells with viruses can also lead to loss of cilia and 
impairment of mucocilliary clearance. However, these effects could be secondary to the release of pro-inflammatory cytokines by damaged cells [168].

Also the antiviral response in asthmatics is impaired. This was indicated for the first time when Corne and colleagues showed that viral infections induced more severe and prolonged symptoms in asthmatics as compared to nonasthmatics [171]. Later studies suggested that the underlying mechanism could be an impaired interferon response to viral infections in asthmatics. In a seminal study, Wark and colleagues showed that in response to HRV infection bronchial epithelial cells from asthmatics produce less IFN- $\beta$ than cells from non-asthmatics [183]. In line with this, Contoli and colleagues also observed decreased production of type-III IFN- $\lambda$, when bronchoalveolar lavage cells from asthmatics were infected with HRV. They also found that levels of IFN- $\lambda$ were negatively correlated with asthma symptoms and viral load [184]. Further insight was provided by Bullens and colleagues, who showed that IFN- $\lambda 1$ mRNA levels were negatively correlated with asthma symptoms [185]. These studies show impairment of the antiviral response in asthmatics and importance of interferons in antiviral defense. Yet, the precise underlying mechanisms responsible for the impaired interferon response following viral infections in asthmatics are still unknown.

Normal functioning of some of the immune cells may also be disturbed in asthma. Oliver and colleagues demonstrated that HRV impairs antibacterial defense of alveolar macrophages [186]. Similarly after experimental HRV infection, prolonged infiltration of eosinophils was observed in asthmatics as compared to healthy subjects [187]. However, whether this prolonged infiltration is beneficial or destructive is not clear [188].

In contrast to healthy subjects, interleukin-8 (IL-8) levels in nasal lavages from asthmatics are significantly increased after HRV infection and increased IL-8 levels are correlated with airway hyperresponsiveness $[189,190]$. This suggests that HRV infection in asthmatics can increase the neutrophilic inflammation which may then lead to exacerbation. 


\section{Aims and outline of the thesis}

Acute exacerbations in both asthma and COPD negatively affect the quality of life of patients. They not only deteriorate the lung function but they are also major contributors to morbidity and mortality. Unfortunately, currently available strategies and therapies for the prevention and treatment of AEs have limited efficacy. Thus, studies focusing on the exploration of new possibilities to treat or prevent AEs are urgently needed. Along with this, the identification and a better understanding of the factors, which play important roles in the induction of exacerbations by some of the most common triggers, could also help to formulate new strategies to prevent AEs.

Among these triggers for AEs in asthma and COPD, viral infections are currently considered as the most important ones. Moreover, antiviral responses in asthmatics and COPD patients seem to be impaired. Alternatively, apart from direct cytopathological effects of viral infections, also an exaggeration of the inflammatory response, which is a core feature in CRDs, by viral infections could also lead to AEs. Thus prevention of viral infections as well as excessive inflammation could significantly reduce the frequency of AEs. Because of their potent antiviral characteristics prophylactic treatment with exogenous interferons could be one possible therapeutic option. Moreover, anti-inflammatory characteristics have been attributed to IFNs which may also be beneficial to prevent $A E$. In the present thesis we tested the hypothesis that prophylactic treatment with exogenous IFNs is a valuable option to prevent viral infections and excessive inflammation of the respiratory tract. To examine this hypothesis, different in vitro studies were conducted to determine the antiviral and antiinflammatory effects of administration of exogenous interferons to airway epithelial cells.

Previously we have shown that IFN- $\beta$, a member of the type-I interferon family, provides long lasting protection against viral infections in airway epithelial cells. IFN- $\lambda 1$, on the other hand, is a member of newly discovered type-III interferon family, which are speculated to be more important for the respiratory tract than type-I interferons. In chapter 2, we examined the hypothesis that prophylactic administration of exogenous IFN- $\lambda 1$ is equally or even more effective than IFN- $\beta$ in protecting epithelial cells against subsequent rhinovirus infections.

Inflammation is an important feature in AEs and can be induced by different exogenous triggers. These triggers might act through different mechanisms to induce inflammation but it can finally lead to the induction of AEs. 
Therefore, prevention of inflammation might be a useful strategy to avoid acute exacerbations in chronic respiratory patients. Interestingly, besides antiviral characteristics also anti-inflammatory properties have been attributed to IFN- $\beta$. However, the effects of IFN- $\lambda$ on inflammation have been studied less extensively. In chapter $\mathbf{3}$ we evaluated the hypothesis that, next to anti-viral properties, both IFN- $\beta$ and IFN- $\lambda$ have anti-inflammatory features. To study this hypothesis, the inflammatory response of (infected) macrophages and epithelial cells, both in mono and co-cultures, upon administration of exogenous interferons was investigated.

Majority of the patients with chronic respiratory diseases, and in particular COPD, are either current smokers or ex-smokers. Previously, it has been demonstrated that cigarette smoke impairs the pulmonary immune system. However, it is unclear whether cigarette smoke also has a negative effect on the capacity of exogenous interferons to provide protection against viral infections in epithelial cells thereby limiting its potential clinical applicability. Thus in chapter 4 we evaluated the ability of exogenous interferon to provide protection against viral infection in epithelial cells which were first treated with cigarette smoke extracts.

Among viruses, HRVs are the major inducers of exacerbations and about $90 \%$ of the known HRVs are part of the major group HRV family. Major group HRVs use the intercellular adhesion molecule-1 (ICAM1) as their receptor for attachment to the cells. Previously, $H$. influenzae, which is commonly isolated from COPD patients, has been shown to up-regulate the ICAM1 expression on epithelial cells leading to increased binding of HRV to the cells. Although this indicates that $H$. influenzae might assist HRV to establish the infection definite proof for is still lacking. In chapter 5, we evaluated the hypothesis that $H$. influenzae treatment enhances the replication of virus and also the inflammatory response upon subsequent infection. Apart from the effects of $H$. influenzae on major group HRV infections, we also tested the effects on minor group HRV infections (which use the LRL-receptor for adherence to cells) and the unrelated RSV to determine whether effects of $H$. influenzae are specific for major group HRV or induce a more general effect in bronchial epithelial cells.

In the last chapter of the thesis, chapter 6 findings are summarized and discussed. 


\section{References}

1. Gill S, Wight TN, Frevert CW (2010) Proteoglycans: key regulators of pulmonary inflammation and the innate immune response to lung infection. Anat Rec (Hoboken) 293: 968-981.

2. Mizgerd JP (2012) Respiratory infection and the impact of pulmonary immunity on lung health and disease. Am J Respir Crit Care Med 186: 824-829.

3. Levitzky MG (1995) Pulmonary physiology: McGraw-Hill.

4. Denny FW, Jr. (1995) The clinical impact of human respiratory virus infections. Am J Respir Crit Care Med 152: S4-12.

5. Moini J (2011) Anatomy and Physiology for Health Professionals: Jones \& Bartlett Publishers.

6. Duijvestijn YC, Mourdi N, Smucny J, Pons G, Chalumeau M (2009) Acetylcysteine and carbocysteine for acute upper and lower respiratory tract infections in paediatric patients without chronic broncho-pulmonary disease. Cochrane Database Syst Rev: CD003124.

7. Kassel JC, King D, Spurling GK (2010) Saline nasal irrigation for acute upper respiratory tract infections. Cochrane Database Syst Rev: CD006821.

8. Liberati A, D'Amico R, Pifferi S, Torri V, Brazzi L, et al. (2009) Antibiotic prophylaxis to reduce respiratory tract infections and mortality in adults receiving intensive care. Cochrane Database Syst Rev: CD000022.

9. Heikkinen T, Jarvinen A (2003) The common cold. Lancet 361: 51-59.

10. Gonzales R, Bartlett JG, Besser RE, Hickner JM, Hoffman JR, et al. (2001) Principles of appropriate antibiotic use for treatment of nonspecific upper respiratory tract infections in adults: background. Ann Intern Med 134: 490-494.

11. Winther B (2011) Rhinovirus infections in the upper airway. Proc Am Thorac Soc 8: 79-89.

12. Fendrick AM (2003) Viral respiratory infections due to rhinoviruses: current knowledge, new developments. Am J Ther 10: 193-202.

13. Kaiser L, Lew D, Hirschel B, Auckenthaler R, Morabia A, et al. (1996) Effects of antibiotic treatment in the subset of common-cold patients who have bacteria in nasopharyngeal secretions. Lancet 347: 1507-1510.

14. Eccles R (2005) Understanding the symptoms of the common cold and influenza. Lancet Infect Dis 5 : 718-725.

15. Shah SA, Sander S, White CM, Rinaldi M, Coleman Cl (2007) Evaluation of echinacea for the prevention and treatment of the common cold: a meta-analysis. Lancet Infect Dis 7: 473-480.

16. Thompson WW, Shay DK, Weintraub E, Brammer L, Cox N, et al. (2003) Mortality associated with influenza and respiratory syncytial virus in the United States. JAMA 289: 179-186.

17. Thompson WW, Shay DK, Weintraub E, Brammer L, Bridges CB, et al. (2004) Influenza-associated hospitalizations in the United States. JAMA 292: 1333-1340.

18. Poole MD (2004) Acute bacterial rhinosinusitis: clinical impact of resistance and susceptibility. Am J Med 117 Suppl 3A: 29S-38S.

19. Wright WL (2005) Viral or acute bacterial rhinosinusitis? Determining the difference. Nurse Pract 30 : 30-31, 34, 36-37 passim; quiz 41-33.

20. Klein JO (1994) Otitis media. Clin Infect Dis 19: 823-833.

21. Heikkinen T, Thint M, Chonmaitree T (1999) Prevalence of various respiratory viruses in the middle ear during acute otitis media. N Engl J Med 340: 260-264.

22. Chonmaitree T (2000) Viral and bacterial interaction in acute otitis media. Pediatr Infect Dis J 19: S24-30.

23. Bruck L, Donofrio J, Munden J, Thompson G (2005) Anatomy \& physiology made incredibly easy: Lippincott Williams \& Wilkins.

24. Panpanich R, Lerttrakarnnon $P$, Laopaiboon $M(2008)$ Azithromycin for acute lower respiratory tract infections. Cochrane Database Syst Rev: CD001954.

25. Graffelman AW, Knuistingh Neven A, le Cessie S, Kroes AC, Springer MP, et al. (2004) Pathogens involved in lower respiratory tract infections in general practice. Br J Gen Pract 54: 15-19.

26. Gonzales R, Sande MA (2000) Uncomplicated acute bronchitis. Ann Intern Med 133: 981-991.

27. Smith S, Fahey T, Smucny J, Becker Lorne A (2004) Antibiotics for acute bronchitis. Cochrane Database Syst Rev 4. 
28. Ruuskanen O, Lahti E, Jennings LC, Murdoch DR (2011) Viral pneumonia. Lancet 377: 1264-1275.

29. Guthrie R (2001) Community-acquired lower respiratory tract infections: etiology and treatment. Chest 120: 2021-2034.

30. Fang GD, Fine M, Orloff J, Arisumi D, Yu VL, et al. (1990) New and emerging etiologies for community-acquired pneumonia with implications for therapy. A prospective multicenter study of 359 cases. Medicine (Baltimore) 69: 307-316.

31. Angeles Marcos M, Camps M, Pumarola T, Antonio Martinez J, Martinez E, et al. (2006) The role of viruses in the aetiology of community-acquired pneumonia in adults. Antivir Ther 11: 351359.

32. Debiaggi M, Canducci F, Ceresola ER, Clementi M (2012) The role of infections and coinfections with newly identified and emerging respiratory viruses in children. Virol J 9: 247.

33. Jones N (2001) The nose and paranasal sinuses physiology and anatomy. Adv Drug Deliv Rev 51: 519.

34. Harada RN, Repine JE (1985) Pulmonary host defense mechanisms. Chest 87: 247-252.

35. Newhouse M, Sanchis J, Bienenstock J (1976) Lung defense mechanisms (first of two parts). N Engl J Med 295: 990-998.

36. Davies JA, Garrod DR (1997) Molecular aspects of the epithelial phenotype. Bioessays 19: 699-704.

37. Roche WR, Montefort S, Baker J, Holgate ST (1993) Cell adhesion molecules and the bronchial epithelium. Am Rev Respir Dis 148: S79-82.

38. Voynow JA, Rubin BK (2009) Mucins, mucus, and sputum. Chest 135: 505-512.

39. Widdicombe JH (2002) Regulation of the depth and composition of airway surface liquid. J Anat 201: 313-318.

40. Singh PK, Tack BF, McCray PB, Welsh MJ (2000) Synergistic and additive killing by antimicrobial factors found in human airway surface liquid. Am J Physiol-Lung C 279: L799-L805.

41. Kawai T, Akira S (2011) Toll-like receptors and their crosstalk with other innate receptors in infection and immunity. Immunity 34: 637-650.

42. Lindner SC (2010) Toll-like receptor-mediated regulation of Leukotriene biosynthesis in human monocytes: Frankfurt (Main), Univ., Diss., 2010.

43. Borrow P, Martinez-Sobrido L, de la Torre JC (2010) Inhibition of the type I interferon antiviral response during arenavirus infection. Viruses 2: 2443-2480.

44. Gonzalez-Navajas JM, Lee J, David M, Raz E (2012) Immunomodulatory functions of type I interferons. Nat Rev Immunol 12: 125-135.

45. Martin TR, Frevert CW (2005) Innate immunity in the lungs. Proc Am Thorac Soc 2: 403-411.

46. Suzuki T, Chow CW, Downey GP (2008) Role of innate immune cells and their products in lung immunopathology. Int J Biochem Cell Biol 40: 1348-1361.

47. Kolaczkowska E, Kubes $P$ (2013) Neutrophil recruitment and function in health and inflammation. Nat Rev Immunol 13: 159-175.

48. Message SD, Johnston SL (2004) Host defense function of the airway epithelium in health and disease: clinical background. J Leukoc Biol 75: 5-17.

49. Vermaelen K, Pauwels R (2005) Pulmonary dendritic cells. Am J Respir Crit Care Med 172: 530-551.

50. von Garnier C, Filgueira L, Wikstrom M, Smith M, Thomas JA, et al. (2005) Anatomical location determines the distribution and function of dendritic cells and other APCs in the respiratory tract. J Immunol 175: 1609-1618.

51. Holt PG, Schon-Hegrad MA, Phillips MJ, McMenamin PG (1989) la-positive dendritic cells form a tightly meshed network within the human airway epithelium. Clin Exp Allergy 19: 597-601.

52. Fokkens WJ, Vroom TM, Rijntjes E, Mulder PG (1989) CD-1 (T6), HLA-DR-expressing cells, presumably Langerhans cells, in nasal mucosa. Allergy 44: 167-172.

53. Jahnsen FL, Strickland DH, Thomas JA, Tobagus IT, Napoli S, et al. (2006) Accelerated antigen sampling and transport by airway mucosal dendritic cells following inhalation of a bacterial stimulus. J Immunol 177: 5861-5867.

54. Blank F, Rothen-Rutishauser B, Gehr P (2007) Dendritic cells and macrophages form a transepithelial network against foreign particulate antigens. Am J Respir Cell Mol Biol 36: 669-677.

55. Kadowaki N, Ho S, Antonenko S, Malefyt RW, Kastelein RA, et al. (2001) Subsets of human dendritic cell precursors express different toll-like receptors and respond to different microbial antigens. J Exp Med 194: 863-869. 
56. Caux C, Vanbervliet B, Massacrier C, Ait-Yahia S, Vaure C, et al. (2002) Regulation of dendritic cell recruitment by chemokines. Transplantation 73: S7-S11.

57. Vanbervliet B, Homey B, Durand I, Massacrier C, Ait-Yahia S, et al. (2002) Sequential involvement of CCR2 and CCR6 ligands for immature dendritic cell recruitment: possible role at inflamed epithelial surfaces. Eur J Immunol 32: 231-242.

58. Lukens MV, Kruijsen D, Coenjaerts FE, Kimpen JL, van Bleek GM (2009) Respiratory syncytial virusinduced activation and migration of respiratory dendritic cells and subsequent antigen presentation in the lung-draining lymph node. J Virol 83: 7235-7243.

59. Mellman I, Steinman RM (2001) Dendritic cells: specialized and regulated antigen processing machines. Cell 106: 255-258.

60. Inaba K, Inaba M (2005) Antigen recognition and presentation by dendritic cells. Int J Hematol 81: 181-187.

61. Guermonprez P, Valladeau J, Zitvogel L, Thery C, Amigorena S (2002) Antigen presentation and T cell stimulation by dendritic cells. Annu Rev Immunol 20: 621-667.

62. Lambrecht BN (2005) Dendritic cells and the regulation of the allergic immune response. Allergy 60: 271-282.

63. Moser M, Murphy KM (2000) Dendritic cell regulation of TH1-TH2 development. Nat Immunol 1: 199-205.

64. Sakaguchi S, Yamaguchi T, Nomura T, Ono M (2008) Regulatory T cells and immune tolerance. Cell 133: 775-787.

65. Colonna M, Trinchieri G, Liu YJ (2004) Plasmacytoid dendritic cells in immunity. Nat Immunol 5 : 1219-1226.

66. Kotenko SV (2011) IFN-lambdas. Curr Opin Immunol 23: 583-590.

67. Randall RE, Goodbourn S (2008) Interferons and viruses: an interplay between induction, signalling, antiviral responses and virus countermeasures. J Gen Virol 89: 1-47.

68. Li M, Liu X, Zhou Y, Su SB (2009) Interferon-lambdas: the modulators of antivirus, antitumor, and immune responses. J Leukoc Biol 86: 23-32.

69. Jewell NA, Vaghefi N, Mertz SE, Akter P, Peebles RS, Jr., et al. (2007) Differential type I interferon induction by respiratory syncytial virus and influenza a virus in vivo. J Virol 81: 9790-9800.

70. Moens B, Pannecouque C, Lopez G, Talledo M, Gotuzzo E, et al. (2012) Simultaneous RNA quantification of human and retroviral genomes reveals intact interferon signaling in HTLV-1infected CD4+ T cell lines. Virol J 9: 171.

71. Sommereyns C, Paul S, Staeheli P, Michiels T (2008) IFN-lambda (IFN-lambda) is expressed in a tissue-dependent fashion and primarily acts on epithelial cells in vivo. PLoS Pathog 4: e1000017.

72. Rauch I, Muller M, Decker T (2013) The regulation of inflammation by interferons and their STATs. JAKSTAT 2: e23820.

73. Biron CA, Nguyen KB, Pien GC, Cousens LP, Salazar-Mather TP (1999) Natural killer cells in antiviral defense: function and regulation by innate cytokines. Annu Rev Immunol 17: 189-220.

74. Numasaki M, Tagawa M, Iwata F, Suzuki T, Nakamura A, et al. (2007) IL-28 elicits antitumor responses against murine fibrosarcoma. J Immunol 178: 5086-5098.

75. Wenzel J, Worenkamper E, Freutel S, Henze S, Haller O, et al. (2005) Enhanced type I interferon signalling promotes Th1-biased inflammation in cutaneous lupus erythematosus. J Pathol 205: 435-442.

76. Chen YH, Xiao Y, Wu W, Zhao Y, Speth C, et al. (1997) The immunosuppressive peptide of HIV-1 gp41 like human type I interferons up-regulates MHC class I expression on H9 and U937 cells. Immunol Lett 59: 93-97.

77. Kotenko SV, Gallagher G, Baurin VV, Lewis-Antes A, Shen M, et al. (2003) IFN-lambdas mediate antiviral protection through a distinct class II cytokine receptor complex. Nat Immunol 4: 6977.

78. Sheppard P, Kindsvogel W, Xu W, Henderson K, Schlutsmeyer S, et al. (2003) IL-28, IL-29 and their class II cytokine receptor IL-28R. Nat Immunol 4: 63-68.

79. Tanaka N, Sato M, Lamphier MS, Nozawa H, Oda E, et al. (1998) Type I interferons are essential mediators of apoptotic death in virally infected cells. Genes Cells 3: 29-37. 
80. Maher SG, Sheikh F, Scarzello AJ, Romero-Weaver AL, Baker DP, et al. (2008) IFNalpha and IFNlambda differ in their antiproliferative effects and duration of JAK/STAT signaling activity. Cancer Biol Ther 7: 1109-1115.

81. Sato A, Ohtsuki M, Hata M, Kobayashi E, Murakami T (2006) Antitumor activity of IFN-lambda in murine tumor models. J Immunol 176: 7686-7694.

82. Schoenborn JR, Wilson CB (2007) Regulation of interferon-gamma during innate and adaptive immune responses. Adv Immunol 96: 41-101.

83. Bao Y, Liu X, Han C, Xu S, Xie B, et al. (2014) Identification of IFN-gamma-producing innate B cells. Cell Res 24: 161-176.

84. Yach D, Hawkes C, Gould CL, Hofman KJ (2004) The global burden of chronic diseases: overcoming impediments to prevention and control. JAMA 291: 2616-2622.

85. Bousquet J, Kiley J, Bateman ED, Viegi G, Cruz AA, et al. (2010) Prioritised research agenda for prevention and control of chronic respiratory diseases. Eur Respir J 36: 995-1001.

86. Cruz AA (2007) Global surveillance, prevention and control of chronic respiratory diseases: a comprehensive approach: Who.

87. Ciofu O, Riis B, Pressler T, Poulsen HE, Hoiby N (2005) Occurrence of hypermutable Pseudomonas aeruginosa in cystic fibrosis patients is associated with the oxidative stress caused by chronic lung inflammation. Antimicrob Agents Chemother 49: 2276-2282.

88. Holgate ST (2012) Innate and adaptive immune responses in asthma. Nat Med 18: 673-683.

89. Taylor AE, Finney-Hayward TK, Quint JK, Thomas CM, Tudhope SJ, et al. (2010) Defective macrophage phagocytosis of bacteria in COPD. Eur Respir J 35: 1039-1047.

90. Parameswaran GI, Murphy TF (2007) Infections in chronic lung diseases. Infect Dis Clin North Am 21: 673-695, viii.

91. Brusselle GG, Joos GF, Bracke KR (2011) New insights into the immunology of chronic obstructive pulmonary disease. Lancet 378: 1015-1026.

92. Beasley V, Joshi PV, Singanayagam A, Molyneaux PL, Johnston SL, et al. (2012) Lung microbiology and exacerbations in COPD. Int J Chron Obstruct Pulmon Dis 7: 555-569.

93. Celli BR, MacNee W (2004) Standards for the diagnosis and treatment of patients with COPD: a summary of the ATS/ERS position paper. Eur Respir J 23: 932-946.

94. Lopez AD, Mathers CD, Ezzati M, Jamison DT, Murray CJ (2006) Global and regional burden of disease and risk factors, 2001: systematic analysis of population health data. Lancet 367: 1747-1757.

95. Mathers CD, Loncar D (2006) Projections of global mortality and burden of disease from 2002 to 2030. PLoS Med 3: e442.

96. Salvi SS, Barnes PJ (2009) Chronic obstructive pulmonary disease in non-smokers. Lancet 374: 733 743.

97. Pauwels RA, Rabe KF (2004) Burden and clinical features of chronic obstructive pulmonary disease (COPD). Lancet 364: 613-620.

98. Janciauskiene S (2007) [Hereditary alpha-1-antitrypsin deficiency can cause COPD. Substitution treatment seems to result in fewer infections and prolonged survival]. Lakartidningen 104: 3631-3634, 3637-3638.

99. Rahman I, Adcock IM (2006) Oxidative stress and redox regulation of lung inflammation in COPD. Eur Respir J 28: 219-242.

100. Hogg JC, Timens W (2009) The pathology of chronic obstructive pulmonary disease. Annu Rev Pathol 4: 435-459.

101. Tsuji T, Aoshiba K, Nagai A (2004) Cigarette smoke induces senescence in alveolar epithelial cells. Am J Respir Cell Mol Biol 31: 643-649.

102. Cosio MG, Saetta M, Agusti A (2009) Immunologic aspects of chronic obstructive pulmonary disease. N Engl J Med 360: 2445-2454.

103. Soler-Cataluna JJ, Martinez-Garcia MA, Roman Sanchez P, Salcedo E, Navarro M, et al. (2005) Severe acute exacerbations and mortality in patients with chronic obstructive pulmonary disease. Thorax 60: 925-931.

104. Hurst JR, Vestbo J, Anzueto A, Locantore N, Mullerova H, et al. (2010) Susceptibility to exacerbation in chronic obstructive pulmonary disease. N Engl J Med 363: 1128-1138.

105. Sullivan SD, Ramsey SD, Lee TA (2000) The economic burden of COPD. Chest 117: 5S-9S. 
106. Papi A, Bellettato CM, Braccioni F, Romagnoli M, Casolari $P$, et al. (2006) Infections and airway inflammation in chronic obstructive pulmonary disease severe exacerbations. Am J Respir Crit Care Med 173: 1114-1121.

107. Decramer M, Janssens W, Miravitlles M (2012) Chronic obstructive pulmonary disease. Lancet 379: 1341-1351.

108. Sethi S, Murphy TF (2008) Infection in the pathogenesis and course of chronic obstructive pulmonary disease. N Engl J Med 359: 2355-2365.

109. Wilkinson TMA, Hurst JR, Perera WR, Wilks M, Donaldson GC, et al. (2006) Effect of interactions between lower airway bacterial and rhinoviral infection in exacerbations of COPD. Chest 129: 317-324.

110. Bafadhel M, McKenna S, Terry S, Mistry V, Reid C, et al. (2011) Acute exacerbations of chronic obstructive pulmonary disease: identification of biologic clusters and their biomarkers. Am J Respir Crit Care Med 184: 662-671.

111. Sethi S, Sethi R, Eschberger K, Lobbins P, Cai X, et al. (2007) Airway bacterial concentrations and exacerbations of chronic obstructive pulmonary disease. Am J Respir Crit Care Med 176: 356 361.

112. Hurst JR, Perera WR, Wilkinson TM, Donaldson GC, Wedzicha JA (2006) Systemic and upper and lower airway inflammation at exacerbation of chronic obstructive pulmonary disease. Am J Respir Crit Care Med 173: 71-78.

113. Murphy TF, Brauer AL, Grant BJ, Sethi S (2005) Moraxella catarrhalis in chronic obstructive pulmonary disease: burden of disease and immune response. Am J Respir Crit Care Med 172: 195-199.

114. Sethi S, Wrona C, Grant BJ, Murphy TF (2004) Strain-specific immune response to Haemophilus influenzae in chronic obstructive pulmonary disease. Am J Respir Crit Care Med 169: 448-453.

115. Dimopoulos G, Lerikou M, Tsiodras S, Chranioti A, Perros E, et al. (2012) Viral epidemiology of acute exacerbations of chronic obstructive pulmonary disease. Pulm Pharmacol Ther 25: 12-18.

116. Mohan A, Chandra S, Agarwal D, Guleria R, Broor S, et al. (2010) Prevalence of viral infection detected by PCR and RT-PCR in patients with acute exacerbation of COPD: a systematic review. Respirology 15: 536-542.

117. Mallia P, Message SD, Gielen V, Contoli M, Gray K, et al. (2011) Experimental rhinovirus infection as a human model of chronic obstructive pulmonary disease exacerbation. Am J Respir Crit Care Med 183: 734-742.

118. Sajjan US, Jia Y, Newcomb DC, Bentley JK, Lukacs NW, et al. (2006) H. influenzae potentiates airway epithelial cell responses to rhinovirus by increasing ICAM-1 and TLR3 expression. FASEB J 20: 2121-2123.

119. Avadhanula V, Rodriguez CA, Devincenzo JP, Wang Y, Webby RJ, et al. (2006) Respiratory viruses augment the adhesion of bacterial pathogens to respiratory epithelium in a viral species- and cell type-dependent manner. J Virol 80: 1629-1636.

120. Mehta H, Nazzal K, Sadikot RT (2008) Cigarette smoking and innate immunity. Inflamm Res 57: 497 503.

121. Auerbach O, Forman JB, Gere JB, Kassouny DY, Muehsam GE, et al. (1957) Changes in the bronchial epithelium in relation to smoking and cancer of the lung; a report of progress. N Engl J Med 256: 97-104.

122. Leopold PL, O'Mahony MJ, Lian XJ, Tilley AE, Harvey BG, et al. (2009) Smoking is associated with shortened airway cilia. PLoS One 4: e8157.

123. Verra F, Escudier E, Lebargy F, Bernaudin JF, De Cremoux H, et al. (1995) Ciliary abnormalities in bronchial epithelium of smokers, ex-smokers, and nonsmokers. Am J Respir Crit Care Med 151: 630-634.

124. Lumsden AB, McLean A, Lamb D (1984) Goblet and Clara cells of human distal airways: evidence for smoking induced changes in their numbers. Thorax 39: 844-849.

125. Manzel L, Shi L, O'Shaughnessy PT, Thorne PS, Look DC (2011) Inhibition by cigarette smoke of nuclear factor-kappaB-dependent response to bacteria in the airway. Am J Respir Cell Mol Biol 44: 155-165.

126. Kennedy SM, Elwood RK, Wiggs BJ, Pare PD, Hogg JC (1984) Increased airway mucosal permeability of smokers. Relationship to airway reactivity. Am Rev Respir Dis 129: 143-148. 
127. Heijink IH, Brandenburg SM, Postma DS, van Oosterhout AJ (2012) Cigarette smoke impairs airway epithelial barrier function and cell-cell contact recovery. Eur Respir J 39: 419-428.

128. Barnes PJ (2004) Alveolar macrophages as orchestrators of COPD. COPD 1: 59-70.

129. Shaykhiev R, Krause A, Salit J, Strulovici-Barel Y, Harvey BG, et al. (2009) Smoking-dependent reprogramming of alveolar macrophage polarization: implication for pathogenesis of chronic obstructive pulmonary disease. J Immunol 183: 2867-2883.

130. Smyth LJ, Starkey C, Vestbo J, Singh D (2007) CD4-regulatory cells in COPD patients. Chest 132: 156163.

131. Hagiwara E, Takahashi KI, Okubo T, Ohno S, Ueda A, et al. (2001) Cigarette smoking depletes cells spontaneously secreting Th(1) cytokines in the human airway. Cytokine 14: 121-126.

132. Hoenderdos K, Condliffe A (2013) The neutrophil in chronic obstructive pulmonary disease. Am J Respir Cell Mol Biol 48: 531-539.

133. Yoshikawa T, Dent G, Ward J, Angco G, Nong G, et al. (2007) Impaired neutrophil chemotaxis in chronic obstructive pulmonary disease. Am J Respir Crit Care Med 175: 473-479.

134. Tsoumakidou M, Koutsopoulos AV, Tzanakis N, Dambaki K, Tzortzaki E, et al. (2009) Decreased small airway and alveolar CD83+ dendritic cells in COPD. Chest 136: 726-733.

135. Rogers AV, Adelroth E, Hattotuwa K, Dewar A, Jeffery PK (2008) Bronchial mucosal dendritic cells in smokers and ex-smokers with COPD: an electron microscopic study. Thorax 63: 108-114.

136. Mian MF, Lauzon NM, Stampfli MR, Mossman KL, Ashkar AA (2008) Impairment of human NK cell cytotoxic activity and cytokine release by cigarette smoke. J Leukoc Biol 83: 774-784.

137. Prieto A, Reyes E, Bernstein ED, Martinez B, Monserrat J, et al. (2001) Defective natural killer and phagocytic activities in chronic obstructive pulmonary disease are restored by glycophosphopeptical (inmunoferon). Am J Respir Crit Care Med 163: 1578-1583.

138. Arcavi L, Benowitz NL (2004) Cigarette smoking and infection. Arch Intern Med 164: 2206-2216.

139. Stampfli MR, Anderson GP (2009) How cigarette smoke skews immune responses to promote infection, lung disease and cancer. Nat Rev Immunol 9: 377-384.

140. HuangFu WC, Liu J, Harty RN, Fuchs SY (2008) Cigarette smoking products suppress anti-viral effects of Type I interferon via phosphorylation-dependent downregulation of its receptor. FEBS Lett 582: 3206-3210.

141. Bauer CM, Dewitte-Orr SJ, Hornby KR, Zavitz CC, Lichty BD, et al. (2008) Cigarette smoke suppresses type I interferon-mediated antiviral immunity in lung fibroblast and epithelial cells. J Interferon Cytokine Res 28: 167-179.

142. Sajjan U, Ganesan S, Comstock AT, Shim J, Wang Q, et al. (2009) Elastase- and LPS-exposed mice display altered responses to rhinovirus infection. Am J Physiol Lung Cell Mol Physiol 297: L931-944.

143. Schneider D, Ganesan S, Comstock AT, Meldrum CA, Mahidhara R, et al. (2010) Increased cytokine response of rhinovirus-infected airway epithelial cells in chronic obstructive pulmonary disease. Am J Respir Crit Care Med 182: 332-340.

144. Bousquet J, Jeffery PK, Busse WW, Johnson M, Vignola AM (2000) Asthma. From bronchoconstriction to airways inflammation and remodeling. Am J Respir Crit Care Med 161: 1720-1745.

145. Busse WW, Lemanske RF, Jr. (2001) Asthma. N Engl J Med 344: 350-362.

146. Hoskins G, McCowan C, Neville RG, Thomas GE, Smith B, et al. (2000) Risk factors and costs associated with an asthma attack. Thorax 55: 19-24.

147. Segal R, Ried LD, Mackowiak J (1995) Cost of asthma illnesses: emergency department visits without admission. Pharm Pract Manag Q 15: 72-82.

148. Vercelli D (2008) Discovering susceptibility genes for asthma and allergy. Nat Rev Immunol 8: 169182.

149. Karmaus W, Ziyab AH, Everson T, Holloway JW (2013) Epigenetic mechanisms and models in the origins of asthma. Curr Opin Allergy Clin Immunol 13: 63-69.

150. Beuther DA, Sutherland ER (2007) Overweight, obesity, and incident asthma: a meta-analysis of prospective epidemiologic studies. Am J Respir Crit Care Med 175: 661-666.

151. Shore SA (2008) Obesity and asthma: possible mechanisms. J Allergy Clin Immunol 121: 1087-1093; quiz 1094-1085. 
152. Almqvist C, Worm M, Leynaert B, working group of GALENWPG (2008) Impact of gender on asthma in childhood and adolescence: a GA2LEN review. Allergy 63: 47-57.

153. Vink NM, Postma DS, Schouten JP, Rosmalen JG, Boezen HM (2010) Gender differences in asthma development and remission during transition through puberty: the TRacking Adolescents' Individual Lives Survey (TRAILS) study. J Allergy Clin Immunol 126: 498-504 e491-496.

154. Lau S, Illi S, Sommerfeld C, Niggemann B, Bergmann R, et al. (2000) Early exposure to house-dust mite and cat allergens and development of childhood asthma: a cohort study. Multicentre Allergy Study Group. Lancet 356: 1392-1397.

155. Rochat MK, Illi S, Ege MJ, Lau S, Keil T, et al. (2010) Allergic rhinitis as a predictor for wheezing onset in school-aged children. J Allergy Clin Immunol 126: 1170-1175 e1172.

156. Wu P, Dupont WD, Griffin MR, Carroll KN, Mitchel EF, et al. (2008) Evidence of a causal role of winter virus infection during infancy in early childhood asthma. Am J Respir Crit Care Med 178: $1123-1129$.

157. Jackson DJ, Gangnon RE, Evans MD, Roberg KA, Anderson EL, et al. (2008) Wheezing rhinovirus illnesses in early life predict asthma development in high-risk children. Am J Respir Crit Care Med 178: 667-672.

158. Bisgaard H, Hermansen MN, Buchvald F, Loland L, Halkjaer LB, et al. (2007) Childhood asthma after bacterial colonization of the airway in neonates. N Engl J Med 357: 1487-1495.

159. Burke H, Leonardi-Bee J, Hashim A, Pine-Abata H, Chen Y, et al. (2012) Prenatal and passive smoke exposure and incidence of asthma and wheeze: systematic review and meta-analysis. Pediatrics 129: 735-744.

160. Gehring U, Wijga AH, Brauer M, Fischer P, de Jongste JC, et al. (2010) Traffic-related air pollution and the development of asthma and allergies during the first 8 years of life. Am J Respir Crit Care Med 181: 596-603.

161. de Nijs SB, Venekamp LN, Bel EH (2013) Adult-onset asthma: is it really different? Eur Respir Rev 22: 44-52.

162. Johnston SL, Pattemore PK, Sanderson G, Smith S, Lampe F, et al. (1995) Community study of role of viral infections in exacerbations of asthma in 9-11 year old children. BMJ 310: 1225-1229.

163. Nicholson KG, Kent J, Ireland DC (1993) Respiratory viruses and exacerbations of asthma in adults. BMJ 307: 982-986.

164. Leung TF, To MY, Yeung AC, Wong YS, Wong GW, et al. (2010) Multiplex molecular detection of respiratory pathogens in children with asthma exacerbation. Chest 137: 348-354.

165. Johnston NW, Johnston SL, Norman GR, Dai J, Sears MR (2006) The September epidemic of asthma hospitalization: school children as disease vectors. J Allergy Clin Immunol 117: 557-562.

166. Heymann PW, Carper HT, Murphy DD, Platts-Mills TA, Patrie J, et al. (2004) Viral infections in relation to age, atopy, and season of admission among children hospitalized for wheezing. J Allergy Clin Immunol 114: 239-247.

167. Johnston SL, Pattemore PK, Sanderson G, Smith S, Campbell MJ, et al. (1996) The relationship between upper respiratory infections and hospital admissions for asthma: a time-trend analysis. Am J Respir Crit Care Med 154: 654-660.

168. Jackson DJ, Johnston SL (2010) The role of viruses in acute exacerbations of asthma. J Allergy Clin Immunol 125: 1178-1187; quiz 1188-1179.

169. Khetsuriani N, Kazerouni NN, Erdman DD, Lu X, Redd SC, et al. (2007) Prevalence of viral respiratory tract infections in children with asthma. J Allergy Clin Immunol 119: 314-321.

170. DeMore JP, Weisshaar EH, Vrtis RF, Swenson CA, Evans MD, et al. (2009) Similar colds in subjects with allergic asthma and nonatopic subjects after inoculation with rhinovirus-16. J Allergy Clin Immunol 124: 245-252, 252 e241-243.

171. Corne JM, Marshall C, Smith S, Schreiber J, Sanderson G, et al. (2002) Frequency, severity, and duration of rhinovirus infections in asthmatic and non-asthmatic individuals: a longitudinal cohort study. Lancet 359: 831-834.

172. Murray CS, Poletti G, Kebadze T, Morris J, Woodcock A, et al. (2006) Study of modifiable risk factors for asthma exacerbations: virus infection and allergen exposure increase the risk of asthma hospital admissions in children. Thorax 61: 376-382. 
173. Green RM, Custovic A, Sanderson G, Hunter J, Johnston SL, et al. (2002) Synergism between allergens and viruses and risk of hospital admission with asthma: case-control study. BMJ 324: 763.

174. Chauhan AJ, Inskip HM, Linaker CH, Smith S, Schreiber J, et al. (2003) Personal exposure to nitrogen dioxide (NO2) and the severity of virus-induced asthma in children. Lancet 361: 1939-1944.

175. Bisgaard H, Hermansen MN, Bønnelykke K, Stokholm J, Baty F, et al. (2010) Association of bacteria and viruses with wheezy episodes in young children: prospective birth cohort study. BMJ 341 .

176. Cunningham AF, Johnston SL, Julious SA, Lampe FC, Ward ME (1998) Chronic Chlamydia pneumoniae infection and asthma exacerbations in children. Eur Respir J 11: 345-349.

177. Wark PA, Johnston SL, Simpson JL, Hensley MJ, Gibson PG (2002) Chlamydia pneumoniae immunoglobulin A reactivation and airway inflammation in acute asthma. Eur Respir J 20: 834-840.

178. Sykes A, Johnston SL (2008) Etiology of asthma exacerbations. J Allergy Clin Immunol 122: 685-688.

179. Johnston SL (2006) Macrolide antibiotics and asthma treatment. J Allergy Clin Immunol 117: 1233 1236.

180. Xiao C, Puddicombe SM, Field S, Haywood J, Broughton-Head V, et al. (2011) Defective epithelial barrier function in asthma. J Allergy Clin Immunol 128: 549-556 e541-512.

181. Sajjan U, Wang Q, Zhao Y, Gruenert DC, Hershenson MB (2008) Rhinovirus disrupts the barrier function of polarized airway epithelial cells. Am J Respir Crit Care Med 178: 1271-1281.

182. Hackett TL, Singhera GK, Shaheen F, Hayden P, Jackson GR, et al. (2011) Intrinsic phenotypic differences of asthmatic epithelium and its inflammatory responses to respiratory syncytial virus and air pollution. Am J Respir Cell Mol Biol 45: 1090-1100.

183. Wark PA, Johnston SL, Bucchieri F, Powell R, Puddicombe S, et al. (2005) Asthmatic bronchial epithelial cells have a deficient innate immune response to infection with rhinovirus. J Exp Med 201: 937-947.

184. Contoli M, Message SD, Laza-Stanca V, Edwards MR, Wark PA, et al. (2006) Role of deficient type III interferon-lambda production in asthma exacerbations. Nat Med 12: 1023-1026.

185. Bullens DM, Decraene A, Dilissen E, Meyts I, De Boeck K, et al. (2008) Type III IFN-lambda mRNA expression in sputum of adult and school-aged asthmatics. Clin Exp Allergy 38: 1459-1467.

186. Oliver BG, Lim S, Wark P, Laza-Stanca V, King N, et al. (2008) Rhinovirus exposure impairs immune responses to bacterial products in human alveolar macrophages. Thorax 63: 519-525.

187. Fraenkel DJ, Bardin PG, Sanderson G, Lampe F, Johnston SL, et al. (1995) Lower airways inflammation during rhinovirus colds in normal and in asthmatic subjects. Am J Respir Crit Care Med 151: 879-886.

188. Phipps S, Lam CE, Mahalingam S, Newhouse M, Ramirez R, et al. (2007) Eosinophils contribute to innate antiviral immunity and promote clearance of respiratory syncytial virus. Blood 110: 1578-1586.

189. de Kluijver J, Grunberg K, Pons D, de Klerk EP, Dick CR, et al. (2003) Interleukin-1beta and interleukin-1ra levels in nasal lavages during experimental rhinovirus infection in asthmatic and non-asthmatic subjects. Clin Exp Allergy 33: 1415-1418.

190. Grunberg K, Timmers MC, Smits HH, de Klerk EP, Dick EC, et al. (1997) Effect of experimental rhinovirus 16 colds on airway hyperresponsiveness to histamine and interleukin- 8 in nasal lavage in asthmatic subjects in vivo. Clin Exp Allergy 27: 36-45. 


\title{
CHAPTER 2
}

\section{Efficacy of IFN- $\lambda 1$ to Protect Human Airway Epithelial Cells against Human Rhinovirus 1B Infection}

\author{
Fahad Gulraiz \\ Carla Bellinghausen \\ Mieke A Dentener \\ Niki L Reynaert \\ Giel R Gaajetaan \\ Erik V Beuken \\ Gernot G Rohde \\ Cathrien A Bruggeman \\ Frank R Stassen
}

PLoS One. 2014 Apr 21;9(4):e95134 


\section{Abstract}

\section{Background}

Impaired interferon (IFN) production has been observed in various obstructive respiratory diseases. This contributes to enhanced sensitivity towards viral infections triggering acute exacerbations. To compensate for this impaired host IFN response, there is need to explore new therapeutic strategies, like exogenous administration of IFNs as prophylactic treatment. In the present study, we examined the protective potential of IFN- $\lambda 1$ and compared it with the previously established protecting effect of IFN- $\beta$.

\section{Methods}

A549 cells and human primary bronchial epithelial cells were first treated with either IFN- $\beta(500 \mathrm{IU} / \mathrm{ml})$ or IFN- $\lambda 1(500 \mathrm{ng} / \mathrm{ml})$ for $18 \mathrm{~h}$. For infection, two approaches were adopted: i) Continuous scenario: after pre-treatment, cells were infected immediately for $24 \mathrm{~h}$ with human rhinovirus $1 \mathrm{~B}$ (HRV1B) in IFN-containing medium, or were cultured for another $72 \mathrm{~h}$ in IFN-containing medium, and then infected for 24h with HRV1B, ii) Pre-treatment scenario: IFN-containing medium was replaced after $18 \mathrm{~h}$ and cells were infected for $4 \mathrm{~h}$ either immediately after pretreatment or after additional culturing for $72 \mathrm{~h}$ in IFN-free medium. The protective effect was evaluated in terms of reduction in the number of viral copies/infectious progeny, and enhanced expression of IFN-stimulated genes (ISGs).

\section{Results}

In both cell types and in both approaches IFN- $\lambda 1$ and IFN- $\beta$ treatment resulted in pronounced and long-lasting antiviral effects exemplified by significantly reduced viral copy numbers and diminished infectious progeny. This was associated with strong up-regulation of multiple ISGs. However, in contrast to the IFN- $\beta$ induced expression of ISGs, which decreased over time, expression of ISGs induced by IFN$\lambda 1$ was sustained or even increased over time. 


\section{Conclusion}

Here we demonstrate that the protective potential of IFN- $\lambda 1$ is comparable to IFN-

$\beta$. Yet, the long-lasting induction of ISGs by IFN- $\lambda 1$ and most likely less incitement of side effects due to more localized expression of its receptors could make it an even more promising candidate for prophylactic treatment than IFN- $\beta$. 


\section{Introduction}

Acute exacerbations are the major cause of morbidity and mortality in chronic respiratory diseases like asthma and chronic obstructive pulmonary disease (COPD). Also, they increase the economic burden because of extra healthcare, which has to be provided to the patients [1,2]. Among others, viral infections, especially infections with human rhinovirus (HRV), are strongly implicated as important triggers for the induction of acute exacerbations [3-6]. Following HRV infections, healthy individuals develop upper respiratory symptoms (common cold) but patients with chronic respiratory diseases frequently develop more severe lower respiratory tract symptoms $[7,8]$.

The airway epithelium provides the first line of defense against invading pathogens. In response to viral infections, airway epithelial cells become activated and start producing different antiviral mediators and pro-inflammatory cytokines. These mediators and cytokines not only combat invading viruses, but also recruit and activate other immune cells and initiate mechanisms of adaptive immunity $[9,10]$. Three different types of interferons (type-I [IFN- $\alpha / \beta]$, type-II [IFN- - ] and the more recently discovered type-III [IFN- $\lambda$ ]) are among the most important antiviral mediators produced by epithelial cells. Although all three types have antiviral properties, type-I and type-III are the IFNs which are produced in direct response to viral infection [11-14]. Nonetheless, type-III IFNs are considered to be more important for mucosal antiviral defense, while type-I IFNs might be more important for clearance of systemic viral infections $[15,16]$.

Viral infections result in the activation of transcription factors like nuclear factor kappaB (NFkB) and interferon regulatory factor (IRF) -3 and IRF-7, which regulate the production of IFNs at the transcriptional level. Yet, different subtypes of IFNs respond differently to IRF-3 and IRF-7. Transcription of IFN- $\lambda 1$ (type-III) and IFN- $\beta$ (type-I) genes is controlled by both IRF-3 and IRF-7, while transcription of other subtypes genes (type-III IFN- $\lambda 2 / 3$ and type-I IFN- $\alpha$ ) is predominantly regulated by IRF-7 [17]. This differential regulation plays an important role in the kinetics of induction of different subtypes. IRF-3 is constitutively and ubiquitously expressed in human cells. Due to this, when activated upon viral entry, it upregulates the expression of IFN- $\lambda 1$ and IFN- $\beta$. In contrast, IRF-7 is not constitutively expressed in most cells and is induced in response to IFNs. Because of this IFN- $\lambda 1$ and IFN- $\beta$ behave as early response genes while IFN- $\lambda 2 / 3$ and IFN- $\alpha$ genes are expressed with delayed kinetics $[18,19]$. 
Deficient production of IFNs has been observed in cells isolated from asthma and COPD patients upon HRV infections [8,20]. This indicates an impaired antiviral response which makes these patients more susceptible to viral infections and which may ultimately lead to the induction of acute exacerbations. Unfortunately, currently available strategies and therapies for the prevention and treatment of virus-induced acute exacerbations have limited efficacy [21] and new options need to be explored. One potential therapeutic strategy could be the prophylactic exogenous administration of IFNs.

In a previous in vitro study, we have shown that exogenous application of low amounts of IFN- $\beta$ induces pronounced and long-lasting protective effects against HRV infections in human respiratory epithelial cells [22]. Alternatively, despite the increasing recognition of the importance of type-III IFN in airway antiviral defense $[9,16,23,24]$, their potential as prophylactic agents still needs to be evaluated. In the present study we evaluated the potential protective effects of IFN- $\lambda 1$ against HRV1B infection in airway epithelial cells and compared it with the protective effects of IFN- $\beta$. 


\section{Materials and Methods}

\section{Cell Culture}

A549 cells (ATCC CCL-185; Rockville, MD, USA) were cultured in RPMI 1640 medium (Invitrogen, Grand Island, NY, USA) supplemented with $10 \%$ fetal calf serum (FCS; Lonza, Verviers, Belgium) and incubated at $37^{\circ} \mathrm{C} / 5 \% \mathrm{CO}_{2}$.

Primary bronchial epithelial cells (PBECs) were isolated from bronchus rings obtained from patients who underwent surgery for solitary pulmonary nodules. Lung tissues used for isolation were located at the remotest possible distance from the nodule and were macroscopically cancer free. PBECs were isolated and cultured as previously described [25]. Tissue was obtained from the Maastricht Pathology Tissue Collection (MPTC). Collection, storage and use of tissue and patient data were performed in agreement with the "Code for Proper Secondary Use of Human Tissue in the Netherlands" (http://www.fmwv.nl). Patient's characteristics are summarized in table S1.

MRC5 cells (ATCC CCL-171) were maintained in EMEM (Invitrogen, Grand Island, NY, USA) supplemented with non-essential amino acids (MP Biomedicals, Solon, Ohio, USA) L-glutamine ( $2 \mathrm{mM}$ ) and 10\% FCS (Lonza, Verviers, Belgium). Cells were incubated at $37^{\circ} \mathrm{C} / 5 \% \mathrm{CO}_{2}$.

\section{Ethics Statement}

After reviewing the protocol within the context of the Medical Research Involving Human Subjects Act, the local Medical Ethics Committee of the Maastricht University Medical Center (METC azM/UM) waived the need for ethical approval or informed consent.

\section{Virus Culture}

HRV1B was purchased from American Type Culture Collection (ATCC, VR-1645). Viral stocks were generated as previously described [22]. Briefly, MRC5 were infected in EMEM with 2\% FCS, non-essential amino acids, L-glutamine (2 mM). Once $100 \%$ cytopathogenic effect (CPE) was obtained, cell debris was removed by centrifugation and viral titers were determined by TCID50 (50\% tissue culture infectivity dose) on MRC-5 cells. 
Respiratory syncytial virus A2 (RSV) was obtained from the Netherlands Vaccine institute and propagated on Vero cells. After $2 \mathrm{~h}$ of infection, cells were washed and incubated further in DMEM with $1 \%$ FCS until $>80 \%$ CPE was attained. Cell debris was removed by centrifugation for 10 minutes at $1000 \mathrm{x}$ g. The virus pool was then precipitated using polyethylene glycol (PEG): PEG stock (50\% PEG6000 in $150 \mathrm{mM} \mathrm{NaCl}, 1 \mathrm{mM}$ EDTA, $6.1 \mathrm{~g} / \mathrm{L}$ TRIS, pH 7.5), was mixed with the virus pool to achieve a final concentration of $10 \%$ PEG (1:5), stirred $2 \mathrm{~h}$ at $4{ }^{\circ} \mathrm{C}$, centrifuged $30 \mathrm{~min}$ at $3000 \times \mathrm{g}$ and the pellet was resuspended in PBS $+25 \%$ sucrose $(10 \%$ of original volume $=10 \times$ concentrated $)$. Viral titers were determined by TCID50.

\section{Determination of cytotoxicity of IFNs}

Because in some experiments cells were cultured for more than 100 hours in the continuous presence of either IFN- $\beta$ or IFN- $\lambda 1$, cytotoxic effects of both cytokines were determined with a colorimetric thiazolyl blue tetrazolium bromide (MTT) (Sigma-Aldrich, St. Louis, MO, USA) assay as described previously [22]. Briefly, A549 cells were seeded in a 96-well plate and exposed for $114 \mathrm{~h}$ to IFN- $\beta$ (500 IU/ml) or IFN- $\lambda 1(500 \mathrm{ng} / \mathrm{ml})$. Afterwards the MTT assay was performed according to the manufacturer's instructions. The percentage of metabolic activity of exposed A549 cells was calculated by comparing to non-exposed controls (absorbance exposed/ absorbance non-exposed x 100\%).

\section{Protective effects of IFN- $\beta /-\lambda 1$ treatment}

Recombinant human IFN- $\beta$ and IFN- $\lambda 1$ were purchased from PBL Biomedical Laboratories (NJ, USA). In order to determine the maximum protective potential of the two IFNs, dose-dependent induction of ISGs was determined in A549 cells. Maximal expression of ISGs was achieved at $500 \mathrm{IU} / \mathrm{ml}$ for IFN- $\beta$ and at $500 \mathrm{ng} / \mathrm{ml}$ for IFN- $\lambda 1$ (Fig. S1). These doses of the respective IFNs were therefore used in all further experiments. The protective effect of IFNs against HRV infections was examined in 2 different experimental approaches (Fig. S2). In all cases, A549 cells were seeded in 24-well tissue culture plates (Becton Dickinson, NJ, USA) at a density of $2 \times 10^{5}$ cells per well in RPMI 1640 ( $10 \%$ FCS). After $24 \mathrm{~h}$, the medium was replaced by fresh RPMI 1640 ( $2 \%$ FCS) and the experiments were started. 


\section{IFN pre-treatment}

In the first approach, cells were pre-treated with either IFN- $\lambda 1$ or IFN- $\beta$ for $18 \mathrm{~h}$. Then IFN-containing medium was replaced with fresh IFN-free medium and cells were infected immediately with HRV1B at a multiplicity of infection of 1 (MOI-1) for $4 \mathrm{~h}$ at $33^{\circ} \mathrm{C} / 5 \% \mathrm{CO}_{2}$. Also, to examine how long the protective effect of the pretreatment was maintained, we incubated cells for another $72 \mathrm{~h}$ after pre-treatment before infection. After $4 \mathrm{~h}$ of infection, HRV1B containing medium was removed and replaced by fresh IFN-free medium. Cells were cultured for another $24 \mathrm{~h}$ and then collected and processed for further analyses.

\section{Continuous exposure}

Although the approach described above may reveal important information regarding the antiviral properties of the two types of IFN, it may not reflect the natural course of both treatment and infection. Therefore we also performed a series of experiments in which neither the cytokine nor the virus was removed once added. Thus, after the $18 \mathrm{~h}$ pre-treatment period, HRV1B (MOI-1) was added to the cells in the continuous presence of either IFN- $\lambda 1$ or IFN- $\beta$ and cells were cultured for another $24 \mathrm{~h}$ in the presence of IFN- $\beta$, IFN $\beta+H R V 1 B$, IFN $\lambda 1$ or IFN $\lambda 1+H R V 1 B$. After this infection period cells were washed and collected for further analyses. Also, the long-lasting effect of IFN- $\beta$ or IFN- $\lambda 1$ treatment was examined when cells were infected after $72 \mathrm{~h}$ of IFN treatment.

For PBECs, cells were seeded in Greiner 24-well plates in BD medium (contains 50\% DMEM (Gibco) and 50\% bronchial epithelial basal medium (BEBM, Lonza) supplemented with BEGM SingleQuots (Lonza) and BSA (1.5 $\mu \mathrm{g} / \mathrm{ml}$; Sigma). When cell layers were approximately $80 \%$ confluent, growth medium was replaced with BD starvation medium (BD medium without EGF, BPE, BSA and gentamicin) and the treatment with IFNs was initiated $24 \mathrm{~h}$ later. Cells were then treated for $18 \mathrm{~h}$ with either IFN- $\lambda 1$ or IFN- $\beta$ and subsequently infected with HRV1B as described above. In PBECs the long-lasting effect of either pre-treatment or continuous treatment could not be examined because of deterioration of cell viability after $72 \mathrm{~h}$ of culturing.

\section{RSV infection and poly (I: C)/LyoVec treatment}

With the purpose of determining the induction of IFN expression in response to stimuli other than HRV1B, cells were infected with RSV at MOI-1 for one hour at $37^{\circ} \mathrm{C}$ or stimulated with $500 \mathrm{ng} / \mathrm{ml}$ of poly (I:C)/Lyovec (low molecular weight) 
(Invitrogen) and incubated at $37^{\circ} \mathrm{C} / 5 \% \mathrm{CO}_{2}$ for $24 \mathrm{~h}$. With poly (I:C)/Lyovec, A549 were stimulated for $18 \mathrm{~h}$. Afterwards cells were collected and processed for further analyses.

\section{TCID50}

Virus titration assay was performed as previously described [26] with some modifications. Supernatants from infected PBECs were collected and serially diluted 1:2 in MEM containing 2\% FCS (Lonza, Verviers, Belgium), non-essential amino acids and L-glutamine ( $2 \mathrm{mM}$ ). Dilutions were added on confluent MRC-5 in 96-well plates. Each dilution was assayed in six wells and TCID50 was calculated according to Spearman-Karber formula.

\section{Plasmid construction for the generation of standard curves}

For determination of the actual number of viral RNA copies present in the cells, a plasmid was constructed as previously described [27] with some modifications. In summary, after reverse transcription of viral RNA, a PCR was performed. The PCR fragment was cloned into the pGEMT-easy vector (Promega) and sequenced. The resulting plasmid, designated p1123, was transcribed in vitro and the resulting RNA was quantified. Serial dilutions of the quantified RNA were used for the generation of a standard curve.

\section{Quantification of virus load in infected cells}

Total RNA was isolated with RNeasy kit (Qiagen, Hilden, Germany) according to manufacturer's instructions. After DNase treatment (Turbo DNA-free kit, Ambion, Austin, TX, USA), the amount of RNA in the samples was quantified with a Nanodrop ND-1000 and $1 \mu \mathrm{g}$ of RNA was reverse transcribed into cDNA using the iScript cDNA Synthesis kit (Bio-Rad, Hercules, CA, USA). qPCR was performed to amplify cDNA as described previously [28]. For HRV and the IFN genes, cDNA was amplified in a volume of $25 \mu \mathrm{l}$ containing IQ Supermix (Bio-Rad, Hercules, CA, USA). For all other genes, HOT FIREPol EvaGreen qPCR mix plus (Solis Biodyne, Tartu, Estonia) was used. The sequences of the primers are given in table S2. For determination of viral RNA copy numbers, standard curves were generated for every qPCR run along with the samples. Gene expression was normalized to $\beta$-actin level and fold changes were calculated by using $2^{-\Delta \Delta C t}$ method. In case basal 
expression of a gene was not detectable, expression was expressed using the $2^{-\Delta C t}$ method [29].

\section{Statistical analysis}

The overall significance of the experimental effect was determined by KruskalWallis tests. Once overall significance was achieved, the differences between multiple groups were analyzed by Mann-Whitney test. Values of $p<0.05$ were considered statistically significant for both Kruskal-Wallis test and Mann-Whitney test. Data are expressed as mean \pm SEM. 


\section{Results}

\section{Long term exposure to recombinant IFNs has no toxic effects on A549 cells}

Since our experimental design involved long-term exposure of cells to IFNs, possible toxic effects of this exposure were determined first. For this, cells were exposed to IFNs for about $114 \mathrm{~h}$, which was the maximum time for which the cells were to be exposed to IFNs in our main experiments. After that, metabolic activity of cells was determined by MTT test as an indication of cellular viability. No significant differences were observed between IFNs exposed and non-exposed cells. This indicates that long term IFNs exposure has no negative effect on the viability of cells (Fig. S3).

\section{IFN- $\lambda 1$ induces strong antiviral state in A549 cells}

In our previous study we have shown that exogenous administration of IFN- $\beta$ induced a strong up-regulation of ISGs in respiratory epithelial cells [22]. Previously, ISGs have been shown to contribute significantly to antiviral defense [30]. Here we demonstrate that in vitro treatment of A549 cells for $18 \mathrm{~h}$ with IFN- $\lambda 1$ likewise induces a significant up-regulation of various ISGs (Fig. 1A). Though our initial doseresponse evaluation experiments showed maximum induction of ISGs mRNA levels at $500 \mathrm{ng} / \mathrm{ml}$ of IFN- $\lambda 1$, they were significantly lower as compared to IFN- $\beta$. Therefore, in the following experiments we examined whether the IFN- $\lambda 1$ induced up-regulation of ISGs is sufficient to protect cells against a subsequent viral infection.

\section{IFN- $\boldsymbol{\lambda} 1$-induced antiviral state protects against HRV1B infection}

Next we tested the antiviral potency of IFN- $\lambda 1$ and compared it to the previously demonstrated potency of IFN- $\beta$. Therefore A549 cells were first treated with IFNs for $18 \mathrm{~h}$ and then infected with HRV1B according to two different protocols.

\section{- Pre-treatment only}

First, and in line with other papers demonstrating a protective effect of IFNs [31], we only pre-treated cells for $18 \mathrm{~h}$ with either IFN- $\lambda 1$ or IFN- $\beta$, removed the IFN containing medium and then infected them for $4 \mathrm{~h}$ with HRV1B. After another $24 \mathrm{~h}$, cells were collected and HRV1B RNA copy numbers were determined. Figure 1B 
clearly demonstrates that both IFNs protected the cells against HRV1B infection, as HRV RNA copy numbers were significantly lower in IFN pre-treated cells when compared to untreated cells. This decrease in viral copies tended to be more pronounced in IFN- $\beta$ treated samples when compared to IFN- $\lambda 1$, which corresponds with a more pronounced up-regulation of ISGs in IFN- $\beta$ treated samples as compared to IFN- $\lambda 1$ (Fig. $1 \mathrm{~A}$ ).

\section{A}

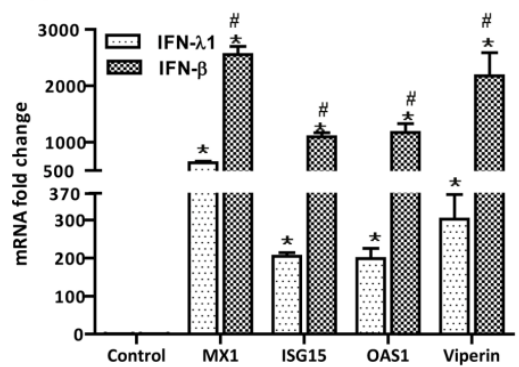

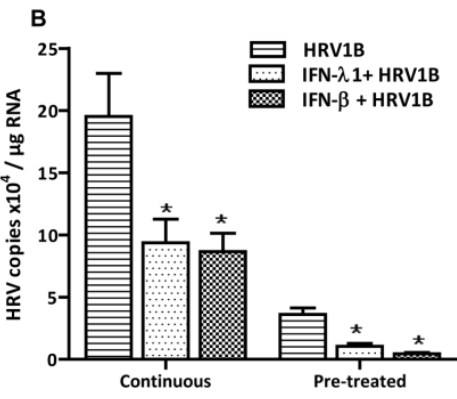

Figure 1. IFN-induced antiviral state protects against HRV1B infection in A549: A549 were treated with IFNs for $18 \mathrm{~h}$ and then mRNA expression of different ISGs was determined by qPCR $(n=6)$. Fold-changes were calculated with the $2^{-\Delta \mathrm{Ct}}$ method (A). A549 were first treated with IFNs for $18 \mathrm{~h}$. Next, according to the continuous and pre-treatment approaches, cells were infected with HRV1B and incubated for another $24 \mathrm{~h}(\mathrm{n}=6)$. After that, cells were collected for further analyses. Viral copies were determined by qPCR and fold-changes were calculated with the $2^{-\Delta \Delta C t}$ method (B). ${ }^{*}, p<0.05$ Control vs IFNs, HRV1B vs IFNs+HRV1B. \# $p<0.05$ IFN- $\lambda 1$ vs IFN- $\beta$.

\section{- Continuous exposure}

Although pre-treatment followed by an infection for a limited time is a wellaccepted model in literature, it may not reflect the natural course of both treatment and infection. Therefore, in an attempt to mimic the in vivo situation more closely, we first treated cells with either of the IFNs for $18 \mathrm{~h}$ and subsequently infected them with HRV1B in the continuous presence of the IFNs. Also, virus was not removed after $4 \mathrm{~h}$ as in the pre-treatment protocol, but was kept present in the incubation medium until cells were collected (after $24 \mathrm{~h}$ ). As expected, at $24 \mathrm{~h}$ after infection viral copy numbers were markedly higher in the untreated cells when compared to cells infected for only $4 \mathrm{~h}$ ( $4 \mathrm{~h}: 3.6 \times 10^{4}$ vs. $24 \mathrm{~h}: 2.0 \times 10^{5}$ copies $/ \mu \mathrm{g}$ RNA). Nevertheless, despite these higher viral copy numbers, both types of IFNs were still able to reduce the number of HRV RNA copies significantly (Fig. 1B). 


\section{IFN- $\lambda 1$-induced antiviral state provides long-lasting protection against HRV1B infection}

Previously, we have shown that exogenous administration of IFN- $\beta$ provides a longlasting protection against viral infection [22]. After confirming that cells were protected against a viral infection immediately after IFN- $\lambda 1$ treatment, we aimed to explore whether IFN- $\lambda 1$ also has the potential to provide a long-lasting protection. A549 cells were therefore treated with IFN- $\lambda 1$ or IFN- $\beta$ for $18 \mathrm{~h}$ only. Then the IFNcontaining medium was either washed away (pre-treatment only) and cells were cultured for another $72 \mathrm{~h}$ in the absence of IFNs, or cells were cultured for another $72 \mathrm{~h}$ in the continuous presence of either one of the IFNs (continuous exposure).

A

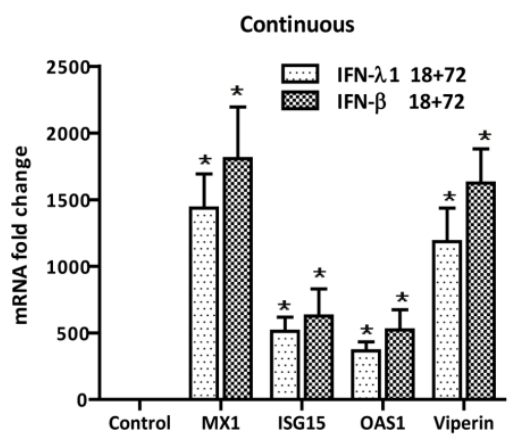

C

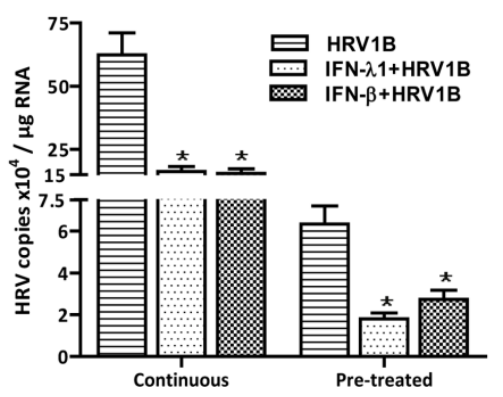

B

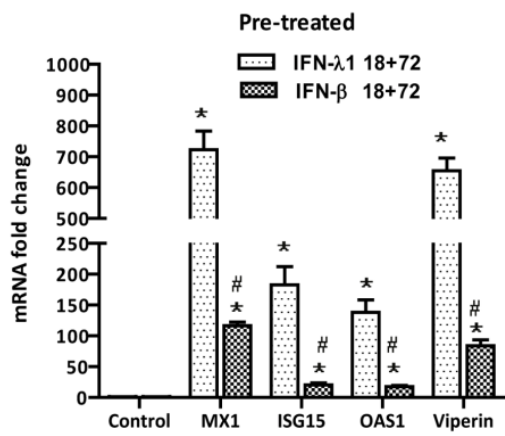

Figure 2. Long-lasting antiviral state induced by IFNs: A549 were treated with IFNs for $18 \mathrm{~h}$. Next, according to the continuous and pre-treatment approaches, cells cultured for another $72 \mathrm{~h}$ and collected afterwards for further analyses $(n=4)$. mRNA expression of different genes was determined by GPCR and fold changes were calculated with the $2^{-\Delta \Delta C t}$ method (A \& B). Moreover, to evaluate the antiviral status of the cells after $72 \mathrm{~h}$ of culturing, cells were infected with HRV1B and incubated for another $24 \mathrm{~h}(\mathrm{n}=5)$. After that, viral copies were determined by $\mathrm{qPCR}$ and fold changes were calculated with the $2^{-\Delta \Delta C t}$ method (C). ${ }^{*}, p<0.05$ HRV1B vs IFNs+HRV1B, control vs IFNs. \#, $p<0.05$ IFN- $\lambda 1$ vs IFN- $\beta$.

To check whether cells were still in an antiviral state, we determined the expression of the various ISGs under different conditions. As expected, prolonged continuous exposure to IFNs resulted in high levels of all ISGs determined, and no differences were observed between IFN- $\lambda 1$ and IFN- $\beta$ (Fig. $2 A$ ). Also when cells were only pre-treated for 18h, ISG levels were still significantly enhanced even after additional culturing for $72 \mathrm{~h}$ in the absence of the IFNs. Surprisingly, ISG levels 
were significantly higher in cells pre-treated with IFN- $\lambda 1$, suggesting that the protective effects of this type III IFN may last longer than the effect of IFN- $\beta$ (Fig. 2B).

To test whether this antiviral state, either after continuous exposure or pre-treatment only, was sufficient to protect cells against HRV infection, cells were infected with HRV1B for either $4 \mathrm{~h}$ (pre-treatment protocol, cells collected after another $24 \mathrm{~h}$ ) or for $24 \mathrm{~h}$ (continuous protocol) $72 \mathrm{~h}$ after the initial IFN treatment. Figure $2 \mathrm{C}$ shows that in both conditions a significant decrease in viral copies was found in IFN-treated cells as compared to control cells. These data imply that a single treatment with IFN- $\lambda 1$, like IFN- $\beta$, is able to induce an antiviral state in these cells, which protects them for a prolonged time (in this case $72 \mathrm{~h}$ ) against future viral infections.

\section{Priming of cells with IFNs enhances their ability to produce IFNs}

IFNs can act in an autocrine and/or paracrine way to up-regulate their own expression, thereby reinforcing and/or maintaining their antiviral effects ("priming"). In order to determine whether the observed long-lasting protective effect was due to this phenomenon, we determined whether treatment with either IFN- $\beta$ or $-\lambda 1$ resulted in such a (cross-) priming effect. Also, we assessed whether the initial IFN treatment followed by an HRV1B infection affected the induction of IFN- $\beta /-\lambda 1$ expression. Cells were therefore initially treated with either IFN- $\beta$ or $-\lambda 1$ for $18 \mathrm{~h}$ and cultured for another $72 \mathrm{~h}$ according to the pre-treatment or continuous protocol. Afterwards cells were either infected with HRV1B or not and cultured for another $24 \mathrm{~h}$.

\section{- Expression of IFN-B after stimulation with IFNs}

Although it has been shown previously that IFN- $\beta$ priming enhanced the expression of IFN- $\beta$ [32], we were unable to see this effect when cells were only pre-treated (Fig. 3A). Also, no clear evidence for cross-priming was observed as IFN- $\lambda 1$ pretreatment did not have any significant effect on the expression of IFN- $\beta$ mRNA. Surprisingly, subsequent infection with HRV1B also did not enhance the expression of IFN- $\beta$, irrespective of whether cells were pre-treated with IFN- $\beta$ or IFN- $\lambda 1$. Alternatively, when cells were stimulated with IFNs for the entire period, the expression of IFN- $\beta$ mRNA was significantly enhanced both after treatment with IFN- $\beta$ ( 8.5 -fold) or IFN- $\lambda 1$ (3.2-fold) $(p<0.005)$, indicating that (cross-)priming occurred after prolonged exposure. Moreover, when cells were continuously 
stimulated and subsequently infected with HRV1B, the expression of IFN- $\beta$ mRNA was further enhanced irrespective of the type of IFN they were first treated with (16.1-fold with IFN- $\beta$ and 12.4 -fold with IFN- $\lambda 1$ ( $p \leq 0.05$ ) (Fig. $3 A$ ).

A

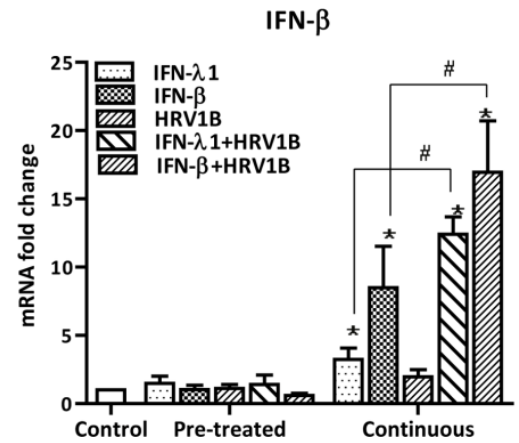

B

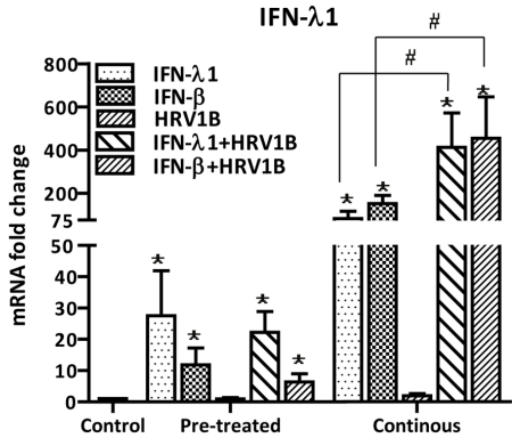

Figure 3. Priming effect of IFNs on HRV1B-induced interferon response: A549 were first treated with IFNs for $18 \mathrm{~h}$. Next, cells were incubated for another $72 \mathrm{~h}$ according to the continuous and pre-treatment approaches. After that cells were infected with HRV1B for $4 \mathrm{~h}$ in the same medium. After the infection period, either same medium was maintained on the cells (continuous) or replaced by fresh medium (pre-treated). Thereafter, cells were incubated for another $24 \mathrm{~h}$ and then collected for further analyses. mRNA levels of IFN- $\beta$ (A) and IFN- $\lambda 1$ (B) were determined by qPCR and fold changes were calculated with the $2^{-\Delta \Delta \mathrm{Ct}}$ method. HRV1B induced average IFN- $\beta$ expression was 1.8 (continuous) and 0.99 (pretreated) folds and average IFN- $\lambda 1$ expression was 1.92 (continuous) and 0.90 folds (pre-treated). *, $p<0.05$ control vs rest of conditions. \#, $p<0.05$ IFN vs IFN+HRV1B. $n=4$

\section{- Expression of IFN- $\lambda 1$ after stimulation with IFNs}

We also examined whether priming resulted in enhanced expression of IFN- $\lambda 1$ (Fig. $3 B$ ). In contrast to priming with IFN- $\beta$, we noticed a significant increase in the expression of IFN- $\lambda 1$ mRNA even when cells were only pre-treated for $18 \mathrm{~h}$ and collected at the end of the experiment $(27.5$-fold with IFN- $\lambda 1$ and 11.8 -fold with IFN- $\beta)(p<0.01)$. However, no further increase was observed when cells were additionally infected with HRV1B (22.0-fold with IFN- $\lambda 1$ and 6.3-fold with IFN- $\beta$ ). On the other hand, continuous stimulation with either of both cytokines was sufficient for a significant induction of the expression of IFN- $\lambda 1$ mRNA ( 90 -fold with IFN- $\lambda 1$ and 180 -fold with IFN- $\beta)(p<0.005)$, which was further increased as a result of HRV1B infection (460-fold with IFN- $\lambda 1$ and 513 -fold with IFN- $\beta$ ) $(p<0.05)$.

Summarizing, we noticed a strong (cross-) priming effect of IFN- $\beta$ and IFN- $\lambda 1$ on the expression of IFN- $\lambda 1$. In contrast, IFN- $\beta$ seemed less prone to (cross-)priming. 


\section{HRV1B does not induce an interferon response}

In the previous experiment we intriguingly noticed that the expression of IFN- $\beta$ was hardly enhanced when cells were infected with HRV1B. Usually, basal IFNs and ISGs mRNA levels are very low in uninfected cells and it is generally assumed that their expression strongly increases after viral infection. Accordingly, previous reports demonstrated an increase in the expression of both type I and III IFN mRNA in epithelial cells following HRV infection [33,34]. Surprisingly, however, we did not observe such an increase in the expression of these genes in the experiments described above. To further explore this observation, we infected A549 cells for $4 \mathrm{~h}$ and determined the expression of IFN- $\beta /-\lambda 1$ and various ISGs after $24 \mathrm{~h}$. However, as already shown in experiments described above, no induction of any of the ISGs was observed even when HRV1B was continuously present for the entire $24 \mathrm{~h}$ period (Fig. 4A). Similarly, no change in IFN- $\beta$ expression was found while IFN- $\lambda 1$ levels remained undetectable. Infection with another SSRNA virus, RSV, or stimulation with the viral mimic polyl:C/LyoVec both resulted in the induction of IFN genes, indicating these cells are well able to produce type I and III IFNs (Fig. 4B).

A

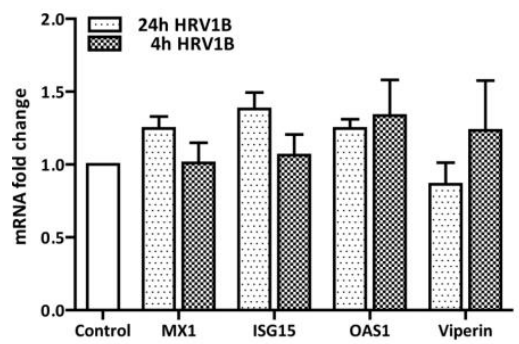

B

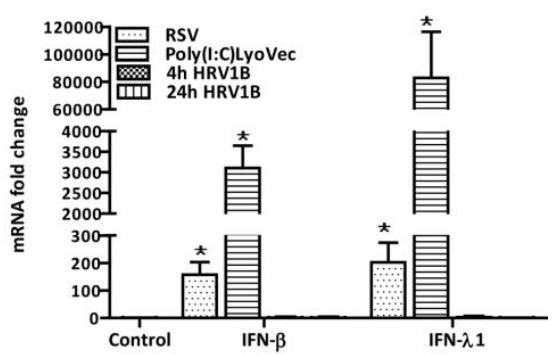

Figure 4. HRV1B induced interferon response in A549: A549 were infected with HRV1B for 4h and collected after $24 \mathrm{~h}$, or for the whole experimental procedure $(n=6)$. The mRNA expression of ISGs was determined with qPCR and fold changes were calculated with the $2^{-\Delta \Delta C t}$ method (A). Cells were infected with RSV (MOI-1, 1h) or HRV1B (4h). After infection, virus containing medium was removed and replaced with fresh medium. Then cells were collected after $24 \mathrm{~h}(n=5)$. While with poly $(\mathrm{I}: \mathrm{C}) / \mathrm{LyoVec}(500$ $\mathrm{ng} / \mathrm{ml}$ ), cells were collected after $18 \mathrm{~h}$ of stimulation ( $\mathrm{n}=3)$. IFN $\beta / \lambda 1 \mathrm{mRNA}$ expression was determined by qPCR and fold changes were calculated with the $2^{-\Delta \Delta C t}$ method $(B){ }^{*}, p<0.05$ control vs rest of the conditions.

IFN- $\lambda 1$ induces an antiviral state in PBECs which provides protection against HRV1B infection

Although A549 cells are basically human alveolar epithelial cells, they were originally derived from an alveolar adenocarcinoma, and it can therefore not be excluded that they respond differently to external stimuli than primary cells. 
Moreover, A549 cells are of alveolar origin while bronchial epithelial cells come in contact with infectious agents before alveolar cells. Therefore, to put our results with A549 cells into perspective, we repeated some of the experiments with PBECs. First we also infected these cells with HRV1B for either 4 or $24 \mathrm{~h}$ and in line with our results found in $A 549$ cells, we were unable to detect an up-regulation of IFN- $\beta$, IFN- $\lambda 1$ or any of the ISGs. Nonetheless, similar to A549, PBECs were also able to express IFNs in response to stimulation with poly (I: C)/LyoVec or to a viral infection as RSV (Fig. 5A, B). The results both in A549 as well as the primary cells strongly suggest that HRV1B is to some extent able to evade the host antiviral response in our experimental settings.
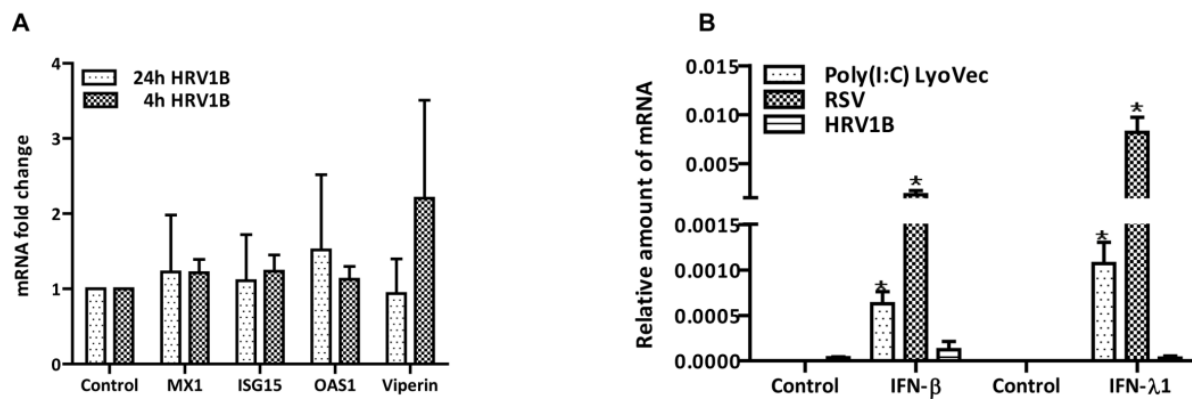

Figure 5. HRV1B induced interferon response in PBECs and its comparison with other stimuli: PBECS were infected with HRV1B for $4 \mathrm{~h}$ and collected after $24 \mathrm{~h}$, or for the whole experimental procedure $(n=4)$. The mRNA expression of ISGs was determined with QPCR and fold changes were calculated with the $2^{-\Delta \Delta C t} \operatorname{method}(\mathrm{A})$.

Cells were infected with RSV (MOI-1, 1h) or HRV1B (4h). After infection, virus-containing medium was removed and replaced with fresh medium. Additionally, cells were stimulated with poly(I:C)/LyoVec $(500$ $\mathrm{ng} / \mathrm{ml}$ ) for $24 \mathrm{~h}(\mathrm{n}=3)$. Then cells were collected and IFN $\beta / \lambda 1 \mathrm{mRNA}$ expression was determined by $\mathrm{qPCR}$ and relative amount of mRNA was calculated with the $2^{-\Delta C t}$ method (B). ${ }^{*}, p<0.05$ control vs rest of the conditions.

Next, we tested whether IFN treatment was able to protect primary cells against HRV infection. Therefore, cells were pre-treated for $18 \mathrm{~h}$ and then infected with HRV1B according to the pre-treatment or continuous protocol. Figure $6 \mathrm{~A}$ shows that, like in A549 cells, both IFNs were well able to protect PBECs against HRV1B infection as viral RNA levels were noticeably reduced in pre-treated cells when compared to control cells. In line with this is the pronounced up-regulation of ISGs as shown in figure 6B. To further confirm the protective effect of IFN pretreatment, we determined the generation of infectious viral particles. Again, and in accordance with viral RNA copy numbers, generation of infectious viral particles in IFN-treated cells was significantly lower as compared to non-treated samples (Fig. 
$6 C)$. It should be mentioned that we were unable to test whether IFNs also had a long-lasting protective effect in PBEC because of viability issues when primary cells were cultured for more than $72 \mathrm{~h}$ regardless of IFN treatment.

A

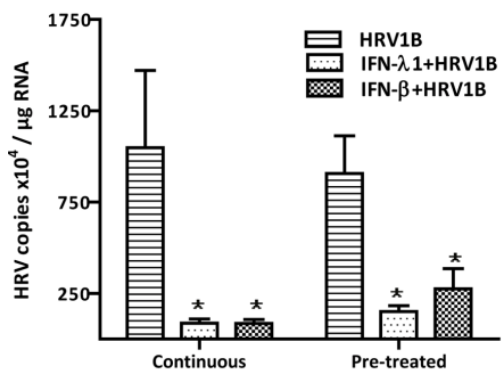

C

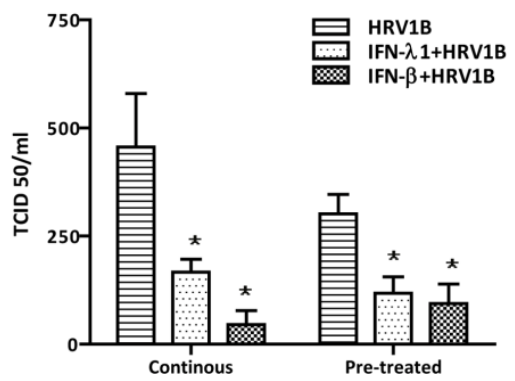

B

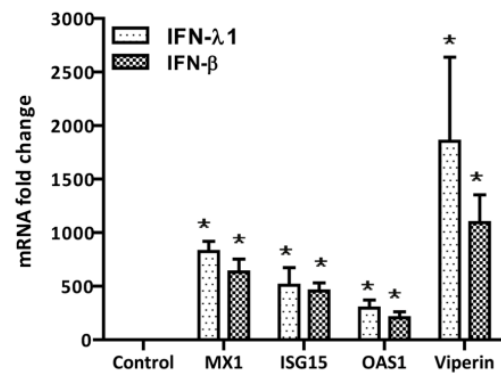

Figure 6. IFNs-induced antiviral state protects against HRV1B infection in PBECs: PBECs were infected with HRV1B for $4 \mathrm{~h}$. After infection period, medium was either maintained on the cells (continuous) or replaced with fresh medium (pretreated). After that cells were incubated for another $24 \mathrm{~h}$. Then the supernatant was collected to determine TCID50 (C) while cells were collected to determine viral copies (A). PBECs were treated with IFNs for $18 \mathrm{~h}$ and then mRNA expression of different ISGs was determined by GPCR. Fold changes were calculated with the $2^{-\Delta \Delta C t}$ method (B). ${ }^{*}, p<0.05$ control vs rest of the conditions $n=4$. 


\section{Discussion}

In this study we assessed the efficacy of IFN- $\lambda 1$ to protect respiratory epithelial cells against HRV1B infection and compared its effects to the previously reported protective effects induced by IFN- $\beta$. Results of the current study revealed that exogenous administration of both IFNs, irrespective of how cells had been treated (pre-treatment vs. continuous), induced a strong antiviral state in both A549 and PBECs, which was associated with a robust up-regulation of various ISGs. This antiviral state provided efficient protection against subsequent viral infection in both conditions. Yet, as compared to IFN- $\beta$, the IFN- $\lambda 1$ - induced antiviral state seemed to strengthen itself over time, as the expression of ISGs induced by IFN- $\lambda 1$ was either sustained or even increased, while expression of IFN- $\beta$-induced ISGs decreased over time.

Type-III IFNs are relatively recently discovered members of the IFN family. Like type-I IFNs, type-III IFNs have also been shown to be induced by viral infections and to possess antiviral properties. Although type-I and type-III IFNs act through different receptors, both types of IFNs activate similar intracellular signaling pathways and because of this, they largely have similar biological activities. Both of them up-regulate the expression of ISGs, which are presumably responsible to provide antiviral resistance to the cells $[35,36]$. However, not all types of cells respond to type-III IFNs, which is due to the fact that expression of receptors for type-III IFNs is limited to a few types of cells. Epithelial cells in the respiratory, gastrointestinal and reproductive tract are considered to be the primary cells which express receptors for type-III IFNs $[15,37]$. Particularly in the respiratory tract, typeIII IFNs have been shown to be important mediators in response to respiratory viral infections $[16,23,24]$. In this study we investigated whether type III IFNs have a potential as prophylactic agents against viral infections.

We and others have previously demonstrated that IFN- $\beta$ treatment of respiratory epithelial cells induces a strong antiviral state in these cells which markedly protects them against viral infections. This antiviral condition was noticeably associated with a distinct up-regulation in the expression of various ISGs. In the present study we demonstrated similar effects when cells were treated with IFN- $\lambda 1$ resulting in a 200- to 700 -fold up-regulation in the expression of all ISGs examined. Although this up-regulation was significantly less than the effects induced by IFN- $\beta$, it was still sufficient to protect the cells from a subsequent HRV1B infection. Interestingly, in primary cells the effects of both IFNs were quite 
comparable, as no significant differences were found in the up-regulation of all ISGs, the presence of viral copies in the cells or the release of infectious progeny.

Induction of ISGs by type-I and -III IFNs is mainly dependent on the activation of the Jak/STAT signal transduction pathway [36,38]. Differences in the activation of the Jak/STAT pathway by type-I and type-III IFNs have already been reported. Earlier, Maher and colleagues [39] have shown that continuous treatment of human keratinocyte cell line $\mathrm{HaCat}$ with IFN- $\lambda 1$ resulted in sustained activation of STAT1 and STAT2 over the course of $24 \mathrm{~h}$. On the contrary, treatment with IFN- $\alpha$, a type-I IFN, resulted in transient activation of STAT1 and STAT2. This could be due to differential regulation of type-I and type-III signaling. They also showed that expression of IFN- $\lambda 1$ induced ISGs continued to increase at $24 \mathrm{~h}$. In the present study, we also observed differences in the kinetics of induction of ISGs by IFN- $\beta$ and IFN- $\lambda 1$. The protective effect induced by an $18 \mathrm{~h}$ pre-treatment with both types of IFNs was persistent and long-lasting. Even when cells were cultured in the absence of the IFNs for an additional $72 \mathrm{~h}$ after the $18 \mathrm{~h}$ pretreatment period, cells were significantly protected against a subsequent HRV infection. However, when cells were pre-treated with IFN- $\beta$, the expression of most of the ISGs peaked immediately after the $18 \mathrm{~h}$ pre-treatment period and declined significantly when cells were cultured for another $72 \mathrm{~h}$ in the absence of IFN- $\beta$. In contrast, when cells were pre-treated with IFN- $\lambda 1$, the expression of all ISGs remained constant or was even increased after an additional $72 \mathrm{~h}$ of culturing in the absence of IFN- $\lambda 1$. We did not determine the activation status of STAT1/STAT2, yet data of mRNA expression of IFNs presented in figure 3 show that the observed expression of ISGs is in line with the expression of IFNs. Also, it shows that IFN- $\lambda 1$, in contrast to IFN- $\beta$, is well able to induce its own expression. This supports the findings of Ank and colleagues who demonstrated that both type I and type III IFNs are able to (cross-)induce the expression of type III IFNs but not type I IFNs [12]. However, in contrast to Ank et. al., we also observed an up-regulation of the IFN- $\beta$ expression in response to long term stimulation with both IFN- $\beta$ itself and also with IFN- $\lambda 1$, both in the presence or absence of infectious agent HRV1B (continuous scenario). In the presence of HRV1B the increase in the IFN- $\beta$ expression could be mediated by IRF-7, as both IFN- $\beta$ and $-\lambda 1$ can prime IRF-7, which will subsequently result in virus-induced nuclear translocation and increased transcription of IFNs $[18,32,40]$. Nonetheless, in the absence of a virus, the increase in the IFN- $\beta$ expression could be driven by IRF-1. IRF-1 can be up-regulated by IFNs and then can induce IFN- $\beta[41,42]$. Due to 
this characteristic of IFN- $\lambda 1$, the strength of the antiviral state induced by this type of IFN may be maintained for a prolonged period.

In order to replicate in host cells, viruses have evolved different strategies to subvert the host interferon response. Also HRVs have been shown to have this ability. For example, when A549 cells were infected with HRV14 only low levels of IFN- $\beta$ mRNA were induced as compared to those induced by vesicular stomatitis virus [43]. This attenuation of the antiviral response by the virus was shown to be due to interference with IRF3 activation. Similar results were found when HeLa cells were infected with HRV1a [44]. Consistent with these observations, one very recent study also showed no induction of IFN- $\beta$ after HRV1B infection in primary bronchial epithelial cells, which were isolated from healthy persons [45]. Likewise, in the present study, we also did not observe an up-regulation of the IFNs or ISGs mRNA expression after infection of A549 or PBECs with HRV1B. In contrast, when PBECS were infected with RSV or were stimulated with poly(I:C)/LyoVec, a synthetic ligand for intracellular sensors of viral RNA, RIG-I and MDA5, we found a strong upregulation in the expression of both IFN- $\beta$ and IFN- $\lambda 1$ mRNA. Similar results were observed in A549 cells. This indicates that cells are well able to respond to viral stimuli and are capable to mount both a type-I and a type-III IFN response. Furthermore, up-regulation of ISGs in response to IFN treatment shows that IFN signaling in these cells was also intact. These data suggest that HRV is able to actively interfere with the IFN-dependent antiviral response in respiratory epithelial cells. Nevertheless, this finding is in conflict with data published by several other groups who demonstrated a moderate to strong up-regulation of IFN$\beta$ mRNA expression $[34,46]$. The reason for this discrepancy is not clear, but could be due to different experimental conditions, different virus strains/stocks or different types or sources of cells. In this study we did not further explore this inconsistency between different studies as it was beyond the scope of the present study, but further investigations are required to unravel the reason for these differences.

Altogether, these data indicate that both IFN- $\beta$ and IFN- $\lambda 1$ are able to provide protection against viral infection with comparable efficacy. However, because of the more restricted distribution of its receptors to the epithelial lining in particular of the respiratory tract, and a sustained long-term induction of ISGs, IFN$\lambda 1$ therapy can have a more important role in the prevention of viral infections with probable causation of fewer side effects. Yet, further work is required in particular regarding the efficacy of the cytokine in an in vivo setting. 


\section{References}

1. Papi A, Bellettato CM, Braccioni F, Romagnoli M, Casolari $P$, et al. (2006) Infections and airway inflammation in chronic obstructive pulmonary disease severe exacerbations. Am J Respir Crit Care Med 173: 1114-1121.

2. Akinbami L, Moorman JE, Liu X (2011) Asthma prevalence, health care use, and mortality: United States, 2005-2009. Natl Health Stat Report: 1-14.

3. Friedlander SL, Busse WW (2005) The role of rhinovirus in asthma exacerbations. J Allergy Clin Immunol 116: 267-273.

4. Mallia P, Johnston SL (2006) How viral infections cause exacerbation of airway diseases. Chest 130 : 1203-1210.

5. Rohde G, Wiethege A, Borg I, Kauth M, Bauer T, et al. (2003) Respiratory viruses in exacerbations of chronic obstructive pulmonary disease requiring hospitalisation: a case-control study. Thorax 58: 37-42.

6. Seemungal TA, Harper-Owen R, Bhowmik A, Jeffries DJ, Wedzicha JA (2000) Detection of rhinovirus in induced sputum at exacerbation of chronic obstructive pulmonary disease. Eur Respir J 16: 677-683.

7. Corne JM, Marshall C, Smith S, Schreiber J, Sanderson G, et al. (2002) Frequency, severity, and duration of rhinovirus infections in asthmatic and non-asthmatic individuals: a longitudinal cohort study. Lancet 359: 831-834.

8. Mallia P, Message SD, Gielen V, Contoli M, Gray K, et al. (2011) Experimental rhinovirus infection as a human model of chronic obstructive pulmonary disease exacerbation. Am J Respir Crit Care Med 183: 734-742.

9. Vareille M, Kieninger E, Edwards MR, Regamey N (2011) The airway epithelium: soldier in the fight against respiratory viruses. Clin Microbiol Rev 24: 210-229.

10. Jackson DJ, Johnston SL (2010) The role of viruses in acute exacerbations of asthma. J Allergy Clin Immunol 125: 1178-1187; quiz 1188-1179.

11. Costa-Pereira AP, Williams TM, Strobl B, Watling D, Briscoe J, et al. (2002) The antiviral response to gamma interferon. J Virol 76: 9060-9068.

12. Ank N, West H, Bartholdy C, Eriksson K, Thomsen AR, et al. (2006) Lambda interferon (IFN-lambda), a type III IFN, is induced by viruses and IFNs and displays potent antiviral activity against select virus infections in vivo. J Virol 80: 4501-4509.

13. Jewell NA, Vaghefi N, Mertz SE, Akter P, Peebles RS, Jr., et al. (2007) Differential type I interferon induction by respiratory syncytial virus and influenza a virus in vivo. J Virol 81: 9790-9800.

14. Mordstein M, Kochs G, Dumoutier L, Renauld JC, Paludan SR, et al. (2008) Interferon-lambda contributes to innate immunity of mice against influenza $A$ virus but not against hepatotropic viruses. PLoS Pathog 4: e1000151.

15. Mordstein M, Neugebauer E, Ditt V, Jessen B, Rieger T, et al. (2010) Lambda interferon renders epithelial cells of the respiratory and gastrointestinal tracts resistant to viral infections. J Virol 84: 5670-5677.

16. Jewell NA, Cline T, Mertz SE, Smirnov SV, Flano E, et al. (2010) Lambda interferon is the predominant interferon induced by influenza A virus infection in vivo. J Virol 84: 11515-11522.

17. Osterlund PI, Pietila TE, Veckman V, Kotenko SV, Julkunen I (2007) IFN regulatory factor family members differentially regulate the expression of type III IFN (IFN-lambda) genes. J Immunol 179: 3434-3442.

18. Sato M, Hata N, Asagiri M, Nakaya T, Taniguchi T, et al. (1998) Positive feedback regulation of type I IFN genes by the IFN-inducible transcription factor IRF-7. FEBS Lett 441: 106-110.

19. Stoltz M, Klingstrom J (2010) Alpha/beta interferon (IFN-alpha/beta)-independent induction of IFNlambda1 (interleukin-29) in response to Hantaan virus infection. J Virol 84: 9140-9148.

20. Wark PA, Johnston SL, Bucchieri F, Powell R, Puddicombe S, et al. (2005) Asthmatic bronchial epithelial cells have a deficient innate immune response to infection with rhinovirus. J Exp Med 201: 937-947.

21. Traves SL, Proud D (2007) Viral-associated exacerbations of asthma and COPD. Curr Opin Pharmacol 7: 252-258. 
22. Gaajetaan GR, Geelen TH, Vernooy JH, Dentener MA, Reynaert NL, et al. (2013) Interferon-beta induces a long-lasting antiviral state in human respiratory epithelial cells. J Infect 66: 163169.

23. Contoli M, Message SD, Laza-Stanca V, Edwards MR, Wark PA, et al. (2006) Role of deficient type III interferon-lambda production in asthma exacerbations. Nat Med 12: 1023-1026.

24. Okabayashi T, Kojima T, Masaki T, Yokota S, Imaizumi T, et al. (2011) Type-III interferon, not type-I, is the predominant interferon induced by respiratory viruses in nasal epithelial cells. Virus Res 160: 360-366.

25. van Wetering S, van der Linden AC, van Sterkenburg MA, de Boer WI, Kuijpers AL, et al. (2000) Regulation of SLPI and elafin release from bronchial epithelial cells by neutrophil defensins. Am J Physiol Lung Cell Mol Physiol 278: L51-58.

26. Gielen V, Johnston SL, Edwards MR (2010) Azithromycin induces anti-viral responses in bronchial epithelial cells. Eur Respir J 36: 646-654.

27. Boncristiani HF, Rossi RD, Criado MF, Furtado FM, Arruda E (2009) Magnetic purification of biotinylated cDNA removes false priming and ensures strand-specificity of RT-PCR for enteroviral RNAs. J Virol Methods 161: 147-153.

28. Gaajetaan GR, Geelen TH, Grauls GE, Bruggeman CA, Stassen FR (2012) CpG and poly(I:C) stimulation of dendritic cells and fibroblasts limits herpes simplex virus type 1 infection in an IFNbetadependent and -independent way. Antiviral Res 93: 39-47.

29. Schmittgen TD, Livak KJ (2008) Analyzing real-time PCR data by the comparative C(T) method. Nat Protoc 3: 1101-1108.

30. Randall RE, Goodbourn S (2008) Interferons and viruses: an interplay between induction, signalling, antiviral responses and virus countermeasures. J Gen Virol 89: 1-47.

31. Hou W, Wang X, Ye L, Zhou L, Yang ZQ, et al. (2009) Lambda interferon inhibits human immunodeficiency virus type 1 infection of macrophages. J Virol 83: 3834-3842.

32. Colonne PM, Eremeeva ME, Sahni SK (2011) Beta interferon-mediated activation of signal transducer and activator of transcription protein 1 interferes with Rickettsia conorii replication in human endothelial cells. Infect Immun 79: 3733-3743.

33. Chattoraj SS, Ganesan S, Faris A, Comstock A, Lee WM, et al. (2011) Pseudomonas aeruginosa suppresses interferon response to rhinovirus infection in cystic fibrosis but not in normal bronchial epithelial cells. Infect Immun 79: 4131-4145.

34. Slater L, Bartlett NW, Haas JJ, Zhu J, Message SD, et al. (2010) Co-ordinated role of TLR3, RIG-I and MDA5 in the innate response to rhinovirus in bronchial epithelium. PLoS Pathog 6: e1001178.

35. Cheng JC, Yeh YJ, Huang YH, Liang KH, Chang ML, et al. (2012) Hepatic expression of MxA and OAS1 in an ex vivo liver slice assay independently predicts treatment outcomes in chronic hepatitis C. J Viral Hepat 19: e154-162.

36. Stark GR, Kerr IM, Williams BR, Silverman RH, Schreiber RD (1998) How cells respond to interferons. Annu Rev Biochem 67: 227-264.

37. Sommereyns C, Paul S, Staeheli P, Michiels T (2008) IFN-lambda (IFN-lambda) is expressed in a tissue-dependent fashion and primarily acts on epithelial cells in vivo. PLoS Pathog 4: e1000017.

38. Kotenko SV, Gallagher G, Baurin VV, Lewis-Antes A, Shen M, et al. (2003) IFN-lambdas mediate antiviral protection through a distinct class II cytokine receptor complex. Nat Immunol 4: 6977.

39. Maher SG, Sheikh F, Scarzello AJ, Romero-Weaver AL, Baker DP, et al. (2008) IFNalpha and IFNlambda differ in their antiproliferative effects and duration of JAK/STAT signaling activity. Cancer Biol Ther 7: 1109-1115.

40. Honda K, Yanai H, Negishi H, Asagiri M, Sato M, et al. (2005) IRF-7 is the master regulator of type-I interferon-dependent immune responses. Nature 434: 772-777.

41. Xie RL, Gupta S, Miele A, Shiffman D, Stein JL, et al. (2003) The tumor suppressor interferon regulatory factor 1 interferes with SP1 activation to repress the human CDK2 promoter. J Biol Chem 278: 26589-26596.

42. Venkatesh D, Ernandez T, Rosetti F, Batal I, Cullere X, et al. (2013) Endothelial TNF receptor 2 induces IRF1 transcription factor-dependent interferon-beta autocrine signaling to promote monocyte recruitment. Immunity 38: 1025-1037. 
43. Kotla S, Peng T, Bumgarner RE, Gustin KE (2008) Attenuation of the type I interferon response in cells infected with human rhinovirus. Virology 374: 399-410.

44. Drahos J, Racaniello VR (2009) Cleavage of IPS-1 in cells infected with human rhinovirus. J Virol 83: 11581-11587.

45. Baines KJ, Hsu AC, Tooze M, Gunawardhana LP, Gibson PG, et al. (2013) Novel immune genes associated with excessive inflammatory and antiviral responses to rhinovirus in COPD. Respir Res 14: 15.

46. Khaitov MR, Laza-Stanca V, Edwards MR, Walton RP, Rohde G, et al. (2009) Respiratory virus induction of alpha-, beta- and lambda-interferons in bronchial epithelial cells and peripheral blood mononuclear cells. Allergy 64: 375-386. 


\section{Supplementary figure-1: Dose titration of IFNs}

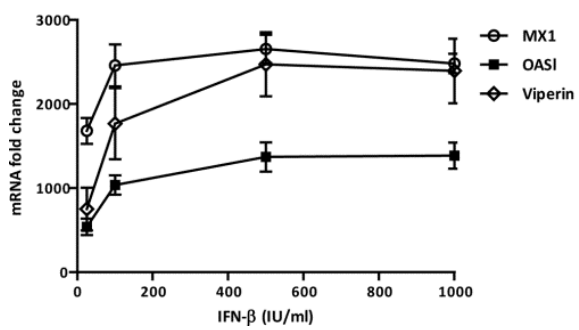

B

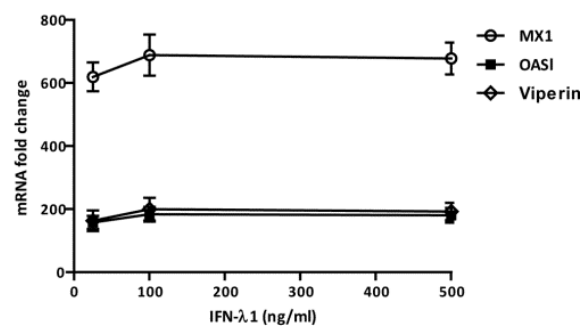

A549 were treated with IFN- $\beta(25,100,500$ and $1000 \mathrm{IU} / \mathrm{ml})(\mathrm{A})$ and IFN- $\lambda 1(25,100$ and $500 \mathrm{ng} / \mathrm{ml})$ (B) for $18 \mathrm{~h}$. mRNA expression of different ISGs was determined by $\mathrm{qPCR}(\mathrm{n}=4)$. Fold-changes were calculated with the $2^{-\Delta \Delta \mathrm{Ct}}$ method.

\section{Supplementary figure-2: Schematic representation of treatment with IFNs and HRV1B infection protocol.}

Infection Immediately after IFN treatment

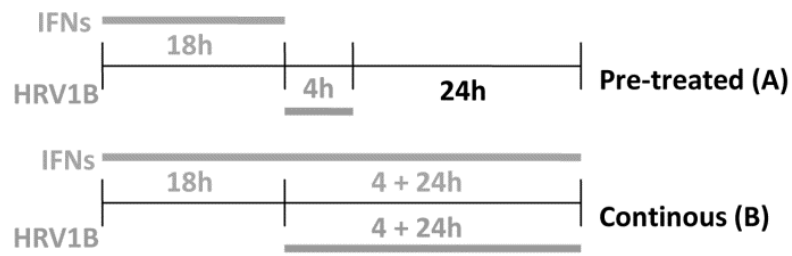

\section{Infection after $72 \mathrm{~h}$ of incubation +/- IFN treatment}

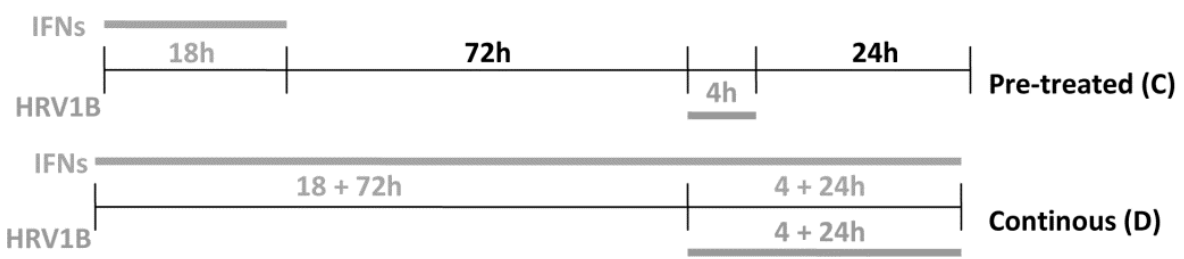

Cells were first treated with IFNs for 18h. After that, two different approaches were followed for infection with HRV1B: i) Pre-treated: IFNs containing medium was replaced with fresh IFN-free medium. Next, for immediate subsequent infection, cells were infected with HRV1B for $4 h(A)$, while for determining the long lasting protective effect, cells were incubated for another $72 \mathrm{~h}$ and then infected with HRV1B for $4 \mathrm{~h}(\mathrm{C})$. After infection period, virus-containing medium was replaced with fresh IFN-free medium and cells were incubated for another 24h. ii) Continuous: After $18 \mathrm{~h}$ treatment with IFNs, for immediate subsequent infection cells were infected with HRV1B in the same medium for another $24 \mathrm{~h}$ (B) while to determine long lasting protective effect cells were infected after $72 \mathrm{~h}$ in the same medium (D) and incubated for another $24 \mathrm{~h}$. 
Supplementary Figure-3: Toxicity of IFNs in A549 cells.

\section{MTT}

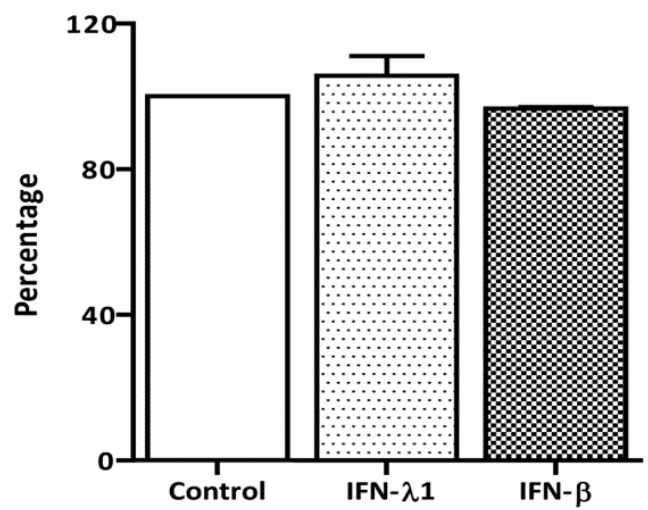

A549 cells were exposed to IFN- $\lambda 1(500 \mathrm{ng} / \mathrm{ml})$ or IFN- $\beta$ (500 IU/ml) for $114 \mathrm{~h}$. Metabolic activity of IFNtreated and non-treated cells was determined by MTT assay and compared to each other. Data are represented as mean +/- SEM of three independent experiments. 
Supplementary table 1. Patient characteristics

\begin{tabular}{|l|l|}
\hline Number of patients & 4 \\
\hline Age in Years & $69.5(65-75)$ \\
\hline $\mathrm{BMI}\left(\mathrm{kg} / \mathrm{m}^{2}\right)$ & $27.8(20-35.26)$ \\
\hline Sex $(\mathrm{F}=$ female, $\mathrm{M}=$ male) & $\mathrm{F}: 1: \mathrm{M}: 3$ \\
\hline Current smokers & 0 \\
\hline Second-hand smoker exposure & 1 \\
\hline Ex-smoker & 1 \\
\hline Pack-years smoked & $15(0-40)$ \\
\hline FEV1 in \% predicted & $114.6(87.8-137.2)$ \\
\hline FVCin in \% predicted & $114.1(77.7-141.3)$ \\
\hline Tiffeneau-Index & $82.9(74.8-105)$ \\
\hline
\end{tabular}

$\mathrm{BMI}=$ Body Mass Index; FEV1 = Forced expiratory volume in 1 second; FVCin = inspiratory forced vital capacity

Supplementary table 2. Primers used for mRNA expression analysis

\begin{tabular}{|c|c|c|}
\hline Gene & & Primer sequences $\left(5^{\prime}-3^{\prime}\right)$ \\
\hline \multirow[t]{2}{*}{ RV } & forward & TGGACAGGGTGTGAAGAGC \\
\hline & reverse & CAAAGTAGTCGGTCCCATCC \\
\hline \multirow[t]{2}{*}{ ISG15 } & forward & GGTGGTGGACAAGTGCGATG \\
\hline & reverse & CGAAGGTCAGCCAGAACAGG \\
\hline \multirow[t]{2}{*}{ Mx1 } & forward & GGACATCGCCACCACAGAGG \\
\hline & reverse & TCCGCACCACATCCACAACC \\
\hline \multirow[t]{2}{*}{ OASL } & forward & TGGGATCTTCTCCCACACTC \\
\hline & reverse & ATAGATCCCCAGACCCAACC \\
\hline \multirow[t]{2}{*}{ Viperin } & forward & AAGCGCATATATTTCATCCAGAATAAG \\
\hline & reverse & CACAAAGAAGTGTCCTGCTTGGT \\
\hline \multirow[t]{2}{*}{ IFN- $\beta$} & forward & AAATTGCTCTCCTGTTGTGC \\
\hline & reverse & TGCAGCTGCTTAATCTCCTC \\
\hline \multirow[t]{2}{*}{ IFN- $\lambda 1$} & forward & GGACGCCTTGGAAGAGTCACT \\
\hline & reverse & AGAAGCCTCAGGTCCCAATTC \\
\hline \multirow[t]{2}{*}{$\beta$-actin } & forward & TGGAGAAATCTGGCACCAC \\
\hline & reverse & GAGGCGTACAGGGATAGCAC \\
\hline
\end{tabular}


Page | 62 


\section{CHAPTER 3}

\section{Effect of exogenous interferons on the inflammatory and antiviral response of macrophages and A549 cells in mono and co- cultures}

Fahad Gulraiz

Gert E Grauls

Erik V Beuken

Cathrien A Bruggeman

Frank R Stassen

Under review in Immunology 


\section{Abstract}

\section{Background}

Administration of exogenous interferons (IFNs) to prevent virus-induced exacerbations in patients of asthma and chronic obstructive pulmonary diseases, could be a therapeutic option. However, the effect of IFNs on the inflammatory response of airway cells, which is a core feature of exacerbations, is not completely understood. In the present in vitro study, we evaluated the effect of exogenous IFN-lambda1 (IFN- $\lambda 1$ ) and IFN-beta (IFN- $\beta$ ) on the inflammatory response of macrophages and epithelial cells in mono- and co-cultures, in terms of production of interleukin 6 (IL-6) and interleukin 8 (IL-8).

\section{Methods}

Type-II like epithelial cells (A549 cell line) and THP-1-derived macrophages were pre-treated with type-III IFN (IFN- $\lambda 1,500 \mathrm{ng} / \mathrm{ml}$ ) and type-I IFN (IFN- $\beta, 500$ IU/ml) for $18 \mathrm{~h}$ in mono- and co-cultures. To determine the effect of pre-treatment with IFNs on the inflammatory and antiviral response upon viral infection in co-cultures, cells were infected with respiratory syncytial virus (RSV) after pre-treatment with IFNs. Media and cells were collected and analyzed further with qPCR and ELISA.

\section{Results}

In mono-cultures, IFNs did not affect IL-6 and IL-8 production in A549, whereas in macrophages IL-8 production was increased. In co-cultures both IFNs significantly increased the IL- 6 and IL- 8 release which was partially mediated by IL- 1 . Upon subsequent RSV infection, both IFNs significantly restricted the viral replication and virus-induced IL- 6 and IL- 8 release, with a more pronounced effect after IFN- $\beta$ treatment. Furthermore, the release of IL- 6 and IL-8, induced by each of the IFNs individually, was moderate when compared to amounts released in response to RSV alone.

\section{Conclusion}

Although administration of both type-I/III IFNs initiated a moderate inflammatory reaction in the co-culture system, the protective effects mediated by the inhibition 
of the viral replication and the reduction in the release of pro-inflammatory cytokines may be far more important. Yet, further studies are warranted to determine the appropriateness of exogenous IFNs to prevent virus-induced exacerbations in patients with chronic respiratory diseases. 


\section{Introduction}

Acute exacerbations (AEs), characterized by acute worsening of the symptoms, are important clinical events in chronic respiratory diseases like asthma and chronic obstructive pulmonary disease (COPD). These exacerbations impose a significant burden on the health care system and deteriorate the quality of life of the patients $[1,2]$. Respiratory infections are the major inducers of AEs and about half of these AEs in asthma and COPD are associated with viral infections $[3,4]$. These viral infections are accompanied by an increased airway inflammation which is an important feature of AEs [1,5]. Thus therapies aiming to prevent viral infections and reduce the inflammation could help to reduce the frequency and morbidity of AEs.

Viral infections result in the induction of interferons (IFNs) by cells as important elements of the host innate antiviral response to control the viral replication [6,7]. On the basis of their amino acid sequence IFNs are divided into three classes, namely type-I, type-II and more recently discovered type-III IFNs. In human, the type-I IFNs contain only one IFN- $\beta$ subtype and multiple IFN- $\alpha$ subtypes. Type-II IFN, on the other hand, has only one subtype, IFN- - , while type-III IFN comprise three subtypes (IFN- $\lambda 1,-\lambda 2$ and $-\lambda 3$ ). Among all three types, type-I and -III IFNs are produced in an immediate response to viral infections and are central to antiviral defense [8]. Although both types bind to distinct receptors $[9,10]$, they activate similar intracellular signaling pathways leading to the induction of a similar set of genes [11,12]. However, unlike the receptors for type-I IFNs, which are ubiquitously expressed [13], expression of receptors for type-III IFNs is restricted to few cell types and mainly epithelial cells and subsets of immune cells are responsive to type-III IFNs [14,15].

Previously it has been shown that the antiviral response is impaired in patients with chronic respiratory diseases, as upon viral infection deficient IFN production has been observed in cells isolated from patients $[16,17]$. Inspired by this observation it has been suggested that strengthening the antiviral response in these patients might be beneficial to prevent infections and consequently AEs. Along this line, we have shown in previous in vitro studies that exogenous application of both IFN- $\beta$ and IFN- $\lambda 1$ provides long lasting protection against human rhinovirus infection in airway epithelial cells [18] suggesting that prophylactic treatment of patients might be an option to prevent viral infections of respiratory tract. Yet, the effect of exogenous IFNs on non-infected cells like 
epithelial cells or macrophages is not completely understood and may eventually elicit an undesirable inflammatory reaction. For example, IFN- $\lambda 1$ has been shown to enhance the production of inflammatory cytokines in peripheral blood mononuclear cells (PBMCs) [14], while IFN- $\beta$ has been shown to have antiinflammatory properties in PBMCs [19] and bronchial epithelial cells [20].

However, results of these studies in individual cell types may not completely depict the effects of the prophylactic application of exogenous IFNs to the respiratory tract. The respiratory tract consists of a complex network of different cells in which particularly macrophages and epithelial cells interact with each other through the production of different mediators to regulate the immune response [21-23]. Thus, studying the effect of prophylactic IFN treatment in cocultures of macrophage and epithelial cells will provide more insight on the inflammatory response of these cells. In the present study we treated THP1derived macrophages and alveolar epithelial cells (A549) with IFN- $\lambda 1$ and IFN- $\beta$, both individually and in co-cultures, and evaluated the inflammatory response in terms of the release of interleukin 6 (IL-6) and interleukin 8 (IL-8). Moreover, in an attempt to extend our previous results in isolated cell cultures regarding the antiviral properties of both IFN types, we also evaluated the effect of prophylactic treatment with IFNs on the antiviral response of cells in these co-cultures. 


\section{Materials and Methods}

\section{Culture Conditions}

The A549 alveolar type-II like cell line (ATCC CCL-185) was maintained in RPMI-1640 medium (Gibco, life technologies, NY, USA) supplemented with $10 \%$ fetal calf serum (FCS; Lonza, Verviers, Belgium) at $37^{\circ} \mathrm{C} / 5 \% \mathrm{CO}_{2}$. The THP1 human monocytic cell line (ATCC TIB-202) was maintained in RPMI-1640 medium supplemented with $100 \mathrm{mM}$ of Sodium pyruvate, $22.5 \%$ Glucose, $25 \mathrm{mM}$ 2-Mercaptoethanol and $10 \%$ $\mathrm{FCS}$ at $37^{\circ} \mathrm{C} / 5 \% \mathrm{CO}_{2}$. To differentiate THP1 monocytes into macrophages, they were cultured for $48 \mathrm{~h}$ in the maintenance medium supplemented with $200 \mathrm{nM}$ phorbol 12-myristate 13-acetate (PMA).

\section{Mono- and co-cultures of A549 and THP1-derived macrophages}

Mono-cultures of A549 and THP1-derived macrophages were prepared by seeding $2.5 \times 10^{5}$ and $2.5 \times 10^{4}$ cells, respectively, in 24-well tissue culture plates (Becton Dickinson, NJ, USA) in one $\mathrm{ml}$ of RPMI-1640 medium supplemented with $10 \%$ FCS.

In co-culture experiments, cell suspensions containing $2.5 \times 10^{5}$ of A549 and $2.5 \times 10^{4}$ of THP1-derived macrophages were prepared in one $\mathrm{ml}$ of the same medium as for mono-cultures and seeded in 24-well tissue culture plates. Both mono- and co-cultures were incubated at $37^{\circ} \mathrm{C} / 5 \% \mathrm{CO}_{2}$ for $24 \mathrm{~h}$ before stimulation.

\section{Virus culture}

Respiratory syncytial virus A2 (RSV) was obtained from Dutch Vaccine institute and propagated on Vero cells. For the generation of viral stocks, cells were infected with RSV at multiplicity of infection of 0.5 (MOI-0.5). After $2 \mathrm{~h}$ of infection cells were washed and incubated further in DMEM with 1\% FCS until > 80\% CPE was attained. Cell debris was removed by centrifugation for 10 minutes at $1000 \times$ g. Virus pool was then polyethylene glycol (PEG) precipitated: PEG stock (50\% PEG6000 in 150 $\mathrm{mM} \mathrm{NaCl}, 1 \mathrm{mM}$ EDTA, $6.1 \mathrm{~g} / \mathrm{L}$ TRIS, $\mathrm{pH} 7.5$ ), mixed with virus pool to get $10 \%$ PEG (1:5), stirred $2 \mathrm{~h}$ at $4 \mathrm{C}$, centrifuged $30 \mathrm{~min}$ at $3000 \times \mathrm{g}$ and the pellet was resuspended in PBS $+25 \%$ sucrose $(10 \%$ of original volume $=10 x$ concentrated). Viral titers were determined by TCID50. 


\section{Stimulation and infection protocol}

Twenty-four hours after seeding the cells, medium was replaced with fresh RPMI1640 medium supplemented with $2 \%$ FCS and both mono- and co-cultures were stimulated with $500 \mathrm{ng} / \mathrm{ml}$ of IFN- $\lambda 1$ and $500 \mathrm{IU} / \mathrm{ml}$ of IFN- $\beta$ (PBL Biomedical Laboratories, NJ, USA) for $18 \mathrm{~h}$. In previous experiments, these concentrations have been shown to effectively prevent viral infections. Next, medium containing IFNs was replaced with fresh medium and cells were infected with RSV at MOI-1 for $1 \mathrm{~h}$ at $37^{\circ} \mathrm{C} / 5 \% \mathrm{CO}_{2}$. Following that, virus-containing medium was replaced with fresh medium, and cells were incubated for another $24 \mathrm{~h}$ at $37^{\circ} \mathrm{C} / 5 \% \mathrm{CO}_{2}$. Supernatants and cells were collected after $18 \mathrm{~h}$ of IFNs stimulation and also after RSV infection at the end of experiment. In order to determine the role of IL-1 in the production of IL- 6 and IL- 8 by IFNs, in co-cultures cells were first pre-treated with Human IL-1-R antagonist (IL-1RA) (PeproTech, London) at $100 \mathrm{ng} / \mathrm{ml}$ for $2 \mathrm{~h}$ and then stimulated with IFNs for $18 \mathrm{~h}$.

\section{Plasmid construction for the generation of standard curves}

In order to determine the number of viral RNA copies present in the cells, a plasmid was constructed as previously described [24] with some modifications. In summary, isolated viral RNA was reverse transcribed in the presence of both RSV primers (supplementary table) (Superscriptll Reverse Transcriptase ,Invitrogen). The obtained cDNA fragment was amplified by PCR and then column-purified (MSB Spin PCRapace kit, Invitek, Germany). After that, it was cloned into the pGEMTeasy vector (Promega, Wisconsin, USA) and sequenced. The resulting plasmid DNA, designated p1092, was in vitro transcribed (T7 RNA polymerase, Fermentas) into RNA and then treated with DNase (DNase I recombinant, RNase free; Roche). RNA concentrations were determined with Nanodrop ND-1000 and copies per $\mu$ l were calculated with Avogadro's number. Serial dilutions of the quantified RNA were used for the generation of a standard curve.

\section{Quantitative real-time PCR}

Total RNA was extracted with FATRK 001 (Favorgen Biotech Corporation, Taiwan) RNA isolation kit according to manufacturer's instructions and DNase treated with Turbo DNA-free kit (Ambion, life technologies, NY, USA). After quantification of RNA with a Nanodrop ND-1000, $1 \mu \mathrm{g}$ of RNA was reverse transcribed with iScript cDNA synthesis kit (Bio-Rad, Hercules, California, USA) in a reaction volume of 20 
$\mu l$. Quantitative real-time PCR (qPCR) was performed as previously described [25]. To quantify the viral RNA copies, standard curves were generated for every qPCR run along with the samples. $\beta$-actin levels were used to normalize the gene expression and fold changes were calculated with $2^{-\Delta \Delta \mathrm{ct}}$ method. In case basal expression of a gene was not detectable, expression was expressed using the $2^{-\Delta C t}$ method [26].

\section{Measurement of cytokines and chemokine at protein levels}

To determine the protein levels of different cytokines within the supernatants, an enzyme-linked immunosorbent assay was performed according to the manufacturer's instructions. For quantification of protein levels of IL-6, IL-10 and IL1beta (IL-1ß), Human ELISA Ready-SET-Go! kits (affymetrix eBioscience, USA) were used. For quantification of IL-8, Human CXCL8/IL-8 Quantikine ELISA Kit (R \& D systems, Minneapolis, USA) was used.

\section{Statistical analysis}

The overall significance of the experimental effect was determined by KruskalWallis tests and the differences between multiple groups were analyzed by MannWhitney test, unless stated otherwise. Values of $p<0.05$ were considered statistically significant. Data are expressed as mean \pm SEM. 


\section{Results}

\section{Effect of IFNs on the inflammatory response of cells}

Earlier macrophages have been shown to be responsive to IFN- $\lambda 1$ [14]. Yet, before stimulating the cells with IFNs, we confirmed that THP1-derived macrophages express the interferon lambda receptor-1 at mRNA level with qPCR (data not shown). Next, to examine the effect of treatment of IFNs on the inflammatory response of THP1-derived macrophages and A549 cells, both in mono- and cocultures, cells were treated with either IFN- $\lambda 1$ or IFN- $\beta$ for $18 \mathrm{~h}$ and protein levels of IL-6 and IL-8 were determined in the supernatants.

\section{Mono-cultures}

In mono-cultures of THP1-derived macrophages and A549, treatment with IFN- $\lambda 1$ or IFN- $\beta$ did not have any effect on the release of IL- 6 and protein levels of IL- 6 remained below detection limit of our ELISA $(6.25 \mathrm{pg} / \mathrm{ml})$. Similarly, and although IL-8 was detected in untreated cells, IFNs did not affect the IL-8 production in mono-cultures of A549 cells (Figure 1A). Mono-cultures of THP1-derived macrophages also released IL-8 under basal conditions and, in contrast to A549, treatment with both IFNs significantly enhanced the production of IL-8 (Figure 1B).
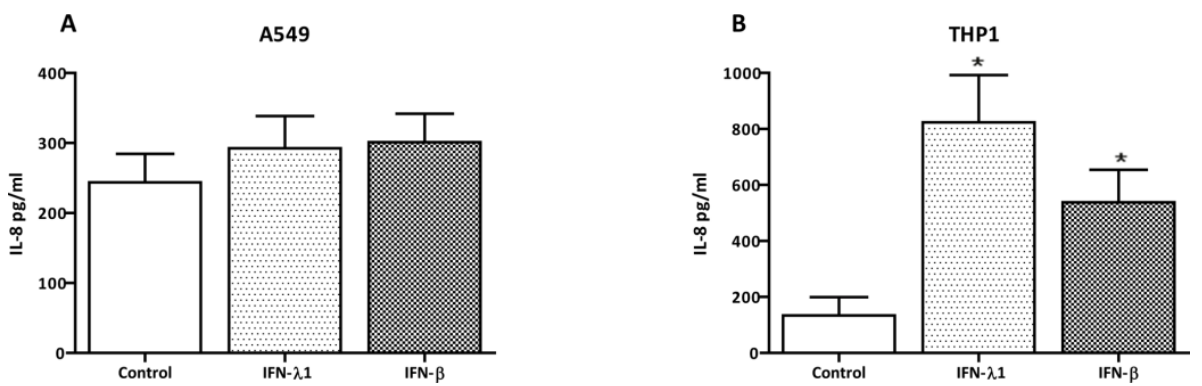

Figure 1. Effect of treatment with IFNs on IL-8 production in mono-cultures: A549 (A) and THP1-derived macrophages (B) were stimulated with IFN- $\lambda 1$ and IFN- $\beta$ for $18 \mathrm{~h}$. After that supernatants were collected and protein levels of IL-8 were determined with ELISA. One way ANOVA with LSD and Dunnett T3 post hoc tests were applied to determine the difference between the groups. ${ }^{*}, p<0.05$ control vs rest of the conditions. $\mathrm{n}=4$ for $\mathrm{A} 549$ and $\mathrm{n}=6$ for macrophages.

\section{Co-culture}

Similar to mono-cultures, basal levels of IL- 6 were also below the detection limit in the co-cultures. For IL-8, noticeably, already at the basal level significantly higher amounts were detected in co-cultures than the combined basal levels of mono- 
cultures of A549 and THP1-derived macrophages (Figure 2A), suggesting some kind of synergistic effect between both cell types. Next, co-cultures were stimulated with either of the IFNs. In contrast to the results found in mono-cultures, stimulation with either of the IFNs significantly induced the release of IL- 6 in cocultures (Figure 2B). Interestingly, levels of IL-6 detected in the supernatants of IFN$\lambda 1$-stimulated cells were significantly lower than those of IFN- $\beta$-stimulated cells.

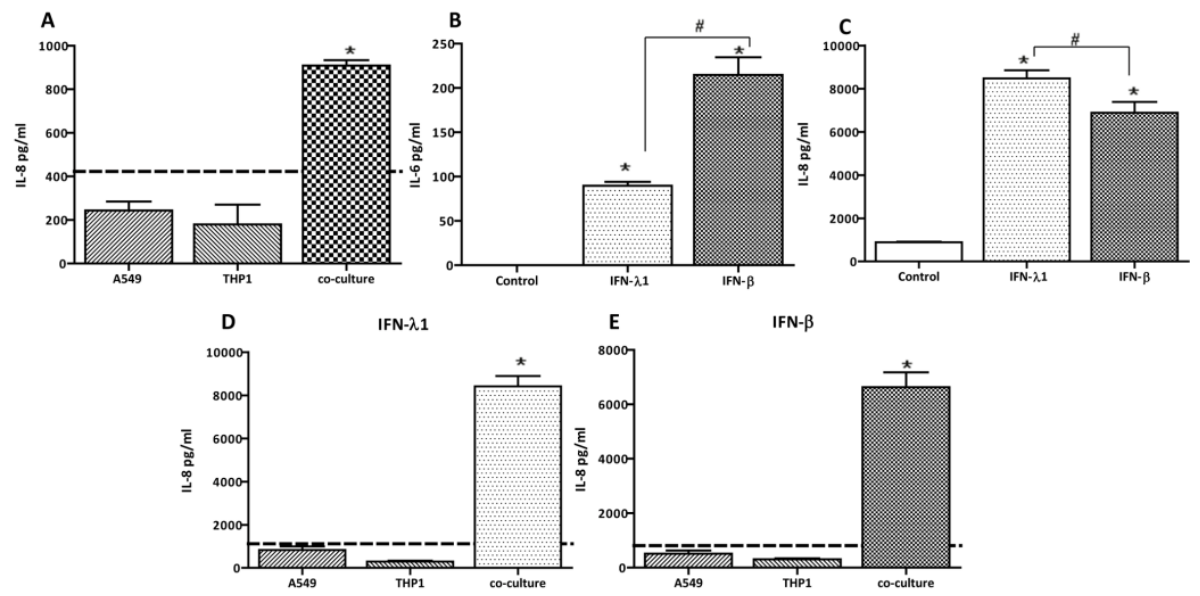

Figure 2. Effect of treatment with IFNs on IL-6 and IL-8 production in co-cultures: Co-cultures of A549 and THP1-derived macrophages were stimulated with IFN- $\lambda 1$ and IFN- $\beta$ for $18 \mathrm{~h}$. After that supernatants were collected and protein levels of IL- 6 and IL- 8 were determined with ELISA. Figure A shows the difference between basal levels of IL- 8 in co-cultures and combined basal levels of IL-8 (represented by dotted line) in two mono cultures of A549 and THP1-derived macrophages. Figure B and C shows the levels of IL- 6 and IL- 8 respectively, induced after IFNs stimulation in co-culture. While difference between levels of IL-8 induced by IFNs in co-culture and combined levels of IL-8 (represented by dotted line) induced by IFNs in monocultures are shown in figure $D$ and $E .{ }^{*}, p<0.05$ control or combined levels vs rest of the condition/s. \#, $p<0.05$ between indicated conditions. $n=5$ for figure $B$ and $C$ and $n=4$ for figure $A, D$ and $E$.

Also, levels of IL-8 in the supernatants of the co-cultures were markedly enhanced following stimulation with both IFNs (Figure 2C). Furthermore, similar to the synergism observed at the basal level in the co-cultures, also a synergistic effect was observed when co-cultured cells were stimulated with IFNs (Figure 2D \& E). Remarkably, the effect of stimulation with the different IFNs regarding the IL-8 production was opposite to IL-6 production as IFN- $\beta$ treatment induced significantly less IL-8 than IFN- $\lambda 1$ treatment (Figure $2 \mathrm{C}$ ). This indicates that cells responded differently to IFN- $\lambda 1$ or IFN- $\beta$ regarding the release of IL- 6 and IL-8. 


\section{Induction of IL-6 and IL-8 by IFNs is partially mediated by IL-1}

In macrophages, activation of STAT1 by IFNs plays a pivotal role in lipopolysaccharide induced production of IL-1ß [27], which is an important inflammatory mediator that potentially augments the inflammatory response of macrophages and epithelial cells $[28,29]$. In order to determine whether the observed increased production of IL-6 and IL-8 in co-cultures after IFN treatment is mediated by IL-1 $\beta$, expression of IL- $1 \beta$ was determined both at mRNA and protein level. Our qPCR data showed strong increase in IL-1 $\beta$ mRNA expression in cells, which were treated with IFNs as compared to non-treated cells (IFN- $\lambda 1$ : 76 -fold increase, IFN- $\beta$ : 16 -fold increase). However, protein levels of IL-1 $\beta$ remained undetectable, regardless of whether cells were treated with IFNs or not. Yet, results of a previous study conducted in our lab showed that even trace amounts of IL-1ß ( 1pg/ml, below the detection limit of the ELISA), could strongly induce the expression of IL-8 (unpublished data). To further elucidate a potential role of trace amounts of IL-1 in the observed effect, cells in co-culture were pre-treated with an antagonist for IL-1 receptors, IL-1RA and then treated with IFNs. To our surprise, blocking of IL-1 receptors significantly decreased the production of both IL-6 and IL8 in response to treatment with IFNs (Figure $3 A \& B$ ). This suggests that production of IL- 6 and IL- 8 in response to treatment with IFNs is partially mediated by IL-1.
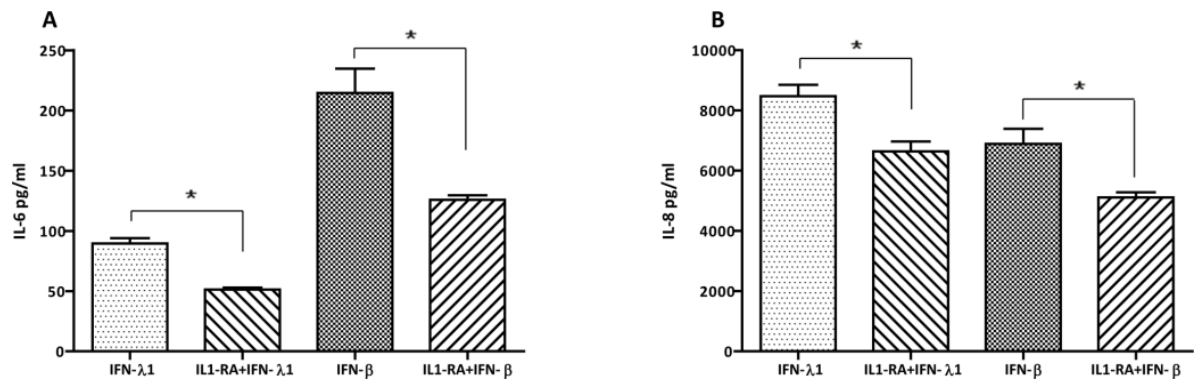

Figure 3. Effect of treatment with IFNs on IL- 6 and IL-8 production is partially mediated by IL-1 $\beta$ : Cocultures were either pre-treated or not with IL-1RA at $100 \mathrm{ng} / \mathrm{ml}$ for $2 \mathrm{~h}$ and then stimulated with IFNs for another 18h. After that supernatants were collected and protein levels of IL-6 (A) and IL-8 (B) were determined with ELISA. Differences between the groups were determined with paired sample $t$ test. *, $p<0.05$ between indicated conditions. $n=5$

\section{Effect of IFNs pre-treatment on antiviral and inflammatory response of cells to viral infection}

Previously, in mono-cultures of airway epithelial cells we have shown that IFN pretreatment protects the cells against subsequent viral infections. Here we investigated whether this protective effect was maintained in a more complex co- 
culture condition. Therefore, co-cultures were first pre-treated with either IFN- $\lambda 1$ or IFN- $\beta$ for $18 \mathrm{~h}$. Then IFN-containing medium was removed and cells were infected with RSV at MOI-1. After another $24 \mathrm{~h}$ supernatants and cells were collected. Supernatants were used to determine the levels of IL-6 and IL-8 with ELISA, while viral RNA copy numbers and mRNA expression of IL-6 and IL-8 were determined with qPCR.

\section{Antiviral effect}

In both IFN- $\lambda 1$ and IFN- $\beta$ pre-treated cells, significantly lower numbers of viral RNA copies were found as compared to control cells (Figure 4). Although it has been suggested previously that type-III IFNs may have weaker antiviral activity than typeI IFNs [30], no significant differences in viral RNA copies were found between IFN- $\beta$ or IFN- $\lambda 1$ treated cells, suggesting that both IFNs had equal potency to prevent RSV infections in macrophage/epithelial cell co-cultures.

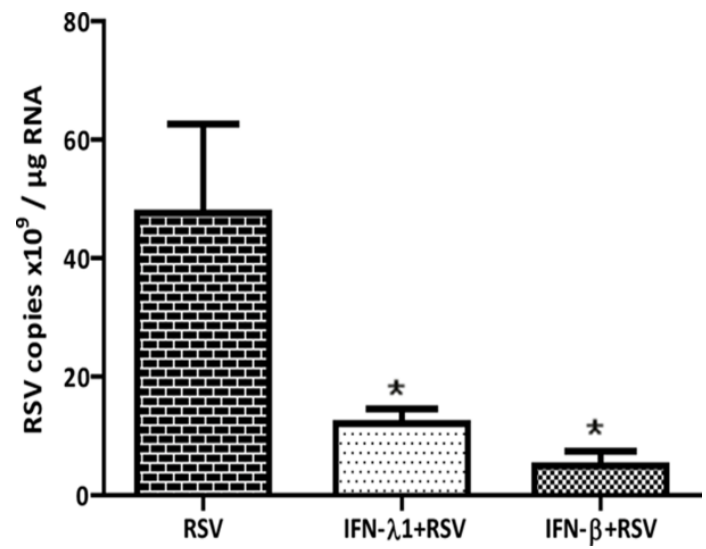

Figure 4. Antiviral response of IFN- $\lambda 1$ and IFN- $\beta$ in co-cultures: Co-cultures were pre-treated with IFNs for $18 \mathrm{~h}$. Then IFNs containing medium was replaced with fresh IFN-free medium. Next cells were infected with RSV at MOI-1 for $1 \mathrm{~h}$ and incubated for another $24 \mathrm{~h}$. After that cells were collected and RNA copies of virus were determined with qPCR. *, $p<0.05$ RSV vs IFN- $\lambda 1+R S V$ or IFN- $\beta+R S V . n=4$

\section{Effect on inflammatory response induced by viral infection}

Detrimental effects of viral infections may either be caused by the cellular damage/death following viral entrance and replication or by the subsequent massive inflammatory reaction resulting in massive tissue damage. In order to determine whether the inflammatory response following infection is affected by pre-treatment with IFNs, both mRNA and protein levels of IL-6 and IL- 8 were determined in the co-cultures after $24 \mathrm{~h}$ of RSV infection. As expected in the 
absence of viral infections, very low levels of both IL-6 and IL-8 mRNA were found. Pre-treatment with IFNs slightly, though significantly, increased the mRNA expression of both IL-6 (IFN- $\beta$ : $6.57 \pm 0.71$ fold, IFN- $\lambda 1: 8 \pm 1.19$ fold) and IL-8 (IFN$\beta: 1.85 \pm 0.29$ fold, IFN- $\lambda 1: 3.3 \pm 0.79$ fold). Nevertheless, despite the higher IL- 6 mRNA levels, no IL- 6 was found in the supernatants. Alternatively, IL- 8 was still detectable $24 \mathrm{~h}$ after the pre-treatment period and remained significantly higher than levels found in control cells (control: $306 \pm 17.06 \mathrm{pg} / \mathrm{ml}$, IFN- $\beta$ : $1208.5 \pm 288.5$ $\mathrm{pg} / \mathrm{ml}$, IFN- $\lambda 1$ : $565 \pm 42 \mathrm{pg} / \mathrm{ml}, \mathrm{p}<0.05$ vs. control).
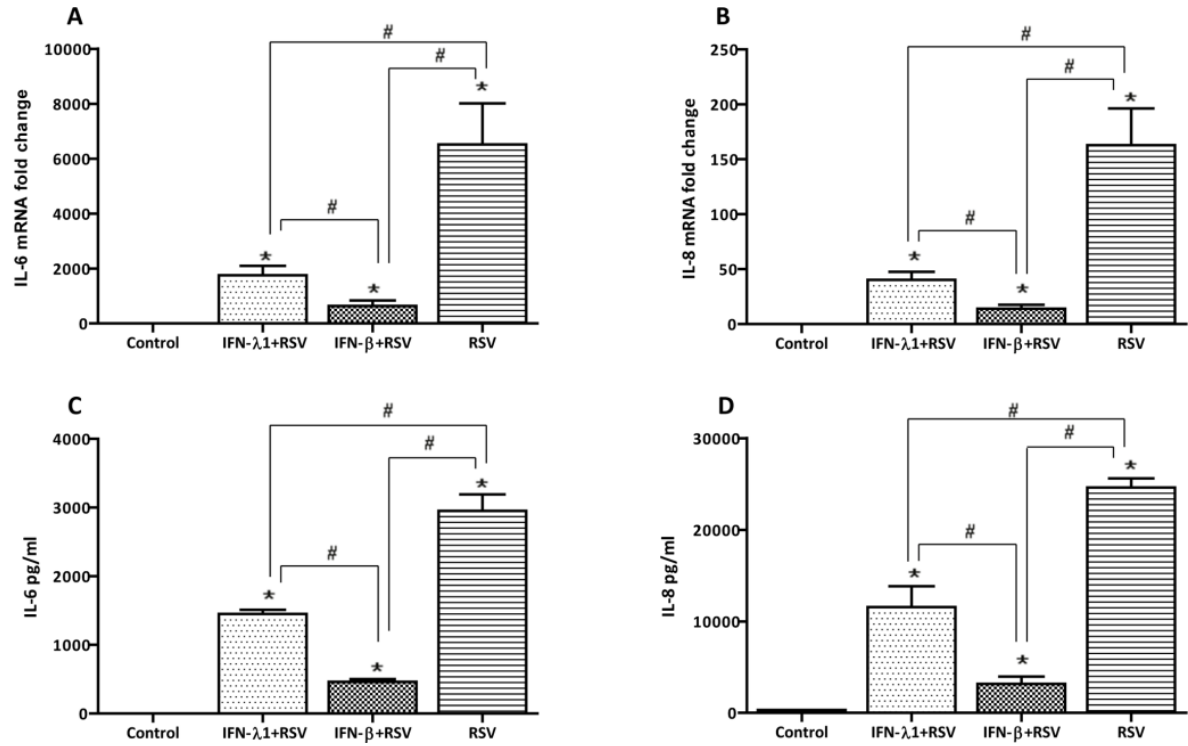

Figure 5. Effect of pre-treatment of co-cultures with IFNs on IL-6 and IL-8 induction by RSV: Co-cultures were pre-treated with IFNs for $18 \mathrm{~h}$ and then IFNs containing medium was replaced with fresh medium. Next cells were either infected with RSV at MOI-1 for $1 \mathrm{~h}$ and incubated for another $24 \mathrm{~h}$. After another $24 \mathrm{~h}$ cells and media were collected and expressions of IL- 6 and IL-8 were determined at mRNA level with qPCR (A \& B) and at protein level with ELISA (C \& D). *, p<0.05 control vs rest of the conditions. \#, $p<0.05$ between indicated conditions. $n=4$

In RSV infected cells a strong induction of both mRNA and protein levels of IL-6 and IL-8 was observed irrespective whether cells were pre-treated with IFNs or not (Figure 5A-D). However this induction was significantly less in samples which were pre-treated with either IFN- $\lambda 1$ or IFN- $\beta$. Noteworthy, the diminished expression of virus-induced IL- 6 and IL- 8 was more pronounced in IFN- $\beta$ pretreated samples than IFN- $\lambda 1$ pre-treated samples.

Summarizing these results shows that pre-treatment of cells with either of the IFNs was not only effective to prevent viral replication but also to restrain the 
virus-induced inflammatory response. Interestingly, the latter was more prominent in IFN- $\beta$ pre-treated co-cultures.

\section{Is the anti-inflammatory effect of IFNs mediated by IL-10?}

IFNs can induce the expression of interleukin 10 (IL-10), which is a potent antiinflammatory cytokine [14,31-34]. In order to determine, whether the observed anti-inflammatory effect of IFNs in our co-culture model is mediated by IL-10, mRNA expression of IL-10 was determined after $18 \mathrm{~h}$ of treatment with IFNs. Indeed, treatment with both IFN- $\lambda 1$ and IFN- $\beta$ significantly increased the mRNA expression of IL-10 (Figure 6).

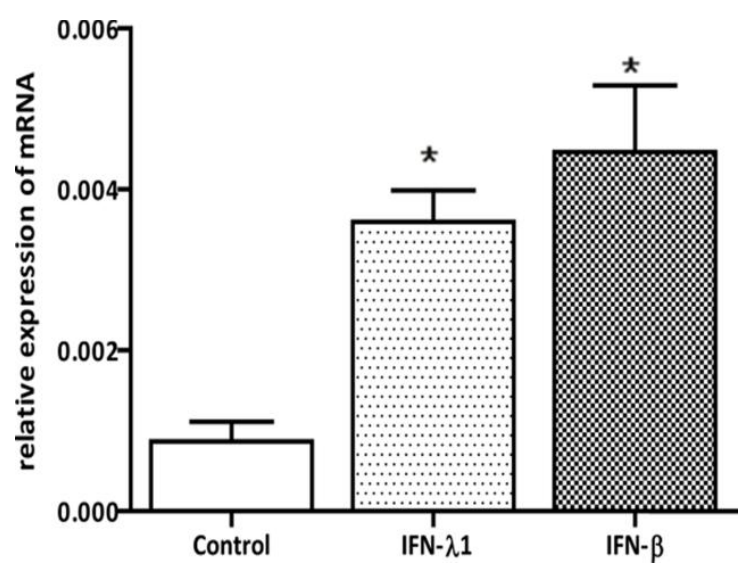

Figure 6. Effect of treatment of co-cultures with IFNs on the induction of IL-10: Co-cultures were treated with IFNs for $18 \mathrm{~h}$ cells and media were collected and expressions of IL-10 was determined with qPCR. *,$p<0.05$ control vs rest of the conditions. $n=4$

Next to see if this increase in mRNA level was also translated into IL-10 protein, ELISA was performed after $18 \mathrm{~h}$ of IFNs treatment and also after $24 \mathrm{~h}$ of RSV infection. However, under all different conditions and at both time points, IL-10 protein levels remained below detection levels (data not shown). To further investigate the role of IL-10, we pre-treated the cells with recombinant IL-10 at a dose of 150 times more than the detection limit of ELISA $(15.6 \mathrm{pg} / \mathrm{ml})$ for $1 \mathrm{~h}$ and then infected with RSV at MOI-1. After 24h of RSV infection, protein expressions of IL-6 and IL- 8 were determined by ELISA. Nevertheless, no difference in the expression of IL- 6 and IL-8 were found between control co-cultures and co-cultures pre-treated with IL-10 (data not shown). Thus, despite the previously reported antiinflammatory effects of IL-10 and the significant increase in the expression of IL-10 mRNA in IFN-pretreated co-cultures, a possible role for IL-10 in the reduced 
expression of inflammatory cytokines in IFN-pretreated co-cultures following RSV infections, seems unlikely. 


\section{Discussion}

Viral infections are among the major triggers of acute exacerbations in asthma and COPD patients $[1,5]$ and inflammation is the core feature of these exacerbations $[35,36]$. One therapeutic option to prevent these virus-induced exacerbations might be the prophylactic administration of IFNs. In a previous in vitro study, we have shown that treatment of airway epithelial cells either with IFN- $\lambda 1$ or IFN- $\beta$ provides a long-lasting protection against viral infection with comparable efficacy for both IFNs. To elaborate this in more detail, in the present in vitro study we evaluated the effects of IFNs treatment on the inflammatory response of A549 and THP1-derived macrophages in mono- and co-cultures. Also, effect of pre-treatment with IFNs on the inflammatory response induced by RSV infections was evaluated. The main finding of this study is that pre-treatment with either of the IFNs does not only prevent viral infections in the co-culture model, but also diminishes the proinflammatory reaction following viral infections in an epithelial cells/macrophage co-culture. As it is anticipated that most of the damage inflicted during virusinduced exacerbations is because of an excessive inflammatory reaction, inhibition of this inflammation by prophylactic IFN- $\beta$ or $-\lambda 1$ therapy may be of clinical importance.

Previously, we and others have shown that airway epithelial cells (both A549 and primary cells) are responsive to the treatment of exogenous IFN- $\lambda 1$ and IFN- $\beta$ and attain an antiviral state by the strong induction of interferon stimulated genes (ISGs) [18,20,37]. Yet, since the respiratory system consist of more than one cell type, we decided to study similar processes in a more complex system in which we co-cultured epithelial cells and macrophages, two cell types intimately involved in resolving bacterial and viral infections of the respiratory tract. The importance of studying these specific processes in more complex systems was already illustrated by the finding that co-culturing both cell types resulted in a synergistic effect regarding the release of IL- 6 and IL-8. For example, no detectable release of IL- 6 was found under basal conditions or following stimulations with IFNs in monocultures of either cell type. However, when cells were co-cultured, significant amounts of IL- 6 could be detected in the supernatants of co-cultures stimulated with either of the IFNs. Likewise, similar synergistic effects were observed with reference to IL-8. This indicates that the differentiation and/or activation state of cells was changed in co-culture due to the complex cross talk between the cells $[23,38]$ and that they had become more responsive to the exogenous IFNs. 
Interestingly, in response to IFN- $\lambda 1$ less IL- 6 but more IL- 8 was released in the coculture system. This suggests that the release of IL- 6 and IL- 8 by IFN- $\lambda 1$ and IFN- $\beta$ is controlled by different mechanisms perhaps due to the use of different receptors, the induction of distinct signal transduction or gene regulation kinetics by IFN- $\lambda 1$ and IFN- $\beta[39,40]$.

Interleukin- 6 and -8 are among the most important inflammatory mediators especially in the lung. IL- 6 is a cytokine which plays a key role in acute phase responses [41], while IL-8 is a chemoattractant which plays an important part in the recruitment and activation of neutrophils and other cells including monocytes and lymphocytes [42,43]. Exacerbations in COPD have been associated with increased levels of IL- 6 and IL-8 [44,45]. Similarly, increased levels of IL- 6 and IL-8 have been detected in asthmatics than non-asthmatics [42,46-48]. Therefore, it has been suggested that in particular excessive production of these inflammatory mediators by airway cells may contribute to the induction of exacerbations in COPD and asthmatic patients. Thus, inhibition of the release of these cytokines may be beneficial in preventing exacerbations. Interestingly it has been shown earlier that type-I IFNs are able to inhibit IL-8 induction in different cells [19,49-51]. However, in our setting both type I and III IFNs induced the release of both IL-6 and IL-8, suggesting that prophylactic administration might more detrimental than beneficial in preventing exacerbations. Nevertheless, levels of both IL-6 and IL-8 detected after treatment with IFNs were moderate (IL-6: 100-200 pg/ml, IL-8: 7-8 ng/ml) as compared to high amounts of IL-6 and IL- 8 detected in the supernatants of cells which were infected with RSV alone (IL-6: $3000 \mathrm{pg} / \mathrm{ml}, \mathrm{IL}-8: \sim 25 \mathrm{ng} / \mathrm{ml}$ ). This moderate increase in IL- 6 and IL- 8 production by IFNs on their own might be required for efficient activation of immune response and clearance of virus without exaggerated inflammation and destruction. More important was the observation that pre-treatment with both IFNs dramatically reduced the release of IL- 6 and IL- 8 when cells were infected with RSV. In particular IFN- $\beta$ was well able to control the release of both IL-6 ( $84 \%$ reduction) and IL-8 ( $87 \%$ reduction). Since both IFNs were equally able to reduce viral loads, it seems unlikely that this difference is solely due to less pronounced activation of the IL-6/8 release because of lower viral loads in IFN- $\beta$ pre-treated co-cultures. To further unravel this we examined the possible involvement of IL-10 in the IFNs-induced inhibition of the IL- 6 and IL- 8 release. It has been shown that both IFN- $\lambda 1$ and IFN- $\beta$ are able to induce the production of IL10 by cells including PBMCs and bone marrow derived cells [14,31-34]. Moreover, IL-10 inhibits the expression of genes induced by type-I IFNs [33,52]. Similarly, IL-10 
has been shown to inhibit IFN- $\lambda 1$ induced IL-6 in PBMCs [14]. However, in our experimental setup we were unable to detect any effect of IL-10 on the virusinduced IL-6 and IL-8 release and further studies are warranted to unravel the underlying mechanisms of the IFNs-related inhibition of IL-6/8 release.

Alternatively, IL-1 $\beta$ is a potent inducer of IL-6 and IL-8 [28,29]. Activated macrophages are among the major producers of IL-1 $\beta$ [53] and in co-culture with A549 the release of IL-1 $\beta$ by THP1 monocyte/macrophages is enhanced [23]. And although different studies have suggested that type-I IFNs are also involved in the activation of the inflammasome and the subsequent release of IL-1 $\beta[27,54,55]$, the role of IFNs in the induction of IL-1 $\beta$ is not completely resolved. Guarda and colleagues, for example, demonstrated that type-I IFNs might also prevent the release of IL-1 $\beta$ through inhibition of inflammasome activation [56] and this discrepancy might be due to the differential activation of different types of inflammasomes [57]. In the present study, we also examined the role of IL-1 $\beta$ as mediator in the release of IL-6/8 following IFN stimulation of the co-cultures. Although we could not detect IL-1 $\beta$ at the protein level, the expression of IL-1 $\beta$ mRNA was significantly increased after treatment with either IFN- $\lambda 1$ or IFN- $\beta$. This suggests a possible involvement of IL- $1 \beta$ in the release of IL- 6 and IL- 8 which was confirmed by the partial inhibition of the IFN-induced IL-6/8 release in the presence of an IL-1 receptor antagonist (IL-1RA). However, since IL-1RA blocks the receptors for both IL-1 $\beta$ and IL-1 $\alpha$, specific involvement of either of the two types of IL-1 cannot be differentiated from these data. Moreover, since the release of IL- 6 and IL-8 was only partially inhibited by IL-1RA, most likely there are also other mediators as well involved along with either IL-1 $\beta$ or IL-1 $\alpha$.

Summarizing, in the present study we expanded our earlier findings and demonstrated that the protective effects of prophylactic treatment with either IFN$\beta$ or IFN- $\lambda 1$ are not only effective in mono-cultures of epithelial cells or macrophages, but also in more complex systems like the co-cultures. Additionally, we demonstrated that pretreatment with either of the IFNs significantly prevented the release of massive amounts of the pro-inflammatory cytokines IL- 6 and IL- 8 in the co-cultures following RSV infections. Since it is assumed that excessive inflammation following viral infections is an important contributor to the initiation and severity of acute exacerbations, this finding may have future clinical significance. Thus, in conclusion, these data provide further arguments that exogenous IFNs could be beneficial to prevent the viral infections and exacerbations. Still, additional in vitro and in vivo studies are warranted to evaluate 
the physiological significance and relevance of administration of exogenous IFNs with virus induced exacerbations in chronic respiratory diseases. 


\section{References}

1. Papi A, Bellettato CM, Braccioni F, Romagnoli M, Casolari P, et al. (2006) Infections and airway inflammation in chronic obstructive pulmonary disease severe exacerbations. Am J Respir Crit Care Med 173: 1114-1121.

2. Akinbami L, Moorman JE, Liu X (2011) Asthma prevalence, health care use, and mortality: United States, 2005-2009. Natl Health Stat Report: 1-14.

3. Rohde G, Wiethege A, Borg I, Kauth M, Bauer TT, et al. (2003) Respiratory viruses in exacerbations of chronic obstructive pulmonary disease requiring hospitalisation: a case-control study. Thorax 58: 37-42.

4. Kurai D, Saraya T, Ishii H, Takizawa H (2013) Virus-induced exacerbations in asthma and COPD. Front Microbiol 4: 293.

5. Nicholson KG, Kent J, Ireland DC (1993) Respiratory viruses and exacerbations of asthma in adults. BMJ 307: 982-986.

6. Stetson DB, Medzhitov R (2006) Type I interferons in host defense. Immunity 25: 373-381.

7. Iversen MB, Paludan SR (2010) Mechanisms of type III interferon expression. J Interferon Cytokine Res 30: 573-578.

8. Randall RE, Goodbourn S (2008) Interferons and viruses: an interplay between induction, signalling, antiviral responses and virus countermeasures. Journal of General Virology 89: 1-47.

9. Huang J, Smirnov SV, Lewis-Antes A, Balan M, Li W, et al. (2007) Inhibition of type I and type III interferons by a secreted glycoprotein from Yaba-like disease virus. Proc Natl Acad Sci U S A 104: 9822-9827.

10. Kotenko SV, Langer JA (2004) Full house: 12 receptors for 27 cytokines. Int Immunopharmacol 4: 593-608.

11. Vilcek J (2003) Novel interferons. Nat Immunol 4: 8-9.

12. Onoguchi K, Yoneyama M, Takemura A, Akira S, Taniguchi T, et al. (2007) Viral infections activate types I and III interferon genes through a common mechanism. J Biol Chem 282: 7576-7581.

13. Trinchieri G (2010) Type I interferon: friend or foe? J Exp Med 207: 2053-2063.

14. Jordan WJ, Eskdale J, Boniotto M, Rodia M, Kellner D, et al. (2007) Modulation of the human cytokine response by interferon lambda-1 (IFN-lambda1/IL-29). Genes Immun 8: 13-20.

15. Mordstein M, Neugebauer E, Ditt V, Jessen B, Rieger T, et al. (2010) Lambda interferon renders epithelial cells of the respiratory and gastrointestinal tracts resistant to viral infections. J Virol 84: 5670-5677.

16. Mallia P, Message SD, Gielen V, Contoli M, Gray K, et al. (2011) Experimental rhinovirus infection as a human model of chronic obstructive pulmonary disease exacerbation. Am J Respir Crit Care Med 183: 734-742.

17. Wark PA, Johnston SL, Bucchieri F, Powell R, Puddicombe S, et al. (2005) Asthmatic bronchial epithelial cells have a deficient innate immune response to infection with rhinovirus. J Exp Med 201: 937-947.

18. Gaajetaan GR, Geelen TH, Vernooy JH, Dentener MA, Reynaert NL, et al. (2013) Interferon-beta induces a long-lasting antiviral state in human respiratory epithelial cells. J Infect 66: 163169.

19. Aman MJ, Rudolf G, Goldschmitt J, Aulitzky WE, Lam C, et al. (1993) Type-I interferons are potent inhibitors of interleukin- 8 production in hematopoietic and bone marrow stromal cells. Blood 82: 2371-2378.

20. Cakebread JA, Xu Y, Grainge C, Kehagia V, Howarth PH, et al. (2011) Exogenous IFN-beta has antiviral and anti-inflammatory properties in primary bronchial epithelial cells from asthmatic subjects exposed to rhinovirus. J Allergy Clin Immunol 127: 1148-1154 e1149.

21. Bulek K, Swaidani S, Aronica M, Li X (2010) Epithelium: the interplay between innate and Th2 immunity. Immunol Cell Biol 88: 257-268.

22. Tao F, Kobzik L (2002) Lung macrophage-epithelial cell interactions amplify particle-mediated cytokine release. Am J Respir Cell Mol Biol 26: 499-505. 
23. Striz I, Brabcova E, Kolesar L, Liu XD, Brabcova I, et al. (2011) Epithelial cells modulate genes associated with NF kappa B activation in co-cultured human macrophages. Immunobiology 216: 1110-1116.

24. Boncristiani HF, Rossi RD, Criado MF, Furtado FM, Arruda E (2009) Magnetic purification of biotinylated cDNA removes false priming and ensures strand-specificity of RT-PCR for enteroviral RNAs. J Virol Methods 161: 147-153.

25. Gaajetaan GR, Geelen TH, Grauls GE, Bruggeman CA, Stassen FR (2012) CpG and poly(I:C) stimulation of dendritic cells and fibroblasts limits herpes simplex virus type 1 infection in an IFNbetadependent and -independent way. Antiviral Res 93: 39-47.

26. Schmittgen TD, Livak KJ (2008) Analyzing real-time PCR data by the comparative C(T) method. Nat Protoc 3: 1101-1108.

27. Joshi VD, Kalvakolanu DV, Chen W, Zhang L, Kang TJ, et al. (2006) A role for Stat1 in the regulation of lipopolysaccharide-induced interleukin-1beta expression. J Interferon Cytokine Res 26: 739747.

28. Standiford TJ, Kunkel SL, Basha MA, Chensue SW, Lynch JP, 3rd, et al. (1990) Interleukin-8 gene expression by a pulmonary epithelial cell line. A model for cytokine networks in the lung. J Clin Invest 86: 1945-1953.

29. Crestani B, Cornillet P, Dehoux M, Rolland C, Guenounou M, et al. (1994) Alveolar type II epithelial cells produce interleukin- 6 in vitro and in vivo. Regulation by alveolar macrophage secretory products. J Clin Invest 94: 731-740.

30. Meager A, Visvalingam K, Dilger P, Bryan D, Wadhwa M (2005) Biological activity of interleukins-28 and -29: comparison with type I interferons. Cytokine 31: 109-118.

31. Wang H, Brown J, Garcia CA, Tang Y, Benakanakere MR, et al. (2011) The role of glycogen synthase kinase 3 in regulating IFN-beta-mediated IL-10 production. J Immunol 186: 675-684.

32. Ziegler-Heitbrock L, Lotzerich M, Schaefer A, Werner T, Frankenberger M, et al. (2003) IFN-alpha induces the human IL-10 gene by recruiting both IFN regulatory factor 1 and Stat3. J Immunol 171: 285-290.

33. Wang $\mathrm{X}$, Chen M, Wandinger KP, Williams G, Dhib-Jalbut S (2000) IFN-beta-1b inhibits IL-12 production in peripheral blood mononuclear cells in an IL-10-dependent mechanism: relevance to IFN-beta-1b therapeutic effects in multiple sclerosis. J Immunol 165: 548-557.

34. Chang EY, Guo B, Doyle SE, Cheng G (2007) Cutting edge: involvement of the type I IFN production and signaling pathway in lipopolysaccharide-induced IL-10 production. J Immunol 178: 67056709.

35. Wark PA, Gibson PG (2006) Asthma exacerbations . 3: Pathogenesis. Thorax 61: 909-915.

36. Bathoorn E, Kerstjens H, Postma D, Timens W, MacNee W (2008) Airways inflammation and treatment during acute exacerbations of COPD. Int J Chron Obstruct Pulmon Dis 3: 217-229.

37. Ank N, West H, Bartholdy C, Eriksson K, Thomsen AR, et al. (2006) Lambda interferon (IFN-lambda), a type III IFN, is induced by viruses and IFNs and displays potent antiviral activity against select virus infections in vivo. J Virol 80: 4501-4509.

38. Kolesar L, Brabcova E, Thorburn E, Sekerkova A, Brabcova I, et al. (2012) Cytokine gene expression profile in monocytic cells after a co-culture with epithelial cells. Immunol Res 52: 269-275.

39. Maher SG, Sheikh F, Scarzello AJ, Romero-Weaver AL, Baker DP, et al. (2008) IFNalpha and IFNlambda differ in their antiproliferative effects and duration of JAK/STAT signaling activity. Cancer Biol Ther 7: 1109-1115.

40. Marcello T, Grakoui A, Barba-Spaeth G, Machlin ES, Kotenko SV, et al. (2006) Interferons alpha and lambda inhibit hepatitis $C$ virus replication with distinct signal transduction and gene regulation kinetics. Gastroenterology 131: 1887-1898.

41. Kushner I (1993) Regulation of the acute phase response by cytokines. Perspect Biol Med 36: 611622.

42. Norzila MZ, Fakes K, Henry RL, Simpson J, Gibson PG (2000) Interleukin-8 secretion and neutrophil recruitment accompanies induced sputum eosinophil activation in children with acute asthma. Am J Respir Crit Care Med 161: 769-774.

43. Mukaida N (2003) Pathophysiological roles of interleukin-8/CXCL8 in pulmonary diseases. Am J Physiol Lung Cell Mol Physiol 284: L566-577. 
44. Bhowmik A, Seemungal TA, Sapsford RJ, Wedzicha JA (2000) Relation of sputum inflammatory markers to symptoms and lung function changes in COPD exacerbations. Thorax 55: 114-120.

45. Perera WR, Hurst JR, Wilkinson TM, Sapsford RJ, Mullerova H, et al. (2007) Inflammatory changes, recovery and recurrence at COPD exacerbation. Eur Respir J 29: 527-534.

46. Neveu WA, Allard JL, Raymond DM, Bourassa LM, Burns SM, et al. (2010) Elevation of IL-6 in the allergic asthmatic airway is independent of inflammation but associates with loss of central airway function. Respir Res 11: 28.

47. Yokoyama A, Kohno N, Fujino S, Hamada H, Inoue Y, et al. (1995) Circulating interleukin-6 levels in patients with bronchial asthma. Am J Respir Crit Care Med 151: 1354-1358.

48. Teran LM, Johnston SL, Schroder JM, Church MK, Holgate ST (1997) Role of nasal interleukin-8 in neutrophil recruitment and activation in children with virus-induced asthma. Am J Respir Crit Care Med 155: 1362-1366.

49. Laver T, Nozell SE, Benveniste EN (2008) IFN-beta-mediated inhibition of IL-8 expression requires the ISGF3 components Stat1, Stat2, and IRF-9. J Interferon Cytokine Res 28: 13-23.

50. Nozell S, Laver T, Patel K, Benveniste EN (2006) Mechanism of IFN-beta-mediated inhibition of IL-8 gene expression in astroglioma cells. J Immunol 177: 822-830.

51. Oliveira IC, Sciavolino PJ, Lee TH, Vilcek J (1992) Downregulation of interleukin 8 gene expression in human fibroblasts: unique mechanism of transcriptional inhibition by interferon. Proc Natl Acad Sci U S A 89: 9049-9053.

52. Ito $S$, Ansari $P$, Sakatsume $M$, Dickensheets $H$, Vazquez N, et al. (1999) Interleukin-10 inhibits expression of both interferon alpha- and interferon gamma- induced genes by suppressing tyrosine phosphorylation of STAT1. Blood 93: 1456-1463.

53. Dinarello CA (1991) Interleukin-1 and interleukin-1 antagonism. Blood 77: 1627-1652.

54. Henry T, Brotcke A, Weiss DS, Thompson L, Monack DM (2007) Type I interferon signaling is required for activation of the inflammasome during Francisella infection. J Exp Med 204: 987994.

55. Fernandes-Alnemri T, Yu JW, Juliana C, Solorzano L, Kang S, et al. (2010) The AIM2 inflammasome is critical for innate immunity to Francisella tularensis. Nat Immunol 11: 385-393.

56. Guarda G, Braun M, Staehli F, Tardivel A, Mattmann C, et al. (2011) Type I interferon inhibits interleukin-1 production and inflammasome activation. Immunity 34: 213-223.

57. Gonzalez-Navajas JM, Lee J, David M, Raz E (2012) Immunomodulatory functions of type I interferons. Nat Rev Immunol 12: 125-135. 
Table Supplementary. Primers used for mRNA expression analysis

\begin{tabular}{lll}
\hline Gene & & Primer sequences $\left(5^{\prime}-3^{\prime}\right)$ \\
\hline RSV & forward & TTTCCACAATATYTAAGTGTCAA \\
& reverse & TCATCWCCATACTTTTCTGTTA \\
IL-8 & Torward & TTTTGCCAAGGAGTGCTAAAGA \\
& reverse & AACCCTCTGCACCCAGTTTTC \\
IL-6 & forward & AACAACCTGAACCTTCCAAAGATG \\
& reverse & CCAACTCCAAAAGACCAGTGATGAT \\
IL-1 $\beta$ & forward & TCGGAGATTCGTAGCTGGAT \\
& reverse & CAGCCAATCTTCATTGCTCA \\
IL-10 & forward & TACGGCGCTGTCATCGATTT \\
& reverse & TAGAGTCGCCACCCTGATGT \\
& forward & TGGAGAAATCTGGCACCAC \\
& reverse & GAGGCGTACAGGGATAGCAC
\end{tabular}




\title{
CHAPTER 4
}

Exogenous interferon- $\beta$ provides protection against rhinovirus infection even in cigarette smoke extract-exposed airway epithelial cells

\author{
Fahad Gulraiz \\ Erik V Beuken \\ Giel R Gaajetaan \\ Carla Bellinghausen \\ Cathrien A Bruggeman \\ Frank R Stassen
}

Manuscript in preparation 


\section{Abstract}

\section{Background}

Previously, it has been demonstrated that patients with chronic obstructive pulmonary disease (COPD) and asthma display an impaired immune response towards viral infections of the respiratory tract, thereby rendering them more susceptible for virus-induced acute exacerbations. In particular the production of interferons (IFNs), seems to be impaired in these patients, perhaps because of prolonged cigarette smoking. Prophylactic treatment with exogenous IFNs might be an effective way to restore this impaired immune response. However, since a considerable number of COPD and also asthma patients are still active smokers, the protective effect of exogenous IFN treatment might be limited in these patients. Yet, whether cigarette smoke attenuates the effects of exogenous IFNs treatment is not clear. In this in vitro study we investigated whether respiratory epithelial cells are still protected against rhinovirus infection by prophylactic IFN- $\beta$ treatment despite exposure to cigarette smoke extracts (CSE).

\section{Methods}

Type-II like epithelial cells (A549 cell line) were first treated with different concentrations of CSE for $6 \mathrm{~h}$ and then treated with IFN- $\beta$ (100 IU/ml) for another $18 \mathrm{~h}$. To determine the effect of CSE on the protective effect of IFN- $\beta$ against viral infection, cells were infected with human rhinovirus 1B (HRV1B) for $1 \mathrm{~h}$ and incubated further for another $24 \mathrm{~h}$. Expression of pattern recognition receptors (PRRs: involved in viral recognition), IFN stimulated genes (ISGs: involved in antiviral response) and viral RNA were determined with qPCR.

\section{Results}

CSE didn't have a pronounced effect on the basal mRNA expression of various PRRs and ISGs. Furthermore, CSE exposure also barely affected the IFN- $\beta$-induced mRNA expression of PRRs and ISGs. Alternatively, both CSE-exposed control and IFN- $\beta$ pretreated cells showed higher viral titers than non-CSE-exposed control or pretreated cells suggesting a higher susceptibility of these CSE-exposed cells for viral infections. Nevertheless, cells pretreated with IFN- $\beta$ were still markedly protected against viral infection irrespective of CSE exposure. 


\section{Conclusion}

These data show that CSE slightly decrease the ability of IFN- $\beta$ to inhibit viral replication. Nonetheless, cells were still strongly protected by IFN- $\beta$ against viral infection which indicates that prophylactic treatment with IFNs might be beneficial even in smokers. 


\section{Introduction}

Viral infections are considered as the most important triggers for acute exacerbations (AEs) in COPD and asthma patients [1-5]. Different studies have shown that COPD and asthmatics are more predisposed to develop severe effects of viral infections of respiratory tract leading to AEs. For instance, Hurst and colleagues have shown that frequency of acquisition of common colds is significantly increased in COPD patients who experience frequent AEs [6]. Similarly, in several in vitro studies an increased viral replication has been observed in bronchial epithelial cells from asthmatics and COPD patients [7,8]. Recently it has been reported that an impairment of innate antiviral immune response system may be responsible for the increase susceptibility of COPD and asthma patients to develop virus-induced AEs. More precisely, in both types of patients the production of both antiviral type I and III interferons (IFN) by epithelial and immune cells seems to be compromised [8-10].

Although the exact underlying causes of this impaired IFN production remains to be elucidated, it has been shown that cigarette smoke - apart from increasing the inflammation itself - also affects several aspects involved in the first line of defense within the airway. For example, cigarette smoke exposure results in impaired mucociliary clearance and enhanced permeability of the airway epithelium [11-13]. Moreover, it has been reported that cigarette smoke impairs the type I IFN production by different cell types [14,15]. Taken together, this suggests that exposure to cigarette smoke may significantly increase the risk for respiratory viral infections.

Previously, we and others have demonstrated that even at low concentrations exogenously added IFN- $\beta$ is well able to protect epithelial cells against subsequent rhinovirus infections [16]. This protective effect was most likely mediated by the strong increase in the expression of various well-known antiviral proteins like Interferon-Stimulated-Gene 15 (ISG15) and myxovirus resistance 1 (MX1) following IFN- $\beta$ treatment of airway epithelial cells. This suggests that for instance intranasal application of a low dose IFN- $\beta$ may create an antiviral environment in susceptible respiratory patients and may as such be useful for prophylactic treatment against virus-induced exacerbations.

However, one pitfall might be that a significant number of COPD and asthma patients, despite a strong medical advice, continue smoking [17-19]. Since cigarette smoke has been shown to impair the antiviral response in epithelial cells 
$[14,15]$, the protective effects of IFN- $\beta$ treatment may be compromised by cigarette smoke and limit the prophylactic effect of such a treatment. Yet in the present paper we demonstrate that, although high concentrations of cigarette smoke extract indeed impair the basal as well as the IFN- $\beta$-induced antiviral response, the protective effect of IFN- $\beta$ treatment is sufficiently maintained and epithelial cells exposed to cigarette smoke extract are still strongly protected against rhinovirus infections. 


\section{Materials and methods}

\section{Cell culture}

The A549 alveolar type-II like cells (ATCC CCL-185) were cultured in RPMI 1640 medium (Gibco, life technologies NY, USA) supplemented with $10 \%$ heatinactivated fetal calf serum (FSC, Lonza, Verviers, Belgium) at $37 \circ \mathrm{C} / 5 \% \mathrm{CO}_{2}$. Human lung fibroblast cells (MRC5, ATCC CCL-171) were cultured in Minimal Essential medium (EMEM 1X, Gibco, life technologies NY, USA) supplemented with $10 \%$ FCS, non-essential amino acids (MP Biomedicals, Solon, Ohio, USA), and Lglutamine ( $2 \mathrm{mmol} / \mathrm{L})$. Cells were incubated at $37^{\circ} \mathrm{C} / 5 \% \mathrm{CO}_{2}$.

\section{Virus culture}

Human rhinovirus 1B (HRV1B) was purchased from American Type Culture Collection (ATCC, VR-1645). Viral stocks were generated in MRC-5 cells as previously described [16]. In brief, confluent monolayers of MRC-5 cells were infected with HRV1B at multiplicity of infection of 1 (MOI-1) for $1 \mathrm{~h}$ at $33^{\circ} \mathrm{C}$. After infection cells were further incubated at $33^{\circ} \mathrm{C}$ until $100 \%$ cytopathogenic effect (CPE) was attained. Next, cell debris was removed by centrifugation and viral titers were determined with $50 \%$ tissue culture infectivity dose (TCID50) assay.

\section{Cigarette smoke extracts}

Cigarette smoke extracts (CSE) were prepared freshly every time before use, by combusting a 3R4F research cigarette (without filter, University of Kentucky) using a vacuum/pressure pump (Model No. 7015; Cole-Parmer, Chicago, IL) at constant speed. Main stream cigarette smoke was bubbled through $2 \mathrm{ml}$ of sterile PBS. To remove bacteria and large smoke particles, the resulting suspension was subsequently filtered with a $0.2 \mu \mathrm{m}$ pore Acrodisk filter (Pall Corporation; Newquay, Cornwall, UK). Optical density ( $\triangle O D$ ) at 320-540 nm of this suspension was monitored using an ELISA reader. Suspensions with a $\triangle O D$ close to 1 (0.9-1.1) were considered to be $100 \%$ CSE. All cigarette smoke extracts were used within 30 minutes of preparation. 


\section{Determination of cytotoxicity of CSE}

Before stimulating the cells with CSE for actual experiments, effect of CSE on the viability of cells was determined with a colorimetric thiazolyl blue tetrazolium bromide (MTT) (Sigma-Aldrich, St. Louis, MO, USA) assay as described previously [16]. Briefly, A549 cells were seeded in 96-wells tissue culture plates and treated with different concentrations of CSE for 24h. Afterwards the MTT assay was performed according to manufacturer's instructions. The percentage of metabolic activity of exposed A549 cells was calculated by comparing to non-exposed controls (absorbance exposed/ absorbance non-exposed x 100\%).

\section{Stimulation of A549 cells with CSE}

To investigate the influence of CSE on the basal expression of various intracellular double-stranded RNA pattern recognition receptors (PRR), A549 cells were propagated in 24-wells tissue culture plates (Becton Dickinson, NJ, USA) until $100 \%$ confluency was reached and subsequently treated with different concentrations of CSE $(0 \%, 2.5 \%, 5,0 \%$, and $7.5 \%$ ) diluted in RPMI 1640 with $2 \%$ FCS. After 6 h of CSE stimulation, the cell layer was washed with PBS and cells were lysed by adding 350 $\mu$ of RLT lysis buffer (RNeasy Mini Kit, Qiagen) and stored at $-80^{\circ} \mathrm{C}$ until further processing.

Next, we determined the effect of CSE on the IFN- $\beta$-induced up-regulation of different antiviral proteins as observed in earlier experiments. Again, A549 cells were initially stimulated with CSE (0\%, 2.5\% and 7.5\%) for 6 hours and then treated with IFN- $\beta$ (100 IU/ml) for 18 hours in the presence of CSE extract. Finally, cells were collected in RTL lysis buffer and stored at $-80^{\circ} \mathrm{C}$ until further processing.

\section{HRV infection of CSE-stimulated IFN- $\beta$ treated A549 cells}

To determine whether CSE exposure affects the protective antiviral effect mediated by IFN- $\beta$ exposure, cells were treated with CSE (6h) and IFN- $\beta$ (18h) as described before. Then, the supernatant of each well was removed and preserved at $33^{\circ} \mathrm{C}$ for later use. Then cells were washed twice with PBS, and infected with HRV1B (MOI=1; RPMI 1640, 2\% FCS) for 1 hour at $33^{\circ} \mathrm{C}$. After infection, the supernatant was removed and cells were washed three times with PBS, and incubated for another $24 \mathrm{~h}$ at $33^{\circ} \mathrm{C}$ with the preserved medium (containing CSE and IFN- $\beta$ ). Lastly, cells were lysed and RNA was isolated as described above. 


\section{Plasmid construction and generation of standard curves}

In order to determine viral RNA copy numbers present in the cells, viral RNA fragments were in vitro transcribed from a plasmid as previously described [20] with some modifications. In brief, viral RNA was reverse transcribed (Superscriptll Reverse Transcriptase, Invitrogen, NY, USA) in the presence of HRV primers (supplementary table). The resulting cDNA served as template and amplified by conventional PCR. The amplified fragments was then cloned into the pGEMT-easy vector (Promega, Wisconsin, USA) and sequenced. The plasmid DNA, designated p1123, was transcribed in vitro (T7 RNA polymerase, Fermentas). After that the obtained RNA was treated with DNAse (DNase I recombinant, RNase free; Roche) and quantified with Nanodrop ND-1000. Copies per $\mu$ l were calculated with Avogadro's number. Serial dilutions of the quantified RNA were used for the generation of a standard curves.

\section{Reverse transcription and qPCR}

RNA was isolated with RNeasy Mini kit (Qiagen, Hilden, Germany) according to manufacturer's instructions. Isolated RNA was first DNase treated with Turbo DNAfree kit (Ambion, life technologies, NY, USA) and then reverse transcribed with the iScript cDNA Synthesis Kit (Bio-Rad, Hercules,CA, USA). Then $2 \mu$ of cDNA was amplified in a final volume of $25 \mu$ l containing $12,5 \mu \mathrm{l}$ iQ SYBR Green Supermix (BioRad) and appropriate primers (supplementary table). Detection was done as described previously [21]. Gene expression were normalized to $\beta$-actin levels and expression was expressed using the $2^{-\Delta C t}$ method [22]. For quantification of HRV RNA copies, standard curves were generated for every qPCR.

\section{Statistical analysis}

The overall significance of the experimental effect was determined by KruskalWallis tests and the differences between multiple groups were analyzed by MannWhitney test. Values of $p<0.05$ were considered statistically significant. Data are expressed as mean \pm SEM. 


\section{Results}

\section{Effect of CSE on the viability of cells}

Since we aimed to use a range of CSE concentrations without any significant effect on the viability of cells, metabolic activity of cells was determined by MTT assay after treatment with different concentrations of CSE. In our experimental settings the use of CSE concentrations up to $7.5 \%$ had no significant effect on the viability of cells when compared to untreated cells (supplementary figure). Thus, to treat the cells with CSE for actual experiments we used a range of CSE concentrations with maximum concentration of $7.5 \%$.

\section{Effect of CSE on mRNA expression of PRRs and ISGs}

Initially, we investigated the effect of CSE on the basal expression of different dsRNA PRR's involved in viral recognition. Apart from a small, though significant upregulation of the TLR3 mRNA expression, incubation for $6 \mathrm{~h}$ in the presence of either $2.5,5$ or $7.5 \%$ CSE had no significant effect on the expression of either MDA5 or RIG-I mRNA (Figure 1A-C).
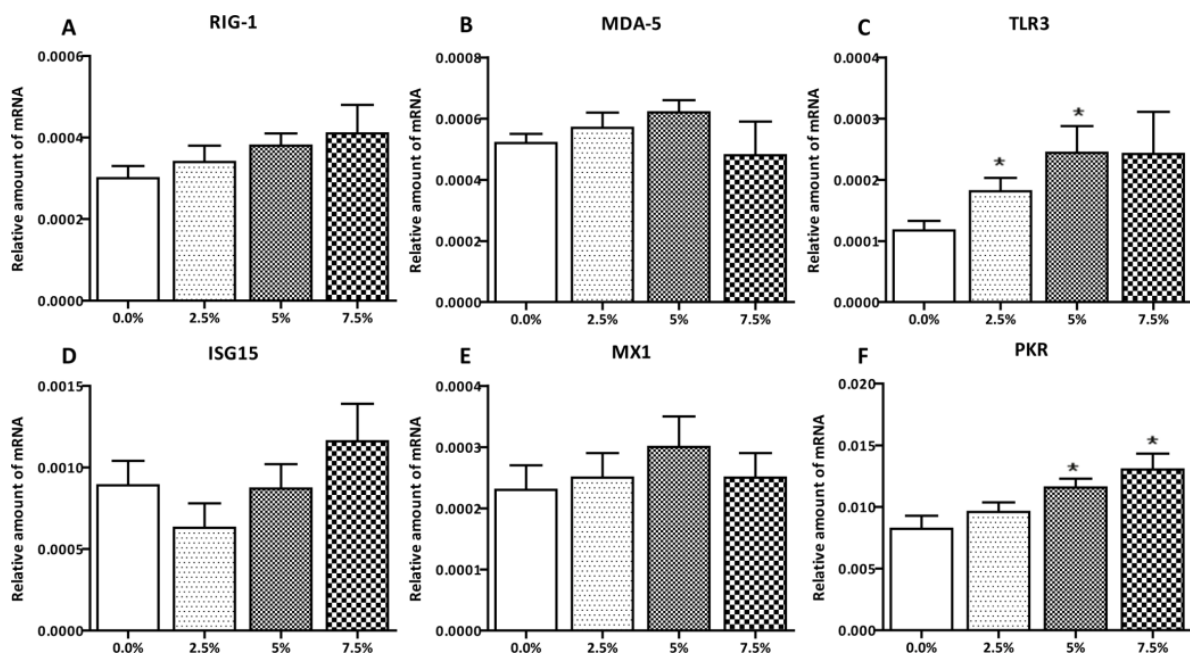

Figure 1. CSE does not affect the basal expression of PRR and ISGs: A549 were stimulated with different concentrations of CSE for $6 \mathrm{~h}$ and afterwards cells were collected in lysis buffer. mRNA expression of RIG$1(A)$, MDA5 (B), TLR3 (C), ISG15 (D), MX1 (E) and PKR (F) genes was determined by qPCR. *, p<0.05 Control vs rest of the conditions. 
Moreover, we examined the effect of CSE on the basal mRNA expression of different antiviral genes. In line with the PRR's, no significant effects of CSE on the basal expression levels of ISG15 or MX1 were observed. However, a small, though significant and dose dependent increase in the expression of protein kinase $R$ (PKR) was observed (Figure 1D-F).

\section{Exogenous IFN- $\beta$ induces a strong antiviral state in A549}

Previously we have demonstrated that the expression of various antiviral genes was dramatically enhanced when cells were treated with IFN- $\beta$ [16]. Here we confirm these results as in particular the mRNA expression of both ISG15 and MX1, and to a lesser extent PKR, was markedly increased when cells were treated for $18 \mathrm{~h}$ with 100 IU of IFN- $\beta$ (Figure 2A). Also, the mRNA expression of the PRRs was significantly enhanced when cells were treated with IFN- $\beta$ (Figure 2B). These data confirm observations by us and others that exogenous IFN- $\beta$ induces a strong antiviral condition in epithelial cells of the respiratory tract $[8,16,23]$.
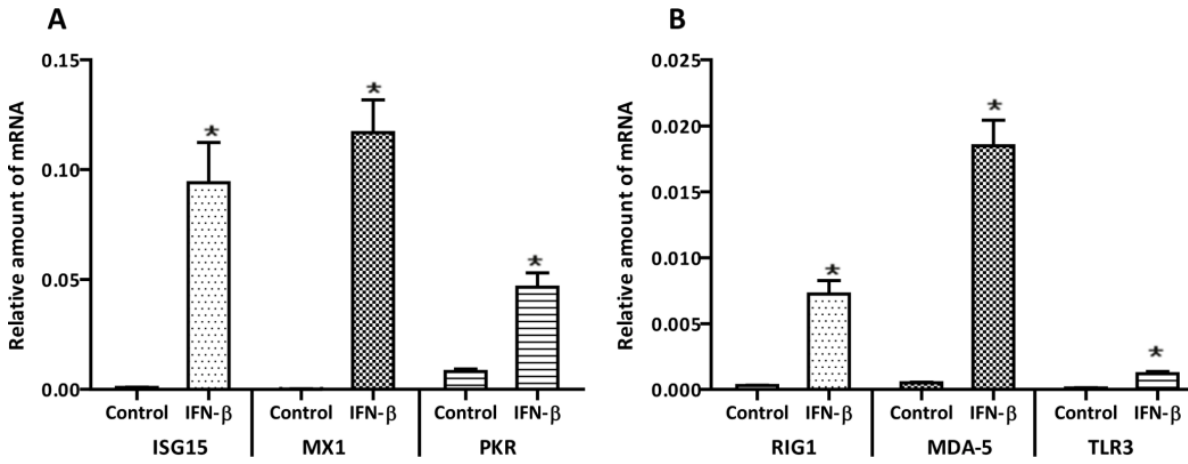

Figure 2. Exogenous IFN- $\beta$ significantly enhances the expression of PRR and ISGs: A549 were stimulated with $100 \mathrm{IU} / \mathrm{ml}$ of IFN- $\beta$ for $18 \mathrm{~h}$ and afterwards cells were collected in lysis buffer. mRNA expression of various ISGs (A) and PRRs (B) genes was determined by qPCR. ${ }^{*}, p<0.05$ Control vs IFN- $\beta$.

\section{Effect of CSE on exogenous IFN- $\beta$ induced expression of PRRs and ISGs}

Although CSE barely affected the basal mRNA expression of various dsRNA PRRs, it cannot be excluded that exposure to CSE impairs the IFN- $\beta$-dependent protective antiviral condition in epithelial cells. Therefore we tested the mRNA expression of the aforementioned antiviral genes and PRRs in A549 cells which were exposed to CSE for $6 \mathrm{~h}$ before being treated with IFN- $\beta$. Yet, the IFN- $\beta$-induced up-regulation of almost all antiviral genes and PRRs was barely affected by prior exposure to CSE. 
Even at the highest CSE concentration (7.5\%) only the expression of RIG-I and MX1 was significantly diminished by CSE (Figure 3 ). This suggests that the protective antiviral effect of exogenous IFN- $\beta$ might be maintained even in smokers.
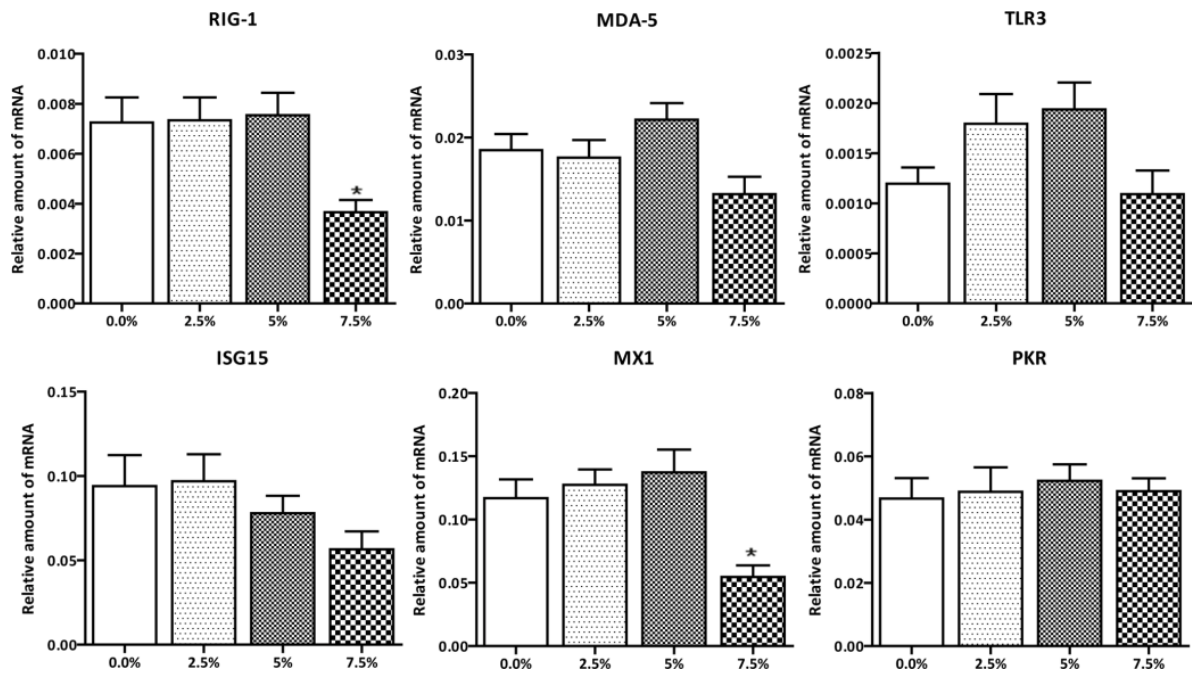

Figure 3. CSE barely affects the induction of PRR and ISGs by exogenous IFN- $\boldsymbol{\beta}$ : A549 were first exposed to different concentrations of CSE for $6 \mathrm{~h}$ and then stimulated with $100 \mathrm{IU} / \mathrm{ml}$ of IFN- $\beta$ for another $18 \mathrm{~h}$. After that, cells were collected in lysis buffer and analyzed further to determine the mRNA expression of various PRR and ISGs genes was determined by qPCR. *, $p<0.05$ Control vs rest of the conditions.

\section{Effect of CSE on the IFN- $\beta$ inhibited viral replication}

To test whether the antiviral effect is indeed maintained when cells are preexposed to CSE, we infected CSE-exposed A549 cells with a human rhinovirus (HRV1B). Previously, we have demonstrated that IFN- $\beta$ pretreated cells were markedly protected against HRV1B infection [16]. In figure 4A we now show that, despite exposure to concentrations up to $7.5 \%$ CSE, IFN- $\beta$-treated cells are still highly protected from HRV1B infection when compared to non-treated A549 cells. Nevertheless, although cells were protected from HRV1B infection when compared to non-treated controls, this protective effect was significantly and dosedependently impaired within the CSE-exposed group, which confirms earlier observations that CSE affects the innate antiviral response in respiratory epithelial cells (Figure 4B). 

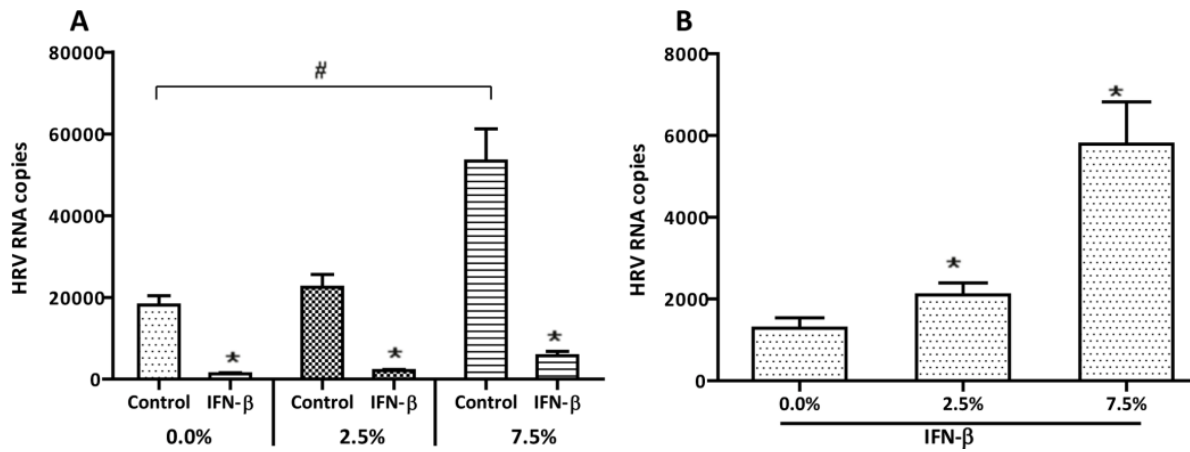

Figure 4. Even CSE treated cells are strongly protected by exogenous IFN- $\beta$ against viral infection: A549 were first exposed to different concentrations of CSE for $6 \mathrm{~h}$ and then stimulated with $100 \mathrm{IU} / \mathrm{ml}$ of IFN- $\beta$ for another $18 \mathrm{~h}$. After that CSE + IFN- $\beta$ containing medium was collected and preserved at $33{ }^{\circ} \mathrm{C}$ and cells were infected with HRV1B for $1 \mathrm{~h}$. Afterwards cells were washed with PBS and preserved medium was added again on the cells. Next cells were incubated for another $24 \mathrm{~h}$ and collected in lysis buffer and analyzed further to determine the viral copies by qPCR. * ${ }^{*}, p<0.05$ Control vs IFN- $\beta$. \# $p<0.05$ between indicated conditions 


\section{Discussion}

In the present study we determined the effects CSE on the expression of various PRRs and ISGs involved in the recognition of HRV and antiviral signaling. Also, the efficacy of exogenous IFN- $\beta$ to protect airway epithelial cells against HRV1B infection in the presence of CSE was determined. Our data show that CSE barely affects the expression of different PRRs and ISGs at baseline or after the stimulation with IFN- $\beta$. Moreover, although the inhibition of viral replication by IFN- $\beta$ was slightly less in CSE-treated cells, the protective effect was still pronounced and efficacious as compared to non-IFN- $\beta$-treated cells.

Viral infections of the respiratory tract are the main cause of AEs in asthma and COPD. In particular HRV has been associated with a high incidence of virus-related $A E^{\prime} s$ [1-5]. Effective clearance of viral infections in the respiratory tract largely depends on the fast recognition of invading viral particles predominantly by epithelial cells [24]. Detection of HRV for example requires the presence of double-stranded RNA pattern recognition receptors like TLR3 and MDA5 [25-27]. Also RIG-I might be involved although conflicting data have been published [27-29]. Activation of these receptors evokes a cascade of intracellular signaling events resulting in the release of the antiviral type I/III IFN's. Subsequently the expression of a variety of antiviral ISG's is initiated, which all contribute to the antiviral resistance in cells [30]. Consequently, impairment of these systems may severely affect the defense against viral infections. Such impairment may result from chronic cigarette smoking as it has been shown repeatedly that cigarette smoke is able to affect this antiviral response. For example, the release of CXCL10 and CCL5 by primary human bronchial epithelial cells or BEAS-2B in response to HRV16 was significantly inhibited by cigarette smoke extract [31,32]. Smoking is big risk factor for the development and progression of COPD $[18,19]$. Similarly, among asthmatics $25-30 \%$ are current smokers [17] and in these patients HRV-induced exacerbations are usually more severe and last longer when compared to nonsmokers [33]. Thus, apart from the fact that it prevents loss of lung function and reduces morbidity and mortality among patients with chronic respiratory diseases $[34,35]$, smoking cessation is also beneficial to restore the respiratory immune response and control the incidence of AEs. However, smoking cessation can be difficult to achieve, especially among those with higher nicotine dependence $[36,37]$.

Previously, we and others have demonstrated that exogenous application of IFN- $\beta$ might be an effective way to prevent HRV infections and subsequent AEs. 
In particular this might be beneficial for patients with chronic respiratory diseases who are not able to quit smoking, and in whom the innate immune defense may be permanently disturbed as a consequence of their smoking behavior. Here we have now extended our earlier observations to show that CSE-exposed epithelial cells are still markedly protected against HRV infections. Nevertheless, both under basal conditions as well as in IFN- $\beta$ treated cells an impaired antiviral defense mechanism was observed as higher viral load were found in CSE treated cells when compared to control cells. Interestingly, however, we didn't observe marked differences in the expression of various PRRs or ISGs under basal conditions when cells were exposed to CSE only. This is in accordance with recent data published by Proud et al. who recently by gene array analyses demonstrated that CSE had no dramatic effects on the expression of various antiviral or PRR genes in airway epithelial cells [38]. Alternatively, in the presence of CSE the expression of HRV-induced genes associated with various functions including viral defenses, inflammation and airway remodeling was significantly diminished. And although we didn't study the direct effects of CSE on HRV-induced expression of these antiviral genes, the observation that viral replication was more pronounced in CSE-exposed epithelial cells suggests that also in our hands CSE affected the antiviral response in untreated cells. Since many of the antiviral genes are so-called Interferon-Stimulated genes (ISG), it has been speculated that this impairment is a consequence of a reduction in the amount of IFNs produced upon infection. The exact nature of this diminished IFN release is still unclear but previous report have shown that exposure to cigarette smoke significantly affected the release of IFN and other cytokines involved in antiviral immunity $[14,15]$. However in the study by Proud, IFN- $\lambda 1$ levels were unaffected while IFN- $\beta$ levels were below the detection limit. Although HRV infections have been shown to result in the pronounced release of IFN- $\beta$ by infected airway epithelial cells [29] this has been questioned by others [39]. Also data from our lab could not reveal clear evidence for the production of IFN- $\beta$ by epithelial cells following HRV infections [16]. Based on this it seems unlikely that a compromised IFN production following smoke exposure is the underlying mechanisms for the impaired expression of the antiviral genes. This is also supported by our finding that CSE hardly affected the mRNA expression of the different ISGs and PRRs in IFN- $\beta$-treated cells; only at the maximum concentration of CSE (7.5\%) the expression of RIG-1 and MX1 was slightly diminished. Taken together, these data imply that the CSE-mediated impairment of HRV-induced genes is not mediated by manipulation of IFN-dependent effects. 
The main goal of the present study was to evaluate whether CSE negatively affected the protection by exogenous IFN- $\beta$ against infections with HRV. HRVs, which in healthy humans usually only cause a harmless common cold, are frequently found in exacerbating asthma and COPD patients. In these patients, perhaps because of chronic smoking, lung epithelial cells as well as alveolar macrophages produce substantially less type I/III interferons in response to viral infections resulting in more severe lower respiratory symptoms and higher viral loads [8,9]. Furthermore, not only the release of IFN, but also the antiviral effects of exogenous IFN have been shown to be impaired in CSE-treated fibroblasts $[15,40]$. In line with this, in the present study we also found that CSE treatment reduced the protective effect of IFN- $\beta$ against viral infection in epithelial cells as HRV copy numbers were significantly augmented in CSE-treated cells. As already stated, this is unlikely that this slight decline in protective effect of exogenous IFN- $\beta$ was due to alterations in the expression PRRs or ISGs as only a small (though significant) decrease in the expression of RIG-I and MX-1 was observed. Alternatively, this CSE-induced effect might be due to the effect of CSE on the expression of type-I IFN receptors which have been shown to be down regulated by CSE treatment in fibroblasts [40]. Despite this small impairment in the protective effect of IFN- $\beta$ in CSE-treated cells, viral replication was still dramatically reduced in CSE+IFN- $\beta$ cells when compared to non-IFN- $\beta$-treated cells. This is also supported by the high expression levels of ISGs which indicate that despite CSE treatment cells were still in a pronounced antiviral state.

In conclusion, our data shows that, despite a higher susceptibility of CSEexposed cells for HRV infections, CSE had no dramatic effect on the protective antiviral effect of exogenous IFN- $\beta$ in airway epithelial cells. This suggests that even in chronic smokers exogenous IFN- $\beta$ could be beneficial to prevent the viral infections and ultimately AEs. 


\section{References}

1. Papi A, Bellettato CM, Braccioni F, Romagnoli M, Casolari P, et al. (2006) Infections and airway inflammation in chronic obstructive pulmonary disease severe exacerbations. Am J Respir Crit Care Med 173: 1114-1121.

2. Rohde G, Wiethege A, Borg I, Kauth M, Bauer TT, et al. (2003) Respiratory viruses in exacerbations of chronic obstructive pulmonary disease requiring hospitalisation: a case-control study. Thorax 58: 37-42.

3. Wos M, Sanak M, Soja J, Olechnowicz H, Busse WW, et al. (2008) The presence of rhinovirus in lower airways of patients with bronchial asthma. Am J Respir Crit Care Med 177: 1082-1089.

4. Nicholson KG, Kent J, Ireland DC (1993) Respiratory viruses and exacerbations of asthma in adults. BMJ 307: 982-986.

5. Johnston SL, Pattemore PK, Sanderson G, Smith S, Lampe F, et al. (1995) Community study of role of viral infections in exacerbations of asthma in 9-11 year old children. BMJ 310: 1225-1229.

6. Hurst JR, Donaldson GC, Wilkinson TM, Perera WR, Wedzicha JA (2005) Epidemiological relationships between the common cold and exacerbation frequency in COPD. Eur Respir J 26: 846-852.

7. Schneider D, Ganesan S, Comstock AT, Meldrum CA, Mahidhara R, et al. (2010) Increased cytokine response of rhinovirus-infected airway epithelial cells in chronic obstructive pulmonary disease. Am J Respir Crit Care Med 182: 332-340.

8. Wark PA, Johnston SL, Bucchieri F, Powell R, Puddicombe S, et al. (2005) Asthmatic bronchial epithelial cells have a deficient innate immune response to infection with rhinovirus. J Exp Med 201: 937-947.

9. Mallia P, Message SD, Gielen V, Contoli M, Gray K, et al. (2011) Experimental rhinovirus infection as a human model of chronic obstructive pulmonary disease exacerbation. Am J Respir Crit Care Med 183: 734-742.

10. Contoli M, Message SD, Laza-Stanca V, Edwards MR, Wark PA, et al. (2006) Role of deficient type III interferon-lambda production in asthma exacerbations. Nat Med 12: 1023-1026.

11. Burns AR, Hosford SP, Dunn LA, Walker DC, Hogg JC (1989) Respiratory epithelial permeability after cigarette smoke exposure in guinea pigs. J Appl Physiol (1985) 66: 2109-2116.

12. Gangl K, Reininger R, Bernhard D, Campana R, Pree I, et al. (2009) Cigarette smoke facilitates allergen penetration across respiratory epithelium. Allergy 64: 398-405.

13. Foster WM (2002) Mucociliary transport and cough in humans. Pulm Pharmacol Ther 15: 277-282.

14. Sonnenfeld G, Hudgens RW (1986) Effect of sidestream and mainstream smoke exposure on in vitro interferon-alpha/beta production by L-929 cells. Cancer Res 46: 2779-2783.

15. Bauer CM, Dewitte-Orr SJ, Hornby KR, Zavitz CC, Lichty BD, et al. (2008) Cigarette smoke suppresses type I interferon-mediated antiviral immunity in lung fibroblast and epithelial cells. J Interferon Cytokine Res 28: 167-179.

16. Gaajetaan GR, Geelen TH, Vernooy JH, Dentener MA, Reynaert NL, et al. (2013) Interferon-beta induces a long-lasting antiviral state in human respiratory epithelial cells. J Infect 66: 163169.

17. Stapleton M, Howard-Thompson A, George C, Hoover RM, Self TH (2011) Smoking and asthma. J Am Board Fam Med 24: 313-322.

18. Mannino DM, Buist AS (2007) Global burden of COPD: risk factors, prevalence, and future trends. Lancet 370: 765-773.

19. Chee A, Sin DD (2008) Treatment of mild chronic obstructive pulmonary disease. Int J Chron Obstruct Pulmon Dis 3: 563-573.

20. Boncristiani HF, Rossi RD, Criado MF, Furtado FM, Arruda E (2009) Magnetic purification of biotinylated cDNA removes false priming and ensures strand-specificity of RT-PCR for enteroviral RNAs. J Virol Methods 161: 147-153.

21. Gaajetaan GR, Geelen TH, Grauls GE, Bruggeman CA, Stassen FR (2012) CpG and poly(I:C) stimulation of dendritic cells and fibroblasts limits herpes simplex virus type 1 infection in an IFNbetadependent and -independent way. Antiviral Res 93: 39-47.

22. Schmittgen TD, Livak KJ (2008) Analyzing real-time PCR data by the comparative $C(T)$ method. Nat Protoc 3: 1101-1108. 
23. Cakebread JA, Xu Y, Grainge C, Kehagia V, Howarth PH, et al. (2011) Exogenous IFN-beta has antiviral and anti-inflammatory properties in primary bronchial epithelial cells from asthmatic subjects exposed to rhinovirus. J Allergy Clin Immunol 127: 1148-1154 e1149.

24. Vareille M, Kieninger E, Edwards MR, Regamey N (2011) The airway epithelium: soldier in the fight against respiratory viruses. Clin Microbiol Rev 24: 210-229.

25. Hewson CA, Jardine A, Edwards MR, Laza-Stanca V, Johnston SL (2005) Toll-like receptor 3 is induced by and mediates antiviral activity against rhinovirus infection of human bronchial epithelial cells. J Virol 79: 12273-12279.

26. Kato A, Favoreto S, Jr., Avila PC, Schleimer RP (2007) TLR3- and Th2 cytokine-dependent production of thymic stromal lymphopoietin in human airway epithelial cells. J Immunol 179: 1080-1087.

27. Kato H, Takeuchi O, Sato S, Yoneyama M, Yamamoto M, et al. (2006) Differential roles of MDA5 and RIG-I helicases in the recognition of RNA viruses. Nature 441: 101-105.

28. Hornung V, Ellegast J, Kim S, Brzozka K, Jung A, et al. (2006) 5'-Triphosphate RNA is the ligand for RIG-I. Science 314: 994-997.

29. Slater L, Bartlett NW, Haas JJ, Zhu J, Message SD, et al. (2010) Co-ordinated role of TLR3, RIG-I and MDA5 in the innate response to rhinovirus in bronchial epithelium. PLoS Pathog 6: e1001178.

30. Randall RE, Goodbourn S (2008) Interferons and viruses: an interplay between induction, signalling, antiviral responses and virus countermeasures. J Gen Virol 89: 1-47.

31. Eddleston J, Lee RU, Doerner AM, Herschbach J, Zuraw BL (2011) Cigarette smoke decreases innate responses of epithelial cells to rhinovirus infection. Am J Respir Cell Mol Biol 44: 118-126.

32. Hudy MH, Traves SL, Wiehler S, Proud D (2010) Cigarette smoke modulates rhinovirus-induced airway epithelial cell chemokine production. Eur Respir J 35: 1256-1263.

33. Venarske DL, Busse WW, Griffin MR, Gebretsadik T, Shintani AK, et al. (2006) The relationship of rhinovirus-associated asthma hospitalizations with inhaled corticosteroids and smoking. J Infect Dis 193: 1536-1543.

34. Anthonisen NR, Skeans MA, Wise RA, Manfreda J, Kanner RE, et al. (2005) The effects of a smoking cessation intervention on 14.5-year mortality: a randomized clinical trial. Ann Intern Med 142: 233-239.

35. Au DH, Bryson CL, Chien JW, Sun H, Udris EM, et al. (2009) The effects of smoking cessation on the risk of chronic obstructive pulmonary disease exacerbations. J Gen Intern Med 24: 457-463.

36. Fagerstrom KO, Kunze M, Schoberberger R, Breslau N, Hughes JR, et al. (1996) Nicotine dependence versus smoking prevalence: comparisons among countries and categories of smokers. Tob Control 5: 52-56.

37. Davila EP, Zhao W, Byrne M, Webb M, Huang Y, et al. (2009) Correlates of smoking quit attempts: Florida Tobacco Callback Survey, 2007. Tob Induc Dis 5: 10.

38. Proud D, Hudy MH, Wiehler S, Zaheer RS, Amin MA, et al. (2012) Cigarette smoke modulates expression of human rhinovirus-induced airway epithelial host defense genes. PLoS One 7: e40762.

39. Spurrell JC, Wiehler S, Zaheer RS, Sanders SP, Proud D (2005) Human airway epithelial cells produce IP-10 (CXCL10) in vitro and in vivo upon rhinovirus infection. Am J Physiol Lung Cell Mol Physiol 289: L85-95.

40. HuangFu WC, Liu J, Harty RN, Fuchs SY (2008) Cigarette smoking products suppress anti-viral effects of Type I interferon via phosphorylation-dependent downregulation of its receptor. FEBS Lett 582: 3206-3210. 
Supplementary Figure: Toxicity of CSE in A549 cells.

MTT

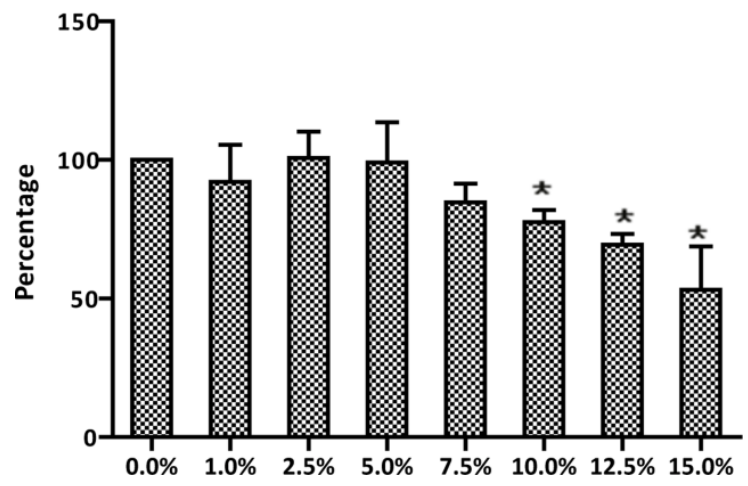

A549 were treated with different concentrations of CSE for 24h. Next metabolic activity of CSE-treated and non-treated cells was determined by MTT assay and compared to each other. ${ }^{*}, p<0.05$ Control vs different CSE concentrations.

Supplementary table. Primers used for mRNA expression analysis

\begin{tabular}{|c|c|c|}
\hline Gene & & Primer sequences $\left(5^{\prime}-3^{\prime}\right)$ \\
\hline \multirow[t]{2}{*}{ HRV } & forward & TGGACAGGGTGTGAAGAGC \\
\hline & reverse & CAAAGTAGTCGGTCCCATCC \\
\hline \multirow[t]{2}{*}{ ISG15 } & forward & GGTGGTGGACAAGTGCGATG \\
\hline & reverse & CGAAGGTCAGCCAGAACAGG \\
\hline \multirow[t]{2}{*}{ Mx1 } & forward & GGACATCGCCACCACAGAGG \\
\hline & reverse & TCCGCACCACATCCACAACC \\
\hline \multirow[t]{2}{*}{ RIG-1 } & forward & АCTCTGGTTGCCAAATCCAC \\
\hline & reverse & TGGAAGGGATCAGCAAAGAG \\
\hline \multirow[t]{2}{*}{ PKR } & forward & TGGCGGTCTTCAGAATCAACATC \\
\hline & reverse & CAGCCATTTCTTCTTCCCGTATCC \\
\hline \multirow[t]{2}{*}{ MDA5 } & forward & CGCAAAGAACGTGTTTGTGCC \\
\hline & reverse & САССАСССТСАТСАСТАТСА \\
\hline \multirow[t]{2}{*}{ TLR3 } & forward & CCTGGTTTGTTAATTGGATTAACGA \\
\hline & reverse & TGAGGTGGAGTGTTGCAAAGG \\
\hline \multirow[t]{2}{*}{$\beta$-actin } & forward & TGGAGAAATCTGGCACCAC \\
\hline & reverse & GAGGCGTACAGGGATAGCAC \\
\hline
\end{tabular}




\title{
CHAPTER 5
}

Haemophilus influenzae increases the susceptibility and inflammatory response of airway epithelial cells to viral infections

\author{
Fahad Gulraiz \\ Carla Bellinghausen \\ Gert E Grauls \\ Erik V Beuken \\ Cathrien A Bruggeman \\ Frank R Stassen
}

Under review in FASEB 


\section{Abstract}

\section{Background}

Co-infections are common in COPD patients and it has been speculated that unrelated pathogens affect the susceptibility to others or synergistically augment the inflammatory reaction in the lungs. For example, non-typeable Haemophilus influenzae (NTHI), a common colonizer of COPD lungs, is able to up-regulate the cellular receptor Intercellular Adhesion Molecule-1 (ICAM-1) which is being used by the major group human rhinoviruses (HRV) for cellular adherence. Yet, the effect of NTHI on the replication of viruses, including major group HRV, is not clear. In this study, the effect of heat-inactivated NTHI (Hi-NTHI) on replication of HRV16 (major group), HRV1B (minor group) and respiratory syncytial virus (RSV) was evaluated in a bronchial epithelial cell line (BEAS-2B). Further, the effect of Hi-NTHI on the inflammatory response of cells upon subsequent viral infection was examined.

\section{Methods}

BEAS-2B were pre-treated with Hi-NTHI for $24 \mathrm{~h}$ and then infected for 10 minutes with HRV16, HRV1B or RSV at a multiplicity of infection of 10 . Next, cells and media were collected after 2, 24 and 48h. Viral copy numbers were determined by qPCR and the concentrations of the inflammatory cytokines IL- 6 and IL- 8 in culture supernatants were assessed by ELISA.

\section{Results}

Pre-treatment with Hi-NTHI significantly increased the expression of ICAM-1, leading to increased numbers of HRV16 RNA copies at all-time points. Likewise, in Hi-NTHI pretreated cells the numbers of RSV and HRV1B RNA copies were augmented at 24 and $48 \mathrm{~h}$, but not $2 \mathrm{~h}$ post-infection. However, the percentage increase in the viral RNA copies for RSV and HRV1B between Hi-NTHI pre-treated and non-Hi-NTHI pre-treated cells was far less than for HRV16. Furthermore, production of interleukin- 6 and IL- 8 was synergistically increased in cells pretreated with Hi-NTHI after RSV infection. 


\section{Conclusions}

Hi-NTHI pre-treatment significantly enhances the replication of HRV16, HRV1B and RSV in BEAS-2B cells. Yet, the effect was most pronounced for major group HRV16, most likely due to increased initial binding/entrance of HRV16 to the cells because of the increased expression of ICAM-1. Furthermore, Hi-NTHI pre-treatment facilitated the production of inflammatory cytokines in response to subsequent RSV infection, suggesting that a pre-existing bacterial infection might exaggerates the inflammatory response when cells are additionally infected by a virus. 


\section{Introduction}

Human rhinoviruses (HRVs) are members of Picornaviridae family. They are positive-sense, single-stranded RNA viruses with more than 100 antigenically distinct serotypes [1,2]. HRVs infect the upper respiratory tract of healthy individuals and are responsible for the majority of common colds. Although these common colds are usually benign and self-limiting, they lead to considerable economic burden in terms of medical visits and work loss [3-5]. Moreover, in patients with underlying chronic respiratory diseases like chronic obstructive pulmonary disease (COPD), HRV infections result in more severe lower respiratory tract symptoms including acute exacerbations $[6,7]$.

Based on their usage of cell surface receptors, HRV serotypes are classified either as minor or major group HRVs. While the minor group HRVs use the lowdensity lipoprotein (LDL) receptors, the major group HRVs, which are about $90 \%$ of the known serotypes, use the intercellular adhesion molecule-1 (ICAM-1) as their receptor to enter the cytoplasm of cells $[2,8,9]$.

Also bacterial infections can initiate acute exacerbations in patients with chronic respiratory diseases [10-12]. Although the human upper respiratory tract is a reservoir of different commensal and potential pathogenic bacteria [13], infections of the lower respiratory tract on the other hand frequently result in severe acute exacerbations [11]. Among these bacteria, non-typeable Haemophilus influenzae (NTHI) is frequently isolated from COPD patients, both when clinically stable or during acute exacerbations [14-17].

Apart from the fact that both bacterial and viral microorganisms can independently cause respiratory infections, it has previously been established that an infection with one pathogen can create a conducive environment for an infection with another unrelated pathogen [18-22]. It has been described extensively that viral infections promote the susceptibility to subsequent bacterial infections. For example, trans-epithelial migration of bacteria is significantly enhanced because of a disrupted epithelial barrier following a viral infection $[23,24]$. Also, enhanced bacterial adhesion and impaired antibacterial immune responses following earlier viral infections have been reported [25-30]. Alternatively, the effects of bacterial colonization on the susceptibility for viral infections have been studied less extensively. Interestingly, earlier studies have shown that infections with NTHI increase the expression of ICAM-1 [19,31]. Thus, being the single cellular receptor for major group HRVs, increased ICAM-1 
expression could lead to increased binding and replication of this type of HRV [3234]. Indeed, previously it has been demonstrated that NTHI infection enhances the binding of major group HRV to airway epithelial cells. Furthermore, the release of HRV-induced chemokines is also increased by NTHI infected cells [19]. Yet, it remains to be determined whether this only results in enhanced binding of the virus to the cells or also augments viral replication. Moreover, it needs to be established whether the enhanced sensitivity is solely due to an increased expression of ICAM-1 making the cells more sensitive to viruses which use the ICAM-1 receptor for attachment, like the major group of HRV, or whether it is a general effect rendering the cells more sensitive to any other viral infection. To understand and differentiate this in a more clear way, we evaluated the effect of NTHI treatment on the replication of HRV16 (major group HRV), HRV1B (minor group HRV) and respiratory syncytial virus (RSV) in the bronchial epithelial cell line BEAS-2B. Furthermore, we hypothesized that co-infections may synergistically enhance the release of inflammatory mediators and contribute as such to the initiation of acute exacerbations and progression of chronic airway diseases. To study this we measured the production of two important inflammatory mediators (interleukin-6 (IL-6) and interleukin-8 (IL-8)) by NTHI-pretreated cells either in the presence or absence of viral infections. 


\section{Materials and Methods}

\section{Cell Culture}

Human bronchial epithelial cells (BEAS-2B, ATCC CRL-9609) were maintained in precoated cell culture flasks (T-75, Greiner bio-one GmbH, Frickenhausen, Germany) in RPMI 1640 medium (Gibco, life technologies, NY, USA), supplemented with $10 \%$ fetal calf serum (FCS) (Lonza, Verviers, Belgium) and incubated at $37^{\circ} \mathrm{C} / 5 \% \mathrm{CO}_{2}$. Flasks were pre-coated with LHC Basal medium (Gibco, life technologies, NY, USA) supplemented with $0.001 \%$ Human natural fibronectin (BD Bioscience, California, USA), $0.003 \%$ bovine collagen type I (Gibco, life technologies, NY, USA), and $0.001 \%$ bovine serum albumin (Boehringer Mannheim $\mathrm{GmbH}$, Mannheim, Germany).

Human lung fibroblast cells (MRC-5, ATCC CCL-171) were maintained in Minimal Essential medium (MEM 1X, Gibco, life technologies, NY, USA). Medium was supplemented with L-glutamine $(2 \mathrm{mmol} / \mathrm{L})$, non-essential amino acids (MP Biomedicals, Solon, Ohio, USA), and 10\% FCS (Lonza). Cells were incubated at $37^{\circ} \mathrm{C}$ in $5 \% \mathrm{CO}_{2}$.

\section{Bacterial preparation and heat inactivation}

The NTHI strain (ATCC 49247) was grown on vitalex supplemented chocolate blood agar plates (Oxoid, Wesel, Germany). In order to prevent bacterial overgrowth in the cell cultures, bacterial suspensions of $0.5 \mathrm{McF}$ arland $\left(1.5 \times 10^{8} \mathrm{cfu} / \mathrm{ml}\right)$ in RPMI 1640 were heat inactivated at $65^{\circ} \mathrm{C}$ for 30 minutes. After cooling down, suspensions were supplemented with $2 \%$ FCS and then added to the wells.

\section{Virus culture}

HRV1B was purchased from American Type Culture Collection (ATCC, VR-1645), while HRV16 was a kind gift from the Department of Virology at Erasmus MC Rotterdam, the Netherlands. Viral stocks were generated in MRC-5 cells as previously described [35]. In brief, cells were grown in culture medium with $2 \%$ FCS. After infection with virus at multiplicity of infection of 1 (MOI-1) for $1 \mathrm{~h}$, cells were incubated at $33^{\circ} \mathrm{C}$ until $100 \%$ cytopathogenic effect (CPE) was attained. After that cell debris was removed by centrifugation. To determine the viral titers, $50 \%$ tissue culture infectivity dose (TCID50) assay was performed. 
Respiratory syncytial virus A2 (RSV) was obtained from Dutch Vaccine institute. Vero cells were used for the generation of viral stocks. After $2 \mathrm{~h}$ of infection, cells were washed with PBS and incubated further in DMEM with 1\% FCS until more than $80 \%$ CPE was attained. Cell debris was removed by centrifugation for 10 minutes at $1000 \times$ g. Virus was subsequently precipitated with polyethylene glycol (PEG). Therefore, PEG stock solution (50\% PEG6000 in $150 \mathrm{mM} \mathrm{NaCl}, 1 \mathrm{mM}$ EDTA, $6.1 \mathrm{~g} / \mathrm{L}$ TRIS, pH 7.5) was mixed with virus pool to get $10 \%$ PEG (1:5), stirred $2 \mathrm{~h}$ at $4 \mathrm{C}$, and then centrifuged 30 minutes at $3000 \times \mathrm{g}$. The pellet was then resuspended in PBS $+25 \%$ sucrose in $10 \%$ of original volume. TCID50 assay was performed to determine the viral titers.

\section{Treatment of cells with heat-inactivated NTHI}

BEAS-2B cells were seeded in 24-well tissue culture plates (Becton Dickinson, NJ, USA) at a density of $2 \times 10^{5}$ cells per well in RPMI 1640 (10\% FCS). After $24 \mathrm{~h}$, the medium was replaced by a 0.5 McFarland suspension of heat-inactivated NTHI (HiNTHI) and cells were incubated for another $24 \mathrm{~h}$.

\section{Virus infection}

After 24h treatment with Hi-NTHI, cells were washed twice with RPMI 1640 (0\% FCS) and then infected in RPMI 1640 (2\% FCS) with HRV16, HRV1B or RSV at MOI10 for 10 minutes at $33^{\circ} \mathrm{C}(\mathrm{HRV} 16 / 1 \mathrm{~B})$ or at $37^{\circ} \mathrm{C}$ (RSV). After the infection period, cells were washed once with RPMI 1640 (0\% FCS) and fresh RPMI 1640 (2\% FCS) was added to the cells. Next, cells were incubated either at $33^{\circ} \mathrm{C}$ (HRV16 or HRV1B infected) or at $37^{\circ} \mathrm{C}$ (RSV infected) for another $2 \mathrm{~h}, 24 \mathrm{~h}$ and $48 \mathrm{~h}$. At each time point, cell-free supernatants and cells were collected stored at $-80^{\circ} \mathrm{C}$ until further analyses.

\section{Plasmid construction for the generation of standard curves}

In order to prepare a standard curve for determining viral RNA copy numbers, viral RNA fragments were in vitro transcribed from a plasmid as previously described [36]. Briefly, viral RNA was reverse transcribed (Superscriptll Reverse Transcriptase, Invitrogen, NY, USA) in the presence of HRV or RSV primers (supplementary table). The resulting CDNA fragments were then amplified by PCR. The PCR fragments was then cloned into the pGEMT-easy vector (Promega, Wisconsin, USA) and sequenced. The resulting plasmid DNA, designated p1123 (HRV) and p1092 (RSV), 
was transcribed in vitro (T7 RNA polymerase, Fermentas). After that the obtained RNA was treated with DNAse (DNase I recombinant, RNase free; Roche) and quantified with Nanodrop ND-1000. Copies per $\mu$ l were calculated with Avogadro's number. Serial dilutions of the quantified RNA were used for the generation of a standard curves.

\section{Quantification of viral load in infected cells}

Total RNA was isolated with FATRK 001 (Favorgen Biotech Corporation, Pingtung County, Taiwan), according to manufacturer's instructions. Isolated RNA was then DNase treated with Turbo DNA-free kit (Ambion, life technologies, NY, USA) and quantified with Nanodrop ND-1000. Next, 1 g of DNase treated RNA was reverse transcribed with the iScript cDNA synthesis kit (Bio-Rad, Hercules, California, USA) and quantitative real-time PCR (qPCR) was performed as previously described [37]. To determine the actual number of copies of viral RNA standard curves were generated for every qPCR. To normalize the gene expression, $\beta$-actin levels were used. Fold changes were calculated using the $2^{-\Delta \Delta c t}$ method [38].

\section{TCID50}

In order to determine the virus titers, a TCID50 assay was performed as previously described [39] with some modifications. Supernatants were collected from infected BEAS-2B and serially diluted 1:2 in MEM (1X) containing 2\% FCS (Lonza), nonessential amino acids and L-glutamine $(2 \mathrm{mmol} / \mathrm{L})$. These dilutions were then added to confluent layers of MRC-5 cells in 96-well plates. TCID50 was calculated according to Spearman-Karber formula.

\section{Western blot analysis}

Hi-NTHI pre-treated and control BEAS-2B cells were collected in $1 \mathrm{ml}$ of phosphatebuffered saline and centrifuged. Proteins were extracted from cell pellets with NP40 lysis buffer (150 mM NaCl, 1\% NP-40 and $50 \mathrm{mM}$ TRIS). Equal volumes of protein suspension were loaded onto $10 \%$ SDS-polyacrylamide gels and separated with electrophoresis. Next, proteins were transferred onto nitrocellulose membranes and blocking of unspecific binding sites was performed in 5\% dried, non-fat milk, dissolved in tris-buffered saline with tween 0.05\% (TBS-T). After that, membranes were incubated overnight with primary antibodies against ICAM1 (R \& D systems, Minneapolis, MN, USA) and $\beta$-actin (antibodies-online $\mathrm{GmbH}$, Aachen, Germany) at 
room temperature. Then membranes were incubated with horseradish peroxidaseconjugated secondary antibodies (R \& D systems, Minneapolis, MN, USA) for $1 \mathrm{~h}$ at room temperature. Finally, after washing with TBS-T, proteins were detected by using an enhanced chemiluminescence system (Luminoscope, Bio-Rad, Hercules, CA, chemiluminescence reagents: Sigma-Aldrich, St. Louis, USA). Quantity one software from Bio-Rad was used to calculate the optical density.

\section{Quantification of IL-6 and IL-8}

To determine the levels of IL- 6 and IL-8, an enzyme-linked immunosorbent assay was performed according to the manufacturer's instructions. For IL-6, Human ELISA Ready-SET-Go! kits (affymetrix eBioscience, USA) was used, while IL-8 was quantified using the Human CXCL8/IL-8 Quantikine ELISA Kit (R \& D systems, Minneapolis, USA).

\section{Statistical analyses}

Overall statistical significance was determined by Kruskal-Wallis test and differences between the multiple groups were determined by using Mann-Whitney test. Data are expressed as mean \pm SEM. 


\section{Results}

\section{Hi-NTHI pre-treatment increases ICAM-1 expression}

In a first set of experiments, we aimed to confirm the increase in the ICAM-1 expression following Hi-NTHI treatment in our experimental setting. For this, BEAS$2 \mathrm{~B}$ cells were treated with $\mathrm{Hi}-\mathrm{NTHI}$ for $24 \mathrm{~h}$ and the expression of ICAM-1 was determined at both mRNA and protein levels. qPCR (Fig. 1A) and western blot (Fig. $1 B \& C)$ data showed a significant increase in the expression of ICAM-1 in the HiNTHI treated cells as compared to non-treated cells.

A
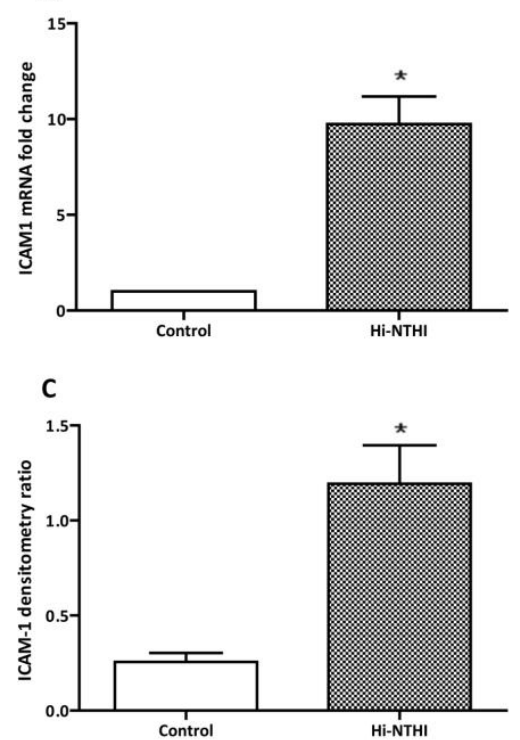

B

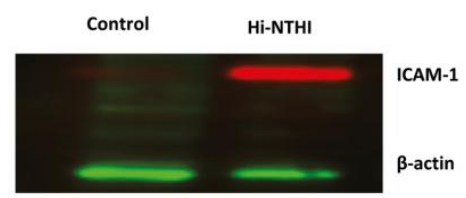

Figure 1. Hi-NTHI pre-treatment induce ICAM1: Cells were either pre-treated with Hi-NTHI or control medium for $24 \mathrm{~h}$. After that cells were collected to determine the mRNA (A) and protein (B \& C) expression of ICAM-1. MannWhitney test was applied to determine the difference between the groups. ${ }^{*}=p<0.05$. $\mathrm{n}=5$ for figure $\mathrm{A}$ and $\mathrm{n}=4$ for figure $\mathrm{C}$.

\section{Effect of Hi-NTHI pre-treatment on HRV16 replication}

As shown above and as demonstrated by others, NTHI increases the expression of ICAM-1 by airway epithelial cells, which results in increased binding of major group HRV to the cells [19]. However, the effect of NTHI on the subsequent replication of major group HRVs is not clear. To determine the effect of NTHI on the viral replication, BEAS-2B cells were infected with HRV16 after $24 \mathrm{~h}$ of treatment with $\mathrm{Hi}$ NTHI. In order to minimize any potential effect of viral infection itself on the expression of ICAM-1, cells were infected just for 10 minutes after which unbound 
virus was removed and cells were further incubated. Viral RNA copies in the cells and infectious viral particles in the supernatants were determined by qPCR and TCID50 respectively.

Increased numbers of HRV16 RNA copies in Hi-NTHI pre-treated bronchial epithelial cells

As expected, already after two hours of infection, significantly more viral RNA copies were detected in Hi-NTHI pre-treated cells as compared to control cells (Fig. $2 \mathrm{~A}$ ) indicating enhanced binding and/or entrance of virus into the cells. Similarly, at later time points the viral RNA copies detected in the Hi-NTHI pre-treated cells were significantly higher than viral RNA copies detected in virus-infected control cells. In both Hi-NTHI pre-treated and control cells, maximal copies numbers were detected at $24 \mathrm{~h}$ post-infection (p.i.). At $48 \mathrm{~h}$ p.i., however, number of viral RNA copies already declined when compared to the $24 \mathrm{~h}$ p.i. time point in both conditions. Yet, in Hi-NTHI pre-treated cells there were still significantly more copies than at $2 \mathrm{~h}$ p.i., whereas in the infected control cells, the number of copies at $48 \mathrm{~h}$ p.i. was no longer different from the number of copies detected at $2 \mathrm{~h}$ p.i. This shows that replication of virus was better and lasted longer in Hi-NTHI pretreated cells as compared to control cells.
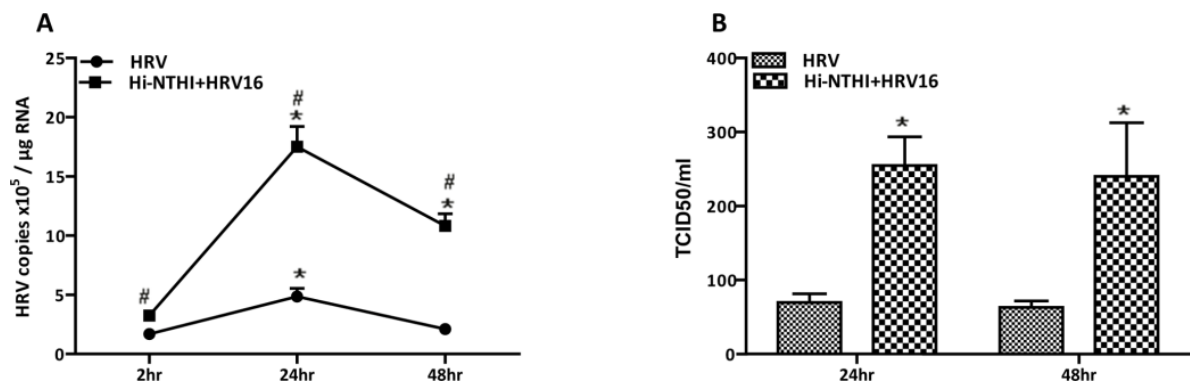

Figure 2. Hi-NTHI pre-treatment results in increased HRV16 replication: Hi-NTHI pre-treated and nonHi-NTHI pre-treated cells were infected with HRV16 for 10 minutes and incubated further for 2, 24 and $48 \mathrm{~h}$. Both cells and media were collected at all time points. The number of viral mRNA copies was determined by qPCR (A) and to determine number of infectious viral particles TCID50 assays was performed (B). For figure $A,{ }^{*}=p<0.05$ between $2 \mathrm{~h}$ and other time points. $\#=p<0.05$ between Hi-NTHI pre-treated and non-Hi-NTHI pretreated conditions at respective time points. For figure $B, *=p<0.05$ between Hi-NTHI pre-treated and non-Hi-NTHI pretreated conditions. $\mathrm{n}=4$

\section{Hi-NTHI pre-treatment increases the generation of HRV16 infectious particles}

Next, we evaluated whether the infectious progeny released by Hi-NTHI pretreated cells was also augmented. Therefore the number of viral particles was 
determined in the supernatants by TCID50. Although the overall number of infectious viral particles detected was low - perhaps because of the limited time of initial infection (10min) - significantly higher numbers of progeny were found in the supernatant of infected Hi-NTHI pre-treated cells as compared to infected control cells both 24 and $48 \mathrm{~h}$ after infection (Fig. 2B). These data confirm that pretreatment with Hi-NTHI not only results in enhanced binding of viral particles to the cells but truly augments the replication of HRV16.

\section{Effect of Hi-NTHI pre-treatment on HRV1B and RSV replication}

From the results presented above it was not clear whether the observed increase in HRV16 replication after Hi-NTHI pre-treatment was solely due to increased binding of virus particles to the cells because of enhanced expression of ICAM-1, or whether it was a general effect of Hi-NTHI pre-treatment resulting in an increased susceptibility of the cells for viral infections. To further unravel this, BEAS-2B cells were infected with HRV1B (which uses the LDL receptor for adherence) and RSV after Hi-NTHI pre-treatment and viral RNA copy numbers were determined by qPCR (Fig. 3A \& B).
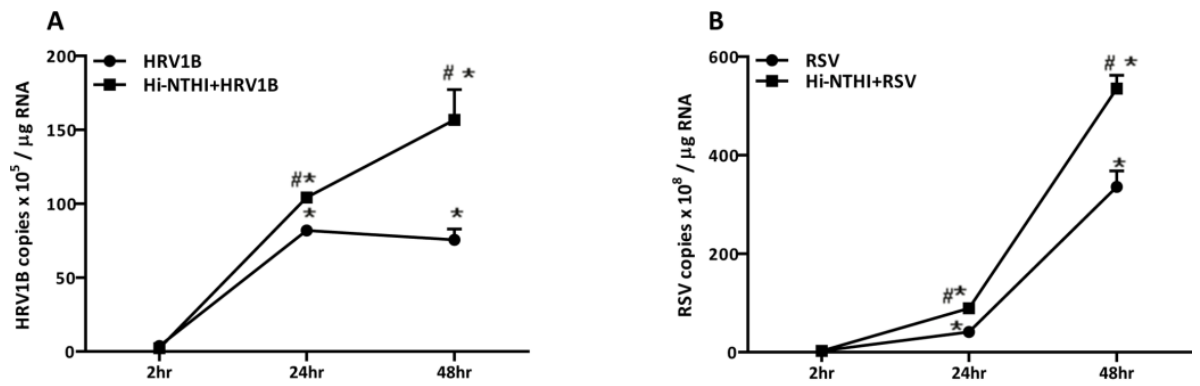

Figure 3. Effect of Hi-NTHI pre-treatment on HRV1B and RSV replication: Hi-NTHI pre-treated and nonHi-NTHI pre-treated cells were infected with either HRV1B (A) or RSV (B) for 10 minutes and incubated further for 2, 24 and 48h. Cells were collected at all-time points and the number of viral mRNA copies was determined by qPCR. ${ }^{*}=p<0.05$ between $2 \mathrm{~h}$ and other time points. $\#=p<0.05$ between $\mathrm{Hi}-\mathrm{NTH}$ pre-treated and non-Hi-NTHI pretreated conditions at respective time points. $n=4$

In contrast to infection with major group HRV, two hours after the infection with HRV1B or RSV the number of viral RNA copies detected in infected Hi-NTHI pre-treated and control cells were not significantly different from each other. At 24 and 48h, however, Hi-NTHI pretreated cells also contained more HRV1B and RSV RNA copies when compared to control cells. Yet, when the increase in viral copies was expressed as percentage increase over cells not pre-treated with 
Hi-NTHI, the increase was significantly higher in cells infected with the major group HRV16 (2h:+93\%, 24h:+273\%, 48h:+413\%) when compared to cells infected with HRV1B (2h:-30\%, 24h:+27\%, 48h:+115\%) or RSV (2h:-5\%, 24h:+81\%, 48h:+61\%) (Fig. 4). This indicates that Hi-NTHI pre-treatment especially enhances the susceptibility for major group HRVs, most likely through the up-regulation of the ICAM-1 entrance receptor.

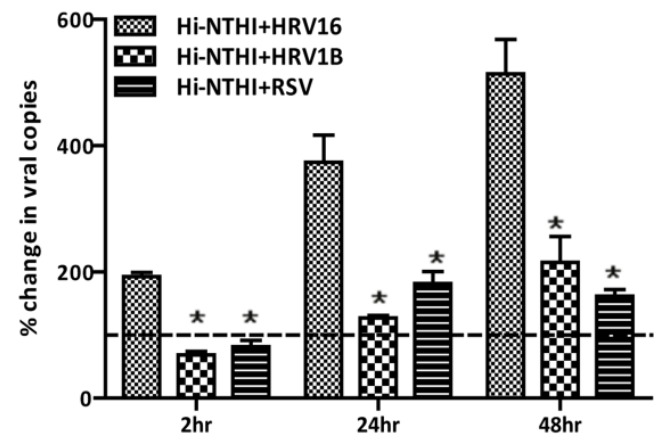

Figure 4. Relative change in viral RNA copies over time: The number of RNA copies detected in non-HiNTHI pre-treated cells for particular virus at particular time was considered $100 \%$ and the percentage change from this for the respective virus at respective time point was calculated. ${ }^{*}=\mathrm{p}<0.05$ between HRV16 and other viruses (HRV1B and RSV) at respective time points. $n=4$

\section{Effect of Hi-NTHI pre-treatment on IL-6 and IL-8 production upon subsequent viral infection}

Earlier, it has been shown that pre-incubation with $\mathrm{HI}$ increases the major group HRV39-induced expression of inflammatory mediators (e.g. IL-8). Furthermore, this increase was shown to be associated with increased binding of virus to the cells [19]. In pursuance of differentiating the effect of Hi-NTHI pre-treatment on the production of inflammatory mediators induced by HRV16, HRV1B and RSV, levels of two different pro-inflammatory cytokines (IL-6 and IL8) were determined. At $2 \mathrm{~h}$ after pre-treatment of cells with Hi-NTHI, significantly increased levels of both IL-6 and IL-8 were detected, which further increased over time. Unexpectedly, neither HRV16 (Fig. 5A \& B) nor HRV1B (Fig. 5C \& D) increased the production of IL-6 or IL-8 by non-Hi-NTHI pre-treated cells at any time point.

Additionally, no increase in the release of the Hi-NTHI-induced production of IL-6 or IL-8 was observed by subsequent infection with either HRV16 or HRV1B. However, in contrast to the HRVs, RSV induced the production of both inflammatory mediators. Although no induction of IL- 6 was observed after RSV infection of control cells at $2 \mathrm{~h}$ time point, significant levels of IL-6 were detected at $24 \mathrm{~h}$ time point, which further increased at $48 \mathrm{~h}$ (Fig. 5E). Moreover, RSV infection of Hi-NTHI pre-treated cells induced a significantly higher release of IL-6 as compared to 
control cells treated with Hi-NTHI or infected with RSV alone. This increase was synergistic and was observed at both 24 and $48 \mathrm{~h}$ time points. Similarly, IL-8 production was also induced by RSV infection but with delayed onset (Fig. 5F).
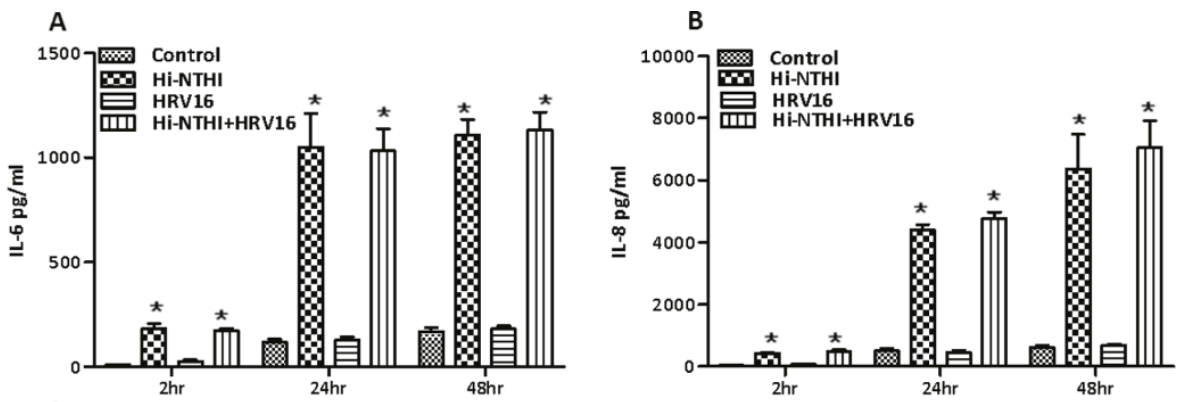

$$
\text { C }
$$$$
\text { D }
$$
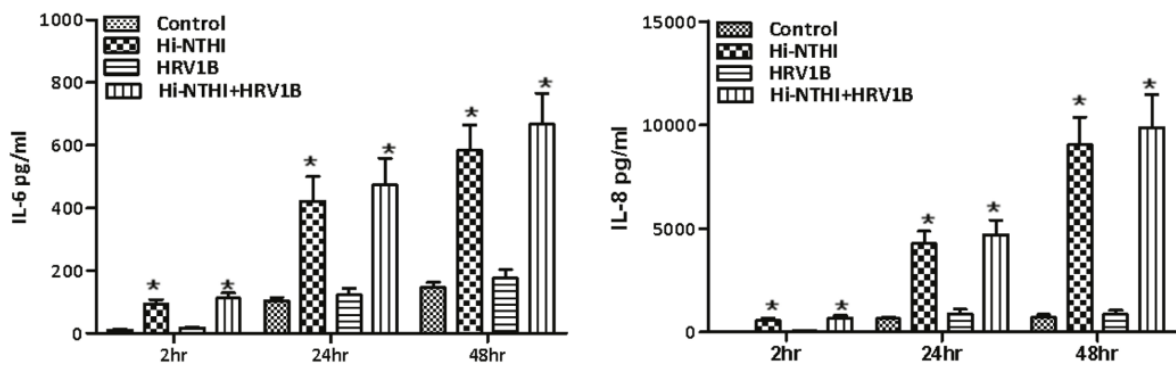

E
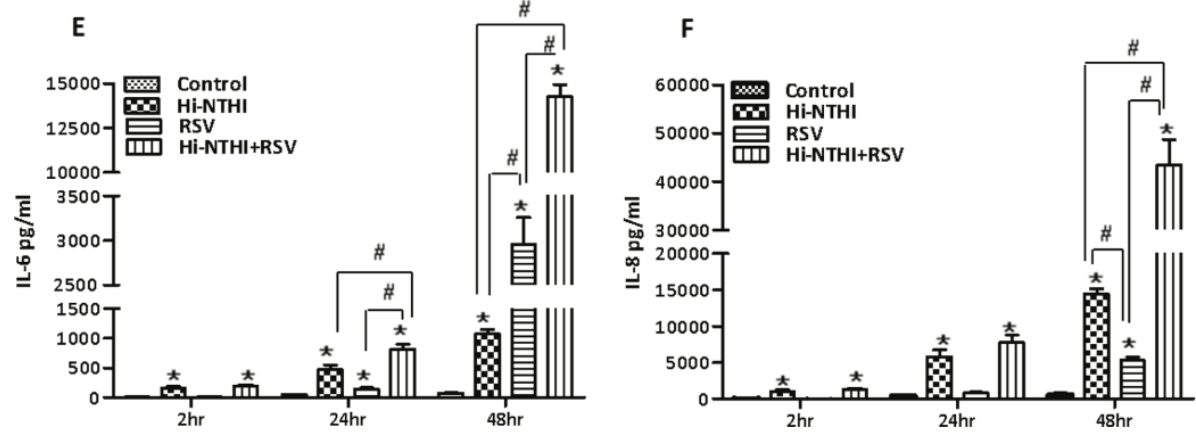

Figure 5. Effect of Hi-NTHI pre-treatment and subsequent viral infection on IL-6 and IL-8: Hi-NTHI pretreated and non-Hi-NTHI pre-treated cells were infected with either HRV16 (A, B), HRV1B (C, D) or RSV $(E, F)$ for 10 minutes and incubated further for 2, 24 and 48h. Media were collected at all-time points and protein levels of IL- $6(A, C, E)$ and IL-8 (B, D, F) were determined by ELISA. ${ }^{*}=p<0.05$ between control and other conditions at respective time point. \# = $p<0.05$ between the two indicated conditions. $\mathrm{n}=4$

At $24 \mathrm{~h}$, the increase in IL-8 levels after RSV infection alone did not achieve statistical significance. At 48h, however, a significant increase in IL-8 was observed after RSV infection of both control and Hi-NTHI pre-treated cells. Also, HRV and Hi- 
NTHI synergized on the release of IL-8 by the cells. Overall, these data suggest that RSV infection in patients colonized by NTHI may experience a more severe inflammatory reaction when subsequently infected with RSV than NTHI-free patients. 


\section{Discussion}

Bacterial and viral co-infections are common in COPD [40]. Infections with either type of pathogen can modulate the host immune responses and enhance the susceptibility to subsequent infections with other pathogens [41]. Infections with HRV, for example, have been shown to promote secondary bacterial infections, including NTHI infection, through different mechanisms [23,27,29,42]. As both HRV and NTHI have been shown to be important triggers for exacerbations in COPD patients, interactions between both may even result in more severe disease in these patients and studying such interactions may help to understand the often detrimental effect of respiratory infections in COPD.

Although it has been demonstrated repeatedly that HRV infections facilitate subsequent infections with NTHI $[23,29,42]$, the reverse has been studied less intensively. In the present study we evaluated the effects of Hi-NTHI pretreatment on the replication and generation of infectious progeny of HRV16, HRV1B and RSV in bronchial epithelial cells. Previously, it has been shown that NTHI infection increases the expression of ICAM-1 [19,31]. This transmembrane glycoprotein is expressed by a variety of cells including epithelial cells. It plays an important role in the host immune response through the recruitment of leukocytes to the site of inflammation and infection $[31,43,44]$. Besides the role of ICAM-1 in the immune response, this glycoprotein is also exploited by major group HRVs as their receptor for the attachment to the cells [8]. Expression of ICAM-1 is regulated at transcriptional level and can be induced in response to different stimuli including NTHI [31,43] which consequently leads to enhanced viral binding [19]. Yet, it is unclear whether this enhanced binding indeed results in enhanced replication and shedding of infectious progeny. In line with previous reports, we also found strong induction of ICAM-1 after Hi-NTHI pre-treatment, both at mRNA (9.74 fold, p<0.05) and protein $(4.7$ fold, $p<0.05$ ) levels (Fig. 1). Concomitantly, there was already a significant increase in the number of viral RNA copies of the major group HRV16 in $\mathrm{Hi}$-NTHI pre-treated cells at $2 \mathrm{~h}$ post infection. Moreover, this increase was even more pronounced at later time points and, even more importantly, we also found a significant increase in the release of infectious viral particles by Hi-NTHI pretreated cells. This implies that Hi-NTHI pre-treatment not only results in increased adherence of HRV16 but that there is a true effect also on viral replication and production of infectious progeny. 
In contrast to HRV16, no significant difference was observed in the number of RNA copies two hours after infection with the minor group HRV1B, which utilizes the LDL receptor [45] instead of ICAM-1 for cell entry. At later time points only a minor increase was observed in Hi-NTHI pre-treated cells. Similar to HRVs, RSV is another important pathogen of the respiratory tract and inducer of acute exacerbations in COPD patients $[46,47]$. Among other different molecules, ICAM-1 has also been claimed to be used by RSV as a receptor $[48,49]$. Yet definite validation is lacking [48] and the results in the present study likewise do not firmly support a role for ICAM-1 in the adherence of RSV to epithelial cells. No increase of RSV RNA copies in the Hi-NTHI pretreated cells were found at $2 \mathrm{~h}$ post infection, while the increase was only moderate at later time points. Together these results imply that the observed effect of Hi-NTHI pre-treatment on viral replication is most pronounced for the major group HRVs, although we cannot exclude a more general effect on the susceptibility of the cells as we also observed a slight though significant increase in viral RNA copy numbers in HRV1B- and RSV-infected cells.

Airway epithelial cells produce different inflammatory mediators in response to viral or bacterial infections [50,51]. IL-6 and IL-8 are two important inflammatory cytokines and acute exacerbations of COPD have been associated with increased levels of these molecules [52,53]. Previously, HRVs, RSV and NTHI have been shown to independently induce the production of these inflammatory mediators in airways epithelial cells [54-56]. Yet, bacterial and viral co-infections can synergistically enhance the inflammatory response of the cells $[19,57]$ and as such contribute to the disease severity. In the present study, we could confirm that bronchial epithelial cells indeed release both IL-6 and IL- 8 in response to Hi-NTHI. Moreover, RSV infections also induced the release of both IL- 6 and IL- 8 in control cells and this effect was synergistically enhanced when cells were first pre-treated with Hi-NTHI. Surprisingly, however, no significant changes in IL-6 and IL-8 protein levels was seen after infection with either HRV16 or HRV1B, irrespective whether cells were pre-treated with Hi-NTHI or not. It should however be noted that viral RNA copy numbers in the HRV-infected cells were substantially lower than those in the RSV infected cells, which may explain the observed difference between the two viruses. Nonetheless, at least for RSV, these results demonstrate that co-infections may dramatically enhance the inflammatory response and thereby in the long run contribute to the induction of acute exacerbations and disease progression.

Taken together, our data suggest that Hi-NTHI pre-treatment enhances the susceptibility of bronchial epithelial cells for viral replication and in particular to 
infections with major group HRVs, most likely through the up-regulation of ICAM-1 expression. Furthermore, our data suggest that a viral infection on top of a bacterial infection may significantly enhance the production of inflammatory mediators. These findings could explain the greater decline of lung function and longer hospital stay associated with COPD exacerbations induced by bacterial and viral co-infection $[40,58]$ and may give us new opportunities for therapeutic strategies to prevent these exacerbations. 


\section{References}

1. Uncapher CR, DeWitt CM, Colonno RJ (1991) The major and minor group receptor families contain all but one human rhinovirus serotype. Virology 180: 814-817.

2. Palmenberg AC, Spiro D, Kuzmickas R, Wang S, Djikeng A, et al. (2009) Sequencing and analyses of all known human rhinovirus genomes reveal structure and evolution. Science 324: 55-59.

3. Nichol KL, D'Heilly S, Ehlinger E (2005) Colds and influenza-like illnesses in university students: impact on health, academic and work performance, and health care use. Clin Infect Dis 40: 12631270 .

4. Roelen CA, Koopmans PC, Notenbomer A, Groothoff JW (2011) Job satisfaction and short sickness absence due to the common cold. Work 39: 305-313.

5. Fendrick AM, Monto AS, Nightengale B, Sarnes M (2003) The economic burden of non-influenzarelated viral respiratory tract infection in the United States. Arch Intern Med 163: 487-494.

6. Corne JM, Marshall C, Smith S, Schreiber J, Sanderson G, et al. (2002) Frequency, severity, and duration of rhinovirus infections in asthmatic and non-asthmatic individuals: a longitudinal cohort study. Lancet 359: 831-834.

7. Mallia P, Message SD, Gielen V, Contoli M, Gray K, et al. (2011) Experimental rhinovirus infection as a human model of chronic obstructive pulmonary disease exacerbation. Am J Respir Crit Care Med 183: 734-742.

8. Greve JM, Davis G, Meyer AM, Forte CP, Yost SC, et al. (1989) The major human rhinovirus receptor is ICAM-1. Cell 56: 839-847.

9. Bochkov YA, Palmenberg AC, Lee WM, Rathe JA, Amineva SP, et al. (2011) Molecular modeling, organ culture and reverse genetics for a newly identified human rhinovirus $C$. Nat Med 17: 627-632.

10. Erkan L, Uzun O, Findik S, Katar D, Sanic A, et al. (2008) Role of bacteria in acute exacerbations of chronic obstructive pulmonary disease. Int J Chron Obstruct Pulmon Dis 3: 463-467.

11. Sethi S, Murphy TF (2008) Infection in the pathogenesis and course of chronic obstructive pulmonary disease. N Engl J Med 359: 2355-2365.

12. Goss CH, Burns JL (2007) Exacerbations in cystic fibrosis. 1: Epidemiology and pathogenesis. Thorax 62: 360-367.

13. Watson K, Carville K, Bowman J, Jacoby P, Riley TV, et al. (2006) Upper respiratory tract bacterial carriage in Aboriginal and non-Aboriginal children in a semi-arid area of Western Australia. Pediatr Infect Dis J 25: 782-790.

14. Bandi V, Apicella MA, Mason E, Murphy TF, Siddiqi A, et al. (2001) Nontypeable Haemophilus influenzae in the lower respiratory tract of patients with chronic bronchitis. Am J Respir Crit Care Med 164: 2114-2119.

15. Monso E, Ruiz J, Rosell A, Manterola J, Fiz J, et al. (1995) Bacterial infection in chronic obstructive pulmonary disease. A study of stable and exacerbated outpatients using the protected specimen brush. Am J Respir Crit Care Med 152: 1316-1320.

16. Soler N, Ewig S, Torres A, Filella X, Gonzalez J, et al. (1999) Airway inflammation and bronchial microbial patterns in patients with stable chronic obstructive pulmonary disease. Eur Respir J 14: 1015-1022.

17. Murphy TF, Brauer AL, Schiffmacher AT, Sethi S (2004) Persistent colonization by Haemophilus influenzae in chronic obstructive pulmonary disease. Am J Respir Crit Care Med 170: 266-272.

18. Avadhanula V, Rodriguez CA, Devincenzo JP, Wang Y, Webby RJ, et al. (2006) Respiratory viruses augment the adhesion of bacterial pathogens to respiratory epithelium in a viral species- and cell type-dependent manner. J Virol 80: 1629-1636.

19. Sajjan US, Jia Y, Newcomb DC, Bentley JK, Lukacs NW, et al. (2006) H. influenzae potentiates airway epithelial cell responses to rhinovirus by increasing ICAM-1 and TLR3 expression. FASEB J 20: 2121-2123.

20. Avadhanula V, Rodriguez CA, Ulett GC, Bakaletz LO, Adderson EE (2006) Nontypeable Haemophilus influenzae adheres to intercellular adhesion molecule 1 (ICAM-1) on respiratory epithelial cells and upregulates ICAM-1 expression. Infect Immun 74: 830-838. 
21. van der Sluijs KF, Nijhuis M, Levels JH, Florquin S, Mellor AL, et al. (2006) Influenza-induced expression of indoleamine 2,3-dioxygenase enhances interleukin-10 production and bacterial outgrowth during secondary pneumococcal pneumonia. J Infect Dis 193: 214-222.

22. Peltola VT, McCullers JA (2004) Respiratory viruses predisposing to bacterial infections: role of neuraminidase. Pediatr Infect Dis J 23: S87-97.

23. Sajjan U, Wang Q, Zhao Y, Gruenert DC, Hershenson MB (2008) Rhinovirus disrupts the barrier function of polarized airway epithelial cells. Am J Respir Crit Care Med 178: 1271-1281.

24. Chattoraj SS, Ganesan S, Jones AM, Helm JM, Comstock AT, et al. (2011) Rhinovirus infection liberates planktonic bacteria from biofilm and increases chemokine responses in cystic fibrosis airway epithelial cells. Thorax 66: 333-339.

25. Okamoto S, Kawabata S, Terao Y, Fujitaka H, Okuno Y, et al. (2004) The Streptococcus pyogenes capsule is required for adhesion of bacteria to virus-infected alveolar epithelial cells and lethal bacterial-viral superinfection. Infect Immun 72: 6068-6075.

26. Hament JM, Aerts PC, Fleer A, Van Dijk H, Harmsen T, et al. (2004) Enhanced adherence of Streptococcus pneumoniae to human epithelial cells infected with respiratory syncytial virus. Pediatr Res 55: 972-978.

27. Ishizuka S, Yamaya M, Suzuki T, Takahashi H, Ida S, et al. (2003) Effects of rhinovirus infection on the adherence of Streptococcus pneumoniae to cultured human airway epithelial cells. J Infect Dis 188: 1928-1939.

28. Oliver BG, Lim S, Wark P, Laza-Stanca V, King N, et al. (2008) Rhinovirus exposure impairs immune responses to bacterial products in human alveolar macrophages. Thorax 63: 519-525.

29. Unger BL, Faris AN, Ganesan S, Comstock AT, Hershenson MB, et al. (2012) Rhinovirus attenuates non-typeable Hemophilus influenzae-stimulated IL-8 responses via TLR2-dependent degradation of IRAK-1. PLoS Pathog 8: e1002969.

30. Hussell T, Cavanagh MM (2009) The innate immune rheostat: influence on lung inflammatory disease and secondary bacterial pneumonia. Biochem Soc Trans 37: 811-813.

31. Frick AG, Joseph TD, Pang L, Rabe AM, St Geme JW, 3rd, et al. (2000) Haemophilus influenzae stimulates ICAM-1 expression on respiratory epithelial cells. J Immunol 164: 4185-4196.

32. Bianco A, Whiteman SC, Sethi SK, Allen JT, Knight RA, et al. (2000) Expression of intercellular adhesion molecule-1 (ICAM-1) in nasal epithelial cells of atopic subjects: a mechanism for increased rhinovirus infection? Clin Exp Immunol 121: 339-345.

33. Othumpangat S, Regier M, Piedimonte G (2012) Nerve growth factor modulates human rhinovirus infection in airway epithelial cells by controlling ICAM-1 expression. Am J Physiol Lung Cell Mol Physiol 302: L1057-1066.

34. Papi A, Johnston SL (1999) Rhinovirus infection induces expression of its own receptor intercellular adhesion molecule 1 (ICAM-1) via increased NF-kappaB-mediated transcription. J Biol Chem 274: 9707-9720.

35. Gaajetaan GR, Geelen TH, Vernooy JH, Dentener MA, Reynaert NL, et al. (2013) Interferon-beta induces a long-lasting antiviral state in human respiratory epithelial cells. J Infect 66: 163169.

36. Boncristiani HF, Rossi RD, Criado MF, Furtado FM, Arruda E (2009) Magnetic purification of biotinylated cDNA removes false priming and ensures strand-specificity of RT-PCR for enteroviral RNAs. J Virol Methods 161: 147-153.

37. Gaajetaan GR, Geelen TH, Grauls GE, Bruggeman CA, Stassen FR (2012) CpG and poly(I:C) stimulation of dendritic cells and fibroblasts limits herpes simplex virus type 1 infection in an IFNbetadependent and -independent way. Antiviral Res 93: 39-47.

38. Schmittgen TD, Livak KJ (2008) Analyzing real-time PCR data by the comparative CT method. Nature protocols 3: 1101-1108.

39. Gielen V, Johnston SL, Edwards MR (2010) Azithromycin induces anti-viral responses in bronchial epithelial cells. Eur Respir J 36: 646-654.

40. Papi A, Bellettato CM, Braccioni F, Romagnoli M, Casolari $P$, et al. (2006) Infections and airway inflammation in chronic obstructive pulmonary disease severe exacerbations. Am J Respir Crit Care Med 173: 1114-1121.

41. Page KR, Scott AL, Manabe YC (2006) The expanding realm of heterologous immunity: friend or foe? Cell Microbiol 8: 185-196. 
42. Wang JH, Kwon HJ, Jang YJ (2009) Rhinovirus enhances various bacterial adhesions to nasal epithelial cells simultaneously. Laryngoscope 119: 1406-1411.

43. van de Stolpe A, van der Saag PT (1996) Intercellular adhesion molecule-1. J Mol Med (Berl) 74: 1333.

44. Prince JE, Brayton CF, Fossett MC, Durand JA, Kaplan SL, et al. (2001) The differential roles of LFA-1 and Mac-1 in host defense against systemic infection with Streptococcus pneumoniae. J Immunol 166: 7362-7369.

45. Vlasak M, Roivainen M, Reithmayer M, Goesler I, Laine $P$, et al. (2005) The minor receptor group of human rhinovirus (HRV) includes HRV23 and HRV25, but the presence of a lysine in the VP1 $\mathrm{HI}$ loop is not sufficient for receptor binding. J Virol 79: 7389-7395.

46. Mohan A, Chandra S, Agarwal D, Guleria R, Broor S, et al. (2010) Prevalence of viral infection detected by PCR and RT-PCR in patients with acute exacerbation of COPD: a systematic review. Respirology 15: 536-542.

47. Varkey JB, Varkey B (2008) Viral infections in patients with chronic obstructive pulmonary disease. Curr Opin Pulm Med 14: 89-94.

48. Mastrangelo P, Hegele RG (2013) RSV fusion: time for a new model. Viruses 5: 873-885.

49. Behera AK, Matsuse H, Kumar M, Kong X, Lockey RF, et al. (2001) Blocking intercellular adhesion molecule-1 on human epithelial cells decreases respiratory syncytial virus infection. Biochem Biophys Res Commun 280: 188-195.

50. Diamond G, Legarda D, Ryan LK (2000) The innate immune response of the respiratory epithelium. Immunol Rev 173: 27-38.

51. Rennard SI, Romberger DJ, Sisson JH, Von Essen SG, Rubinstein I, et al. (1994) Airway epithelial cells: functional roles in airway disease. Am J Respir Crit Care Med 150: S27-30.

52. Bhowmik A, Seemungal TA, Sapsford RJ, Wedzicha JA (2000) Relation of sputum inflammatory markers to symptoms and lung function changes in COPD exacerbations. Thorax 55: 114-120.

53. Perera WR, Hurst JR, Wilkinson TM, Sapsford RJ, Mullerova H, et al. (2007) Inflammatory changes, recovery and recurrence at COPD exacerbation. Eur Respir J 29: 527-534.

54. Bossios A, Gourgiotis D, Skevaki CL, Saxoni-Papageorgiou P, Lotvall J, et al. (2008) Rhinovirus infection and house dust mite exposure synergize in inducing bronchial epithelial cell interleukin-8 release. Clin Exp Allergy 38: 1615-1626.

55. Yoon JS, Kim HH, Lee Y, Lee JS (2007) Cytokine induction by respiratory syncytial virus and adenovirus in bronchial epithelial cells. Pediatr Pulmonol 42: 277-282.

56. Kulkarni R, Rampersaud R, Aguilar JL, Randis TM, Kreindler JL, et al. (2010) Cigarette smoke inhibits airway epithelial cell innate immune responses to bacteria. Infect Immun 78: 2146-2152.

57. Chattoraj SS, Ganesan S, Faris A, Comstock A, Lee WM, et al. (2011) Pseudomonas aeruginosa suppresses interferon response to rhinovirus infection in cystic fibrosis but not in normal bronchial epithelial cells. Infect Immun 79: 4131-4145.

58. Wilkinson TM, Hurst JR, Perera WR, Wilks M, Donaldson GC, et al. (2006) Effect of interactions between lower airway bacterial and rhinoviral infection in exacerbations of COPD. Chest 129: 317-324. 
Supplementary table: Primers used for mRNA expression analysis

\begin{tabular}{lll}
\hline Gene & & Primer sequences $\left(5^{\prime}-3^{\prime}\right)$ \\
\hline RV & forward & TGGACAGGGTGTGAAGAGC \\
& reverse & CAAAGTAGTCGGTCCCATCC \\
RSV & forward & TTTCCACAATATYTAAGTGTCAA \\
& reverse & TCATCWCCATACTTTTCTGTTA \\
ICAM-1 & forward & CTGCAGACAGTGACCATC \\
& reverse & GTCCAGTTTCCCGGACAA \\
& forward & TGGAGAAATCTGGCACCAC \\
& reverse & GAGGCGTACAGGGATAGCAC \\
\hline
\end{tabular}




\section{CHAPTER 6}

\section{General Discussion \& Summary}




\section{General discussion and summary}

In this thesis we tested the following 2 original hypotheses: 1) the prophylactic treatment with exogenous IFNs is a valuable option to prevent viral infections and excessive inflammation of the respiratory tract and 2) $\mathrm{H}$. influenzae infection enhances the viral replication and the inflammatory response upon subsequent viral infections.

Viral infections of the respiratory tract are the most frequent cause of respiratory illnesses and impose a substantial amount of societal and economic burden globally [1]. In healthy individuals the pulmonary immune system most of the time efficiently clears these viral infections. However, in individuals with some underlying chronic condition the immune system may have become impaired and viral infections frequently result in detrimental consequences [2-7]. Chronic obstructive pulmonary disease (COPD) and asthma are two examples of such chronic inflammatory conditions in which impaired immune responses have been observed $[5,6,8,9]$. Acute exacerbations, which are characterized by acute worsening of the respiratory symptoms, are important events in the course of these diseases $[10,11]$. Exacerbations are the major cause of morbidity and mortality in asthma and COPD and viral infections are the predominant causes of these exacerbations $[12,13]$. Unfortunately, currently available antiviral therapies to prevent virus-induced exacerbations are of limited efficacy [14]. Thus, discovery and development of new therapies is an important goal in current antiviral research. To address this problem, identification of abnormalities in the immune response to viral infections and restoration or protection, if possible through external means, could be one option. Also further understanding and identification of those factors, which promote viral infections, might be helpful to formulate new strategies to prevent or cure viral infections.

One apparent abnormality in the immune response to viral infections is the deficient production of interferons (IFNs) in chronic respiratory diseases like asthma and COPD $[15,16]$. Furthermore, in order to establish successful infection, viruses have evolved strategies to evade the immune defense and the extent to which these viruses are able to induce disease is mainly due to their ability to suppress the production of IFNs [17-21]. Therefore, administration of exogenous IFNs could be an approach to prevent virus infections and consequently exacerbations. In the present thesis we investigated in various in vitro studies the different aspects of treatment of airway cells with exogenous IFNs. Furthermore, 
human rhinoviruses (HRVs) are considered as the most important inducers of exacerbations. It has been suggested that co-infection with bacteria like the nontypeable Haemophilus influenzae (NTHI), a common colonizer of airways in COPD patients, promotes the infections with HRVs. These potential effects of $\mathrm{HI}$ on the replication of HRV and inflammatory response of airway epithelial cells upon subsequent viral infections were also investigated.

\section{Type I and III interferons: key antiviral mediators}

IFNs constitute the mainstay of the antiviral response of cells. Viral infections are identified by cells through different sensors which recognize the virus-associated nucleic acid and activate the antiviral signaling pathways [22]. Activation of the signaling pathways results in the production and release of IFNs. Released IFNs then bind to their receptors on the cell surface which leads to the transcriptional induction of interferon stimulated genes (ISGs) [23,24]. Proteins encoded by these ISGs exert the antiviral effects through different mechanisms including interference with translation, degradation of RNA and interference with virus assembly and release [24].

Although the intrinsic ability of cells to produce IFNs in response to viral infection seems impaired in chronic respiratory diseases, there's evidence that cells remain responsive to exogenous IFNs $[16,25]$. This indicates that deficiencies in the antiviral response could perhaps be restored with the administration of exogenous IFNs. Even in patients who are not deficient in their IFN production, exogenous administration of IFNs might be beneficial to prevent viral infections and subsequent consequences. Moreover, in the respiratory tract the local administration of IFNs through intranasal sprays or inhalers could help to prevent the side effects associated with systemic IFNs treatment $[26,27]$. In this thesis, we investigated the different aspects of treatment of airway cells with exogenous type-I IFN (IFN- $\beta$ ) and a member of the more recently discovered type-III IFN family (IFN- $\lambda 1)$.

\section{Antiviral response}

Both IFN- $\beta$ and IFN- $\lambda 1$ have antiviral properties. Earlier our lab has shown that IFN$\beta$-treated airway epithelial cells acquired a long-lasting antiviral state and were fairly well protected against subsequent viral infections [28]. However, accumulating evidence indicates that type-III IFNs could be more important for 
mucosal antiviral defense than type-I IFNs [29,30]. Therefore, in chapter 2 we evaluated the efficacy of IFN- $\lambda 1$ to protect the airway epithelial cells against infections with the human rhinovirus1B (HRV1B) and compared its efficacy with IFN- $\beta$. Our data show that similar to IFN- $\beta$ a single treatment with IFN- $\lambda 1$ also induced a strong long-lasting antiviral state in both the alveolar type II epithelial cell line A549 and primary bronchial epithelial cells. These data indicated that like IFN- $\beta$ also IFN $-\lambda 1$ has strong potential as an antiviral therapeutic. This antiviral state induced by both types of IFNs was associated with a markedly enhanced expression of interferon stimulated genes (ISGs). Above all, the most important observation of this study was that the expression of ISGs was either sustained or even increased overtime when cells were treated with IFN- $\lambda 1$, while the IFN- $\beta$-induced ISG expression decreased over time. This indicates that the antiviral state induced by IFN- $\lambda 1$ lasts even longer than the one induced by IFN- $\beta$. Similar observations have been reported earlier by Maher and colleagues who found that activation of STAT1 and STAT2 after IFN- $\lambda 1$ treatment in human keratinocyte cell line was sustained over the course of $24 \mathrm{~h}$ as compared to IFN- $\alpha$-induced activation which was far more transient [31]. Overall, our results strongly suggest that, like IFN- $\beta$, IFN- $\lambda 1$ also has the potential as prophylactic agent to prevent viral infections and its protective effect might even last longer than the effect induced by IFN- $\beta$.

\section{Inflammatory response}

Although acute exacerbations in asthma and COPD are triggered by multiple factors like allergens, cigarette smoke, respiratory infections etc., airway inflammation is the common pathway used by all the different triggers to induce acute exacerbations [32-34]. Data shown in chapter 2 and in an earlier study published by our lab [28] suggest that a single, local (e.g. intranasal) low dose application of IFNs once every few days may be protective against future viral infections of the respiratory tract. As such, this may prevent the occurrence of side effects as seen frequently throughout repetitive continuous administration in the course of exogenous IFNs therapy $[27,35]$. Furthermore, for the respiratory tract type-III IFNs might be a better choice than type-I IFNs because the expression of type-III IFN receptors seems restricted mainly to epithelial cells. Yet, whether there's a direct effect of exogenous IFNs on the inflammatory reaction in the airways is not completely understood. In chapter $\mathbf{3}$ we addressed this and evaluated the inflammatory response of airway cells to exogenous IFNs. 
To monitor the inflammatory response of either airway epithelial cells or macrophages towards both IFNs, we choose to study the release of both IL-6 and IL- 8 by both cell types. Both IL- 6 and IL- 8 are associated with exacerbations in COPD $[36,37]$ and play an important role also in pathophysiology and exacerbations of asthma [38-41]. Yet, when epithelial cells were stimulated with either IFN- $\lambda 1$ or IFN- $\beta$, no release of either cytokine was observed. In contrast to epithelial cells, stimulation of THP1-derived macrophages with either IFN- $\lambda 1$ or IFN- $\beta$ induced the release of significant amounts of IL-8, which suggests that macrophages are more sensitive to IFN treatment than epithelial cells. However, in the respiratory tract epithelial cells and macrophages (among others) closely interact and respond to noxious stimuli in an interactive manner. Also, the response to (potential) therapeutic agents like the IFNs might be different in more complex networks. To examine this, we also tested the release of both IL-6 and IL-8 in macrophage/epithelial cell co-cultures. Indeed, in co-cultures a synergistic increase in the release of both IL- 6 and IL- 8 in response to IFN- $\lambda 1$ or IFN- $\beta$ was observed. This was the result of complex crosstalk between macrophages and epithelial cells, which was partially mediated by IL-1. These data suggest that exogenous administration of IFNs may have harmful instead of therapeutic consequences, especially in asthma and COPD patients, who already are in a state of permanent inflammation $[42,43]$. However, when co-cultures were infected with RSV, pretreatment with either IFN- $\lambda 1$ or IFN- $\beta$ markedly reduced the release of IL- 6 and IL8. Moreover, levels of IFN- $\lambda 1$ - or IFN- $\beta$-induced IL- 6 and IL-8 were moderate as compared to RSV-induced IL- 6 and IL- 8 . Thus, while moderate induction of IL- 6 and IL- 8 by IFNs might be required to efficiently activate the immune response, IFN pretreatment was well able to control the inflammation upon viral infection and prevent an exaggerated inflammatory response.

Overall we have demonstrated that even low concentrations of IFN- $\lambda 1$ and IFN- $\beta$ are able to provoke a long-lasting antiviral state in airway epithelial cell monocultures as well as macrophage/epithelial cell co-cultures. Additionally we also showed that these IFNs are capable to prevent excessive inflammation in case of a viral infection. Taken together, these data indicate that administration of exogenous IFNs as a prophylactic treatment might be a therapeutic option e.g. in patients with chronic respiratory diseases, but also in the normal population to prevent common colds. Although the economic impact of the common cold is not very well understood, in the United States the common cold leads to 75-100 million physician visits annually at a conservative cost estimate of $\$ 7.7$ billion per 
year. Thus, despite being relatively harmless, a more effective prevention of the common cold will have a significant impact on annual health cost.

\section{Effect of cigarette smoke extracts on antiviral response induced by exogenous IFN} A variety of data exists indicating that cigarette smoke modulates the immune response to pathogens and that smokers have more frequent viral respiratory infections than non-smokers. [44,45]. Among COPD patients, most of them are either current or ex-smokers which is the most important single risk factor for the development of disease $[46,47]$. Similarly, among asthmatics about $25-30 \%$ are current smokers [48] and they seem to be significantly more susceptible to experience virus-induced exacerbations than non-smokers [49]. Different in vitro studies have shown that cigarette smoke impairs the antiviral response of epithelial cells of respiratory tract, in terms of production of IFNs [50-53]. This impaired production of IFNs following cigarette smoke exposure was the result of impaired expression or activation of different important molecules involved in the antiviral signaling [52-54]. Furthermore, it has also been shown that in cigarette smokeexposed fibroblasts the ability of exogenous IFNs to induce an antiviral state is also decreased $[53,55]$. Yet, whether cigarette smoke exerts the same effect in airway epithelial cells was not clear. Thus, once we had established the antiviral and inflammatory response of epithelial cells to exogenous IFNs, in chapter 4 we investigated whether cigarette smoke extracts (CSE) had an impact on the antiviral response provoked by exogenous IFN- $\beta$ in epithelial cells. In line with previous studies we also found increased replication of virus in cells which were pre-treated with CSE, showing that cigarette smoke had indeed enhanced the susceptibility of the cells for viral infections. Furthermore, the ability of exogenous IFN- $\beta$ to provide protection against viral infections in CSE-treated cells was also decreased. However, although the observed inhibition of viral replication by exogenous IFN- $\beta$ in CSE-treated cells was slightly less than in control cells, this inhibition was still pronounced as compared to replication of virus in control cells or cells treated with CSE only. This implies that exogenous IFNs is still able to provide protection against viral infections even in smokers and indicates that also in smokers the epithelial lining of the airways, which is the primary site of viral entrance and replication in the respiratory tract, can be protected against viral infections by administration of exogenous IFNs. 


\section{Haemophilus influenzae promotes the cellular susceptibility for human Rhinovirus}

In order to prevent or reduce virus-induced exacerbations in chronic respiratory diseases, the availability of new appropriate therapies depends not only on development of new drugs, but also on a better understanding of the factors that affect the susceptibility of the host for viral infections. Among viruses, HRVs are the major inducers of acute exacerbations in COPD. Major group HRVs, which comprise about $90 \%$ of the known HRVs, use the Intercellular Adhesion Molecule-1 (ICAM-1) to attach to the cell surface and subsequently enter the cell. Thus factors which increase the cellular ICAM-1 expression will probably enhance the susceptibility of the cells for ensuing infections with major group HRVs. Non-typeable Haemophilus influenza (NTHI), a Gram-negative bacteria which is frequently isolated from COPD patients both during the clinically stable phase or an exacerbation phase [56-59], has been shown to enhance the expression of the ICAM-1 expression on epithelial cells $[60,61]$. Thus prior infections or colonization of the respiratory tract with NTHI may promote HRV infections and any possible exacerbations in patients with chronic respiratory diseases.

After exploring the possibility to use exogenous IFNs to prevent virus induced exacerbations, in chapter $\mathbf{5}$ we tried to better understand the effect of NTHI treatment on the entrance and replication of HRV16, a member of the major group HRV, in bronchial epithelial cells. In line with a previous study we also found increased expression of ICAM-1 after NTHI treatment, which resulted in improved binding/entrance of HRV16 to the cells. Furthermore, replication of HRV16 was also significantly augmented in NTHI-pre-treated cells as compared to control cells. This indicates that NTHI pre-treatment increases the susceptibility of these cells for infection with major group HRVs. We also evaluated whether this effect is specific for major group HRVs or a general characteristic of NTHI-exposed cells. Therefore, experiments were repeated with a minor group HRV (HRV1B) and the unrelated respiratory syncytial virus (RSV). Results revealed that, although there was a slight increase in the replication of both HRV1B and RSV, this increase was markedly less than the increase observed when NTHI pre-treated cells were infected with HRV16. These findings suggest that the enhanced sensitivity of bronchial epithelial cells for major group HRVs is predominantly mediated through the enhanced expression of ICAM-1. Yet, as we also found an slight increase in replication of other non-major group HRV viruses, we cannot exclude that activation of epithelial cells nonselectively increases their susceptibility towards viral infections. Nevertheless, since 
many patients with chronic respiratory diseases are colonized by NTHI, our findings may to some extent explain the enhanced sensitivity of these patients for viral respiratory infections.

Since airway inflammation is a salient aspect of acute COPD exacerbations [33], we next evaluated whether NTHI pre-treatment affected the inflammatory response of cells upon subsequent viral infection. Unexpectedly, neither HRV16 nor HRV1B induced the release of pro-inflammatory mediators by the epithelial cells, irrespective whether cells were first pretreated with NTHI or not. Alternatively, infection of epithelial cells with RSV resulted in the release of significant amount of IL-6 and IL-8. Moreover, infections of NTHI pre-treated cells showed a strong and synergistic increase in the production of these inflammatory mediators. This indicates that an initial infection or colonization with NTHI results in exaggerated inflammatory response upon subsequent viral infection. From a clinical viewpoint, these results imply that for patients with chronic respiratory diseases the chance to develop an acute exacerbation may become significantly enlarged once they have become colonized by NTH. 


\section{Conclusions and clinical perspectives}

Frequent exacerbations of chronic respiratory diseases have been shown to be closely associated with an accelerated decline in lung function. Also, they significantly enhance the chance for future morbidity and mortality. Currently there's compelling evidence that a majority of these exacerbations are induced by respiratory viruses like rhinovirus, respiratory syncytial virus or influenza virus. Unfortunately, current antiviral therapies are usually inefficient to treat these infections. Moreover, there are indications that the pulmonary immune responses towards respiratory viruses are impaired in patients with chronic respiratory diseases. Inspired by this, in this thesis we studied whether the application of exogenous IFNs could be beneficial to prevent such respiratory infections. In various in vitro studies we demonstrated that low doses of both IFN- $\beta$ and INF- $\lambda$ I were well able to induce an antiviral state in airway epithelial cells. Importantly, this antiviral state was maintain for up to three days, suggesting that continuous administration of IFNs, which is usually accompanied by unwanted side effects, might not be necessary. Also, results indicated that IFN- $\lambda 1$ might be better suited for future clinical application because 1 ) the expression of its receptor is less ubiquitous and more restricted to epithelial cells, and 2) the expression levels of the various ISG, which are the effector molecules in the IFN-induced antiviral response, are maintained at higher levels when cells were pretreated with IFN $-\lambda 1$. Moreover, we demonstrated that that the application of IFNs itself induced only a moderate inflammatory response in a more complex model system consisting of co-cultured epithelial cells and macrophages. More importantly, however, IFN pretreatment dramatically reduced the inflammatory reaction in co-cultured cells which were subsequently infected with RSV, providing further evidence that prophylactic IFNs treatment not only prevents viral replication, but also controls excessive inflammation in the airways.

As already mentioned, patients with chronic respiratory diseases are more susceptible for viral infections because of an impaired pulmonary immune system. In this thesis we also revealed an alternative mechanism, which may explain why these patients are more susceptible for viral infections. Although it has been demonstrated earlier that viral infections increase the susceptibility for bacterial infections, the reverse has been addressed less extensively. Here we demonstrated that non-typeable Haemophilus influenzae significantly increased the susceptibility of epithelial cells for major group rhinoviruses, probably by enhancing the 
expression of ICAM-1, which is used by this specific group of rhinoviruses for attachment to the cell surface. Since the airways of the majority of patients with chronic respiratory diseases are colonized with NTHI, this may partially explain why these patients are so susceptible for this specific group of viruses.

Summarizing, the data in this thesis strongly suggest that both type I and III IFNs have potential as prophylactic agents to prevent viral infections of the respiratory tract (Figure 1).

A: Viral infections of healthy airway epithelium

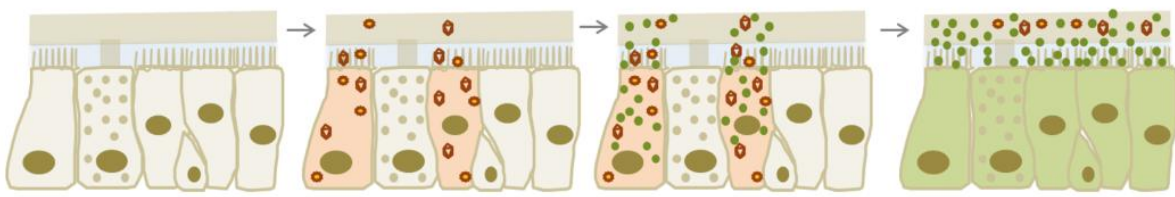

B: Viral infections of airway epithelium with impaired antiviral defense

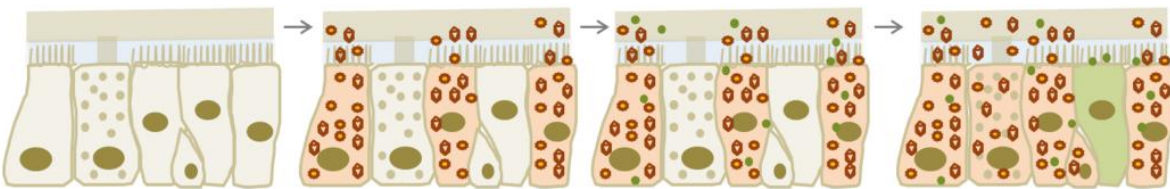

C: Exogenous interferons against viral infections of airway epithelium with impaired antiviral defense
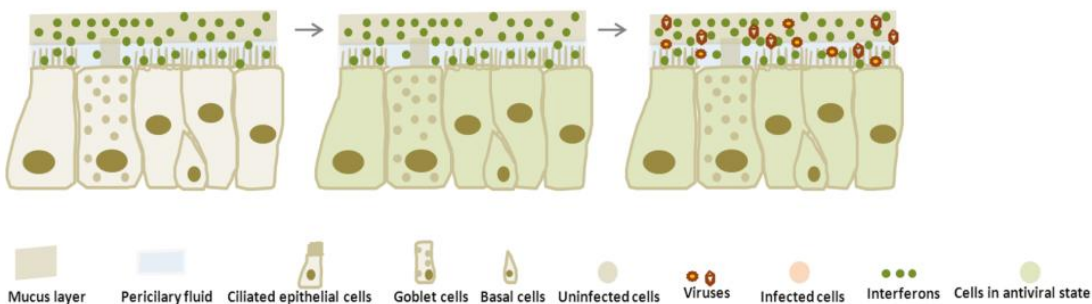

Figure-1. Schematic representation of antiviral defense of airway epithelium in different conditions: Upon viral infections of healthy airway epithelium, cells start producing and releasing IFNs which then bind to their specific receptors in an auto-or paracrine way and protect the infected as well as noninfected cells (A). However, in chronic respiratory diseases like asthma and COPD, antiviral response of airway epithelium becomes impaired. As a result upon viral infections cells produce insufficient amounts of IFNs which do not efficiently protect them against viral infection (B). Yet prophylactic treatment of these cells with exogenous IFNs induces a strong antiviral state, which protects them from subsequent viral infections (C).

Especially in patients with chronic respiratory diseases like asthma or COPD, prophylactic treatment with exogenous IFNs could be beneficial to prevent virusinduced exacerbations. However, the major limitation of the studies presented in this thesis is the fact that only in vitro studies have been performed. As already 
eluded in chapter 3 , the pulmonary immune systems consists of various different cells, which all collaborate in an intense network to combat e.g. invading pathogens. In such a network, responses to exogenous IFNs might be different or less efficient. Therefore, additional clinical studies are mandatory. Earlier, clinical trials examining the effects of type I IFN revealed beneficial effects in corticosteroid-resistant asthmatics by shifting the Th1/Th2 balance [27], or as a prophylactic antiviral agent in healthy individuals [62-64]. However, in most of these studies adverse side effects were noticed including flu-like symptoms, dry pharynx and/or nasal erosion/bleeding. It may be speculated that these side effects result in particularly from the daily administration of IFN. Therefore, a prerequisite for future clinical use will be a sustained antiviral state of the epithelial cells the after application of a single (preferably low) dose as frequent administrations of high doses may cause the aforementioned side effects. And although we have demonstrated that both IFN- $\beta$ as IFN- $\lambda$ indeed meet these criteria in an in vitro model, their efficacy needs to be tested in vivo before being suitable for clinical applications. Interestingly, Djukanovic et al. recently reported that treatment with inhaled IFN- $\beta$ once every 3 days during a period of 15 days significantly attenuated the adverse effects of the common cold in difficult to treat asthma patients [65]. These data strongly suggest that exogenous IFN- $\beta$ might indeed be efficacious to treat or even prevent acute exacerbations in certain patients. Alternatively, although clinical trials of type-III IFNs to treat chronic hepatitis patients are in currently progress, to our knowledge in chronic respiratory patients no studies with type-III IFNs are currently being conducted. Nevertheless, because of its longlasting antiviral effect and due to the restricted expression of its receptors, IFN- $\lambda 1$ might even be a better choice than IFN- $\beta$. Therefore, clinical studies assessing the efficacy of type III IFNs to treat or prevent virus-related acute exacerbations in patients with chronic respiratory diseases are eagerly awaited.

Over the past decade, there has been a continuous discussion regarding the efficacy of long term antibiotic treatment for the prevention of acute exacerbations in chronic respiratory patients. And although the chronic use of antibiotic is usually not recommended because of lack of efficacy and the risk for antibiotic resistance [66], recent data have shown beneficial effects of long-term fluoroquinolone or macrolide use [67-70]. It has been speculated that these positive results should be attributed to the interruption of the vicious circle of (chronic) infection-inflammation, which will ultimately reduce the susceptible of patients for infections by strengthening the lung defense systems. Moreover, the 
data presented in chapter 5 suggest that bacterial colonization may result in enhance the susceptibility for viral infections and result in excessive inflammation once the colonized patients become infected with certain viruses. Thus, these findings also suggest that antibiotic treatment in particular of colonized patients may be helpful in the prevention of virus-induced acute exacerbations in these patients. Yet, future in vivo experiments as well as clinical trials are needed to prove these concepts. 


\section{References}

1. Pavia AT (2011) Viral infections of the lower respiratory tract: old viruses, new viruses, and the role of diagnosis. Clin Infect Dis 52 Suppl 4: S284-289.

2. Levitky MG (2003) Pulmonary physiology 6: McGraw Hill Professional.

3. Gill S, Wight TN, Frevert CW (2010) Proteoglycans: key regulators of pulmonary inflammation and the innate immune response to lung infection. Anat Rec (Hoboken) 293: 968-981.

4. Parameswaran GI, Murphy TF (2007) Infections in chronic lung diseases. Infect Dis Clin North Am 21: 673-695, viii.

5. Holgate ST (2012) Innate and adaptive immune responses in asthma. Nat Med 18: 673-683.

6. Brusselle GG, Joos GF, Bracke KR (2011) New insights into the immunology of chronic obstructive pulmonary disease. Lancet 378: 1015-1026.

7. Taylor AE, Finney-Hayward TK, Quint JK, Thomas CM, Tudhope SJ, et al. (2010) Defective macrophage phagocytosis of bacteria in COPD. Eur Respir J 35: 1039-1047.

8. Beasley V, Joshi PV, Singanayagam A, Molyneaux PL, Johnston SL, et al. (2012) Lung microbiology and exacerbations in COPD. Int J Chron Obstruct Pulmon Dis 7: 555-569.

9. Xiao C, Puddicombe SM, Field S, Haywood J, Broughton-Head V, et al. (2011) Defective epithelial barrier function in asthma. J Allergy Clin Immunol 128: 549-556 e541-512.

10. Kurai D, Saraya T, Ishii H, Takizawa H (2013) Virus-induced exacerbations in asthma and COPD. Front Microbiol 4: 293.

11. Sethi S (2011) Molecular diagnosis of respiratory tract infection in acute exacerbations of chronic obstructive pulmonary disease. Clin Infect Dis 52 Suppl 4: S290-295.

12. Papi A, Bellettato CM, Braccioni F, Romagnoli M, Casolari P, et al. (2006) Infections and airway inflammation in chronic obstructive pulmonary disease severe exacerbations. Am J Respir Crit Care Med 173: 1114-1121.

13. Akinbami LJ, Moorman JE, Liu X (2011) Asthma prevalence, health care use, and mortality: United States, 2005-2009. Natl Health Stat Report: 1-14.

14. Johnston SL (2007) Innate immunity in the pathogenesis of virus-induced asthma exacerbations. Proc Am Thorac Soc 4: 267-270.

15. Mallia P, Message SD, Gielen V, Contoli M, Gray K, et al. (2011) Experimental rhinovirus infection as a human model of chronic obstructive pulmonary disease exacerbation. Am J Respir Crit Care Med 183: 734-742.

16. Cakebread JA, Xu Y, Grainge C, Kehagia V, Howarth PH, et al. (2011) Exogenous IFN-beta has antiviral and anti-inflammatory properties in primary bronchial epithelial cells from asthmatic subjects exposed to rhinovirus. J Allergy Clin Immunol 127: 1148-1154 e1149.

17. Cameron MJ, Bermejo-Martin JF, Danesh A, Muller MP, Kelvin DJ (2008) Human immunopathogenesis of severe acute respiratory syndrome (SARS). Virus Res 133: 13-19.

18. Geiss GK, Salvatore M, Tumpey TM, Carter VS, Wang X, et al. (2002) Cellular transcriptional profiling in influenza A virus-infected lung epithelial cells: the role of the nonstructural NS1 protein in the evasion of the host innate defense and its potential contribution to pandemic influenza. Proc Natl Acad Sci U S A 99: 10736-10741.

19. Imai H, Shinya K, Takano R, Kiso M, Muramoto Y, et al. (2010) The HA and NS genes of human H5N1 influenza A virus contribute to high virulence in ferrets. PLoS Pathog 6: e1001106.

20. Meunier I, von Messling V (2011) NS1-mediated delay of type I interferon induction contributes to influenza A virulence in ferrets. J Gen Virol 92: 1635-1644.

21. Smits SL, de Lang A, van den Brand JM, Leijten LM, van IWF, et al. (2010) Exacerbated innate host response to SARS-CoV in aged non-human primates. PLoS Pathog 6: e1000756.

22. Goubau D, Deddouche S, Reis ESC (2013) Cytosolic sensing of viruses. Immunity 38: 855-869.

23. Moens B, Pannecouque C, Lopez G, Talledo M, Gotuzzo E, et al. (2012) Simultaneous RNA quantification of human and retroviral genomes reveals intact interferon signaling in HTLV-1infected CD4+ T cell lines. Virol J 9: 171.

24. Randall RE, Goodbourn S (2008) Interferons and viruses: an interplay between induction, signalling, antiviral responses and virus countermeasures. J Gen Virol 89: 1-47. 
25. Wark PA, Johnston SL, Bucchieri F, Powell R, Puddicombe S, et al. (2005) Asthmatic bronchial epithelial cells have a deficient innate immune response to infection with rhinovirus. J Exp Med 201: 937-947.

26. George PM, Badiger R, Alazawi W, Foster GR, Mitchell JA (2012) Pharmacology and therapeutic potential of interferons. Pharmacol Ther 135: 44-53.

27. Simon HU, Seelbach H, Ehmann R, Schmitz M (2003) Clinical and immunological effects of low-dose IFN-alpha treatment in patients with corticosteroid-resistant asthma. Allergy 58: 1250-1255.

28. Gaajetaan GR, Geelen TH, Vernooy JH, Dentener MA, Reynaert NL, et al. (2013) Interferon-beta induces a long-lasting antiviral state in human respiratory epithelial cells. J Infect 66: 163169.

29. Jewell NA, Cline T, Mertz SE, Smirnov SV, Flano E, et al. (2010) Lambda interferon is the predominant interferon induced by influenza A virus infection in vivo. J Virol 84: 11515-11522.

30. Mordstein M, Neugebauer E, Ditt V, Jessen B, Rieger T, et al. (2010) Lambda interferon renders epithelial cells of the respiratory and gastrointestinal tracts resistant to viral infections. J Virol 84: 5670-5677.

31. Maher SG, Sheikh F, Scarzello AJ, Romero-Weaver AL, Baker DP, et al. (2008) IFNalpha and IFNlambda differ in their antiproliferative effects and duration of JAK/STAT signaling activity. Cancer Biol Ther 7: 1109-1115.

32. Chen E, Miller GE (2007) Stress and inflammation in exacerbations of asthma. Brain Behav Immun 21: 993-999.

33. Bathoorn E, Kerstjens H, Postma D, Timens W, MacNee W (2008) Airways inflammation and treatment during acute exacerbations of COPD. Int J Chron Obstruct Pulmon Dis 3: 217-229.

34. Wark PA, Gibson PG (2006) Asthma exacerbations . 3: Pathogenesis. Thorax 61: 909-915.

35. Hayden FG, Kaiser DL, Albrecht JK (1988) Intranasal recombinant alfa-2b interferon treatment of naturally occurring common colds. Antimicrob Agents Chemother 32: 224-230.

36. Bhowmik A, Seemungal TA, Sapsford RJ, Wedzicha JA (2000) Relation of sputum inflammatory markers to symptoms and lung function changes in COPD exacerbations. Thorax 55: 114-120.

37. Perera WR, Hurst JR, Wilkinson TM, Sapsford RJ, Mullerova H, et al. (2007) Inflammatory changes, recovery and recurrence at COPD exacerbation. Eur Respir J 29: 527-534.

38. Norzila MZ, Fakes K, Henry RL, Simpson J, Gibson PG (2000) Interleukin-8 secretion and neutrophil recruitment accompanies induced sputum eosinophil activation in children with acute asthma. Am J Respir Crit Care Med 161: 769-774.

39. Neveu WA, Allard JL, Raymond DM, Bourassa LM, Burns SM, et al. (2010) Elevation of IL-6 in the allergic asthmatic airway is independent of inflammation but associates with loss of central airway function. Respir Res 11: 28.

40. Yokoyama A, Kohno N, Fujino S, Hamada H, Inoue Y, et al. (1995) Circulating interleukin-6 levels in patients with bronchial asthma. Am J Respir Crit Care Med 151: 1354-1358.

41. Teran LM, Johnston SL, Schroder JM, Church MK, Holgate ST (1997) Role of nasal interleukin-8 in neutrophil recruitment and activation in children with virus-induced asthma. Am J Respir Crit Care Med 155: 1362-1366.

42. Holgate ST, Church MK, Howarth PH, Morton EN, Frew AJ, et al. (1995) Genetic and environmental influences on airway inflammation in asthma. Int Arch Allergy Immunol 107: 29-33.

43. Rutgers SR, Postma DS, ten Hacken NH, Kauffman HF, van Der Mark TW, et al. (2000) Ongoing airway inflammation in patients with COPD who do not currently smoke. Thorax 55: 12-18.

44. Stampfli MR, Anderson GP (2009) How cigarette smoke skews immune responses to promote infection, lung disease and cancer. Nat Rev Immunol 9: 377-384.

45. Arcavi L, Benowitz NL (2004) Cigarette smoking and infection. Arch Intern Med 164: 2206-2216.

46. Mannino DM, Buist AS (2007) Global burden of COPD: risk factors, prevalence, and future trends. Lancet 370: 765-773.

47. Chee A, Sin DD (2008) Treatment of mild chronic obstructive pulmonary disease. Int J Chron Obstruct Pulmon Dis 3: 563-573.

48. Stapleton M, Howard-Thompson A, George C, Hoover RM, Self TH (2011) Smoking and asthma. J Am Board Fam Med 24: 313-322. 
49. Venarske DL, Busse WW, Griffin MR, Gebretsadik T, Shintani AK, et al. (2006) The relationship of rhinovirus-associated asthma hospitalizations with inhaled corticosteroids and smoking. J Infect Dis 193: 1536-1543.

50. Jaspers I, Horvath KM, Zhang W, Brighton LE, Carson JL, et al. (2010) Reduced expression of IRF7 in nasal epithelial cells from smokers after infection with influenza. Am J Respir Cell Mol Biol 43: 368-375.

51. Eddleston J, Lee RU, Doerner AM, Herschbach J, Zuraw BL (2011) Cigarette smoke decreases innate responses of epithelial cells to rhinovirus infection. Am J Respir Cell Mol Biol 44: 118-126.

52. Proud D, Hudy MH, Wiehler S, Zaheer RS, Amin MA, et al. (2012) Cigarette smoke modulates expression of human rhinovirus-induced airway epithelial host defense genes. PLoS One 7: e40762.

53. Bauer CM, Dewitte-Orr SJ, Hornby KR, Zavitz CC, Lichty BD, et al. (2008) Cigarette smoke suppresses type I interferon-mediated antiviral immunity in lung fibroblast and epithelial cells. J Interferon Cytokine Res 28: 167-179.

54. Wu W, Patel KB, Booth JL, Zhang W, Metcalf JP (2011) Cigarette smoke extract suppresses the RIG-Iinitiated innate immune response to influenza virus in the human lung. Am J Physiol Lung Cell Mol Physiol 300: L821-830.

55. HuangFu WC, Liu J, Harty RN, Fuchs SY (2008) Cigarette smoking products suppress anti-viral effects of Type I interferon via phosphorylation-dependent downregulation of its receptor. FEBS Lett 582: 3206-3210.

56. Bandi V, Apicella MA, Mason E, Murphy TF, Siddiqi A, et al. (2001) Nontypeable Haemophilus influenzae in the lower respiratory tract of patients with chronic bronchitis. Am J Respir Crit Care Med 164: 2114-2119.

57. Monso E, Ruiz J, Rosell A, Manterola J, Fiz J, et al. (1995) Bacterial infection in chronic obstructive pulmonary disease. A study of stable and exacerbated outpatients using the protected specimen brush. Am J Respir Crit Care Med 152: 1316-1320.

58. Soler N, Ewig S, Torres A, Filella X, Gonzalez J, et al. (1999) Airway inflammation and bronchial microbial patterns in patients with stable chronic obstructive pulmonary disease. Eur Respir J 14: 1015-1022.

59. Murphy TF, Brauer AL, Schiffmacher AT, Sethi S (2004) Persistent colonization by Haemophilus influenzae in chronic obstructive pulmonary disease. Am J Respir Crit Care Med 170: 266-272.

60. Sajjan US, Jia Y, Newcomb DC, Bentley JK, Lukacs NW, et al. (2006) H. influenzae potentiates airway epithelial cell responses to rhinovirus by increasing ICAM-1 and TLR3 expression. FASEB J 20: 2121-2123.

61. Frick AG, Joseph TD, Pang L, Rabe AM, St Geme JW, 3rd, et al. (2000) Haemophilus influenzae stimulates ICAM-1 expression on respiratory epithelial cells. J Immunol 164: 4185-4196.

62. Gao L, Yu S, Chen Q, Duan Z, Zhou J, et al. (2010) A randomized controlled trial of low-dose recombinant human interferons alpha-2b nasal spray to prevent acute viral respiratory infections in military recruits. Vaccine 28: 4445-4451.

63. Douglas RM, Moore BW, Miles HB, Davies LM, Graham NM, et al. (1986) Prophylactic efficacy of intranasal alpha 2-interferon against rhinovirus infections in the family setting. N Engl J Med 314: 65-70.

64. Farr BM, Gwaltney JM, Jr., Adams KF, Hayden FG (1984) Intranasal interferon-alpha 2 for prevention of natural rhinovirus colds. Antimicrob Agents Chemother 26: 31-34.

65. Djukanovic R, Harrison T, Monk P, Thomson N, Johnston SL, et al. The effects of interferon beta on cold-induced asthma exacerbations. Eur Respir J 2012; 40: Suppl. 56, 36s

66. Global Strategy for the Diagnosis, Management and Prevention of COPD, Global Initiative for Chronic Obstructive Lung Disease (GOLD) 2013. Available from: www.goldcopd.org.

67. Sethi S, Jones PW, Theron MS, Miravitlles M, Rubinstein E, et al. (2010) Pulsed moxifloxacin for the prevention of exacerbations of chronic obstructive pulmonary disease: a randomized controlled trial. Respir Res 11: 10.

68. Albert RK, Connett J, Bailey WC, Casaburi R, Cooper JA, Jr., et al. (2011) Azithromycin for prevention of exacerbations of COPD. N Engl J Med 365: 689-698. 
69. Seemungal TA, Wilkinson TM, Hurst JR, Perera WR, Sapsford RJ, et al. (2008) Long-term erythromycin therapy is associated with decreased chronic obstructive pulmonary disease exacerbations. Am J Respir Crit Care Med 178: 1139-1147.

70. Pomares X, Monton C, Espasa M, Casabon J, Monso E, et al. (2011) Long-term azithromycin therapy in patients with severe COPD and repeated exacerbations. Int J Chron Obstruct Pulmon Dis 6: 449-456. 
Nederlandse samenvatting 


\section{Samenvatting}

Onder normale omstandigheden inhaleert een volwassen menselijke long zo'n 11.000 liter lucht per dag. Naast deze normale lucht worden er ook potentieel toxische stoffen en micro-organismen, zoals bacteriën, virussen, schimmels of parasieten, ingeademd. In het merendeel van de gevallen is het immuunsysteem van de longen in staat om deze ingeademde stoffen en micro-organismen op te ruimen en daarmee de longen te beschermen tegen infecties en hun normale functie te handhaven. Echter, wanneer deze beschermende werking vermindert, kunnen uiteindelijk longziekten ontstaan. Deze kunnen variëren van acuut (vaak hevig maar kortdurend) tot langdurig en onomkeerbaar.

Hoewel de prevalentie van luchtweginfecties als gevolg van hygiëne maatregelen en de ontwikkeling van nieuwe geneesmiddelen en vaccins drastisch verminderd is, zijn dergelijke infecties nog steeds een grote belasting voor de gemeenschap in termen van ziekte, overlijden en gezondheidskosten. Veelal worden deze infecties veroorzaakt door virussen. De infecties zijn vaak onschuldig - denk hierbij aan een normale verkoudheid - en duren vaak niet langer dan een aantal dagen. Echter, in patiënten met chronische longziekten zoals astma en COPD, waarbij de werking van het immuunsysteem vaak verminderd is, kunnen dergelijke infecties leiden tot een ernstige verslechtering van de conditie van de patiënt (een zogenaamde "acute exacerbatie") en zelfs levensbedreigend zijn.

Helaas blijken de momenteel beschikbare antivirale middelen onvoldoende geschikt om deze door virale infecties veroorzaakte acute exacerbaties te voorkomen of te behandelen. Daarom is het van groot belang dat er op korte termijn nieuwe en betere antivirale therapieën ontwikkeld worden. Een mogelijke strategie hierbij zou kunnen zijn het bestuderen van afwijkingen in de afweerreactie tegen virussen en het mogelijk herstellen van deze afwijkingen. Ook kan het nuttig zijn om te bestuderen welke factoren verantwoordelijk zijn voor de verhoogde gevoeligheid van patiënten met chronische luchtwegklachten voor infecties van de luchtwegen. Met deze kennis zal het eventueel mogelijk zijn om tot nieuwe efficiënte therapieën te komen zodat patiënten met chronische luchtweg klachten beter beschermd zijn tegen respiratoire infecties en de eventueel daaruit voortvloeiende acute exacerbaties.

Wanneer cellen geïnfecteerd raken zullen ze reageren via het produceren van diverse stoffen om de infectie te bestrijden. Tot deze stoffen behoren de 
zogenaamde interferonen, welke een sterk antivirale werking hebben. Wanneer deze interferonen geproduceerd worden, zullen ze de cellen waardoor ze geproduceerd worden stimuleren maar ook cellen in de directe nabijheid. Op deze wijze worden gestimuleerde cellen in een antivirale staat gebracht, waardoor ze beschermd zijn tegen mogelijke infecties. Echter, in patiënten met astma en COPD lijkt dit systeem verstoord en worden er tijdens infecties beduidend minder interferonen geproduceerd door de cellen in de luchtwegen. Daarnaast hebben virussen bepaalde strategieën ontwikkeld om aan het afweersysteem te ontsnappen; deze strategieën zijn meestal gebaseerd op het onderdrukken van de werking van deze interferonen. Ondanks het feit dat cellen minder interferonen produceren en/of dat de productie van interferonen door virussen onderdrukt wordt, blijken de cellen wel nog in staat te zijn op interferonen te reageren. Op basis van deze bevindingen hebben we in dit proefschrift onderzocht in hoeverre het mogelijk is om cellen middels van buitenaf toegevoegde ("exogeen") interferonen te beschermen tegen toekomstige virale infecties en mogelijk tegen de vaak daarmee gepaarde acute exacerbaties. Ook hebben we onderzocht in hoeverre bacteriële infecties het effect van virale infecties kunnen versterken.

De verschillende typen interferonen (IFN) kunnen worden onderverdeeld in 3 groepen:

i) Type I interferonen, waartoe IFN- $\alpha$ en IFN- $\beta$ behoren

ii) Type II interferon, welke groep uitsluitend uit INF- $\gamma$ bestaat

iii) Type II interferonen. Deze groep is het meest recent ontdekt en bestaat uit IFN- $\lambda 1 \lambda-2$ en $\lambda-3$

Van deze 3 groepen zijn de typen I en III de meest belangrijke wanneer het gaat om de antivirale afweer. Beide typen zijn instaat om de cellulaire productie van een groot aantal stoffen met antivirale werking (de zgn. "interferon-stimulated genes"(ISG)) aan te zetten. Echter, ze doen dit via stimulatie van verschillende receptoren op de cel. Hierbij is het van belang dat de receptoren voor type I IFN op vrijwel alle cellen voorkomen, terwijl de receptoren voor type III IFN vrijwel uitsluitend op epitheel cellen voorkomen. Aangezien deze epitheel cellen in de luchtwegen de eerste cellen zijn die door virussen worden geïnfecteerd, is het waarschijnlijk dat de type III IFN in de luchtwegen belangrijker zijn voor de antivirale afweer dan de type I IFNs. In eerdere experimenten in ons lab hebben we reeds aangetoond dat epitheel cellen na blootstelling aan IFN- $\beta$ langdurig beschermend waren tegen daaropvolgende virale infecties. In dit proefschrift 
hebben we onderzocht in hoeverre IFN- $\lambda 1$ ook in staat is om diverse cellen te beschermen tegen virale infecties. De resultaten van deze studie zoals beschreven in hoofdstuk 2 toonden aan dat een eenmalige voorbehandeling met IFN- $\lambda 1$ zorgde voor een langdurige bescherming welke minimaal gelijkwaardig was aan het effect van IFN- $\beta$. Ook bleek dat de expressie van diverse ISGs na stimulatie met IFN- $\lambda 1$ langdurig verhoogd bleef, terwijl de door IFN- $\beta$ geïnduceerde expressie sterk afnam na verloop van tijd. Dit suggereert dat de door IFN- $\lambda 1$ veroorzaakte antivirale conditie mogelijk langer zal aanhouden dan de door IFN- $\beta$ geïnduceerde staat. Samenvattend kunnen we zeggen dat IFN- $\lambda 1$, net als IFN- $\beta$, profylactische en beschermende werking heeft in het voorkomen van virale infecties en dat het effect van IFN- $\lambda 1$ mogelijk langduriger is dan het effect van IFN- $\beta$.

Hoewel acute exacerbaties veroorzaakt worden door diverse prikkels zoals allergenen, sigarettenrook of luchtweginfecties, blijken ontstekingsreacties in vrijwel alle gevallen een rol te spelen. Nu hebben we eerder laten zien dat IFNs beschermend werken tegen virale infecties, maar het was onduidelijk of IFNs zelf ook tot een ontstekingsreactie zouden kunnen leiden. Ook zou de interactie tussen cellen van belang kunnen zijn omdat de afweer in de longen het gevolg is van een direct samenspel tussen diverse celtypen. Als gevolg hiervan zou het uiteindelijke therapeutische effect van bijvoorbeeld IFNs in de menselijke long anders kunnen zijn dan zoals eerder bestudeerd in een celkweek met één enkel celtype (bv epitheel cellen). Om dit te bestuderen hebben we in hoofdstuk 3 gebruik gemaakt van een zogenaamde co-cultuur, waarbij 2 celtypen, die beiden betrokken zijn bij de afweer in de luchtwegen (macrofagen en epitheel cellen), gezamenlijk werden gekweekt en vervolgens werden blootgesteld aan zowel IFN- $\lambda 1$ als IFN- $\beta$. De resultaten toonden aan dat blootstelling aan zowel IFN- $\lambda 1$ als IFN- $\beta$ zorgde voor een lichte ontstekingsreactie. Echter, wanneer de blootstelde cellen vervolgens ook geïnfecteerd werden, bleek dat niet alleen de infectie voorkomen kon worden maar dat de ontstekingsreactie ook sterk verminderd was in vergelijking met de ontstekingsreactie die veroorzaakt werd door het virus in onbehandelde cellen. Dit leidde tot de conclusie dat blootstelling aan IFN weliswaar zorgde voor een geringe ontstekingsreactie, maar dat deze ontstekingsreactie mogelijk noodzakelijk is om een daaropvolgende virale infectie beter te bestrijden en de door het virus veroorzaakte ontsteking binnen de perken te houden. 
Helaas blijkt een deel van alle patiënten met astma en COPD niet in staat te zijn om te stoppen met roken. Nu blijkt roken de gevoeligheid voor virale infecties van de luchtwegen sterk te verhogen, waarschijnlijk via het aantasten van het afweer systeem in de longen. Vooral de productie van IFN lijkt aangetast te worden door de toxische bestanddelen in sigarettenrook. Of sigarettenrook ook de reactie op exogeen IFN kan beïnvloeden was echter onbekend. Dit is bestudeerd in hoofdstuk 4. In de in dit hoofdstuk beschreven experimenten werden epitheel cellen blootgesteld aan een extract van sigarettenrook en werd vervolgens gekeken of de antivirale werking van exogeen IFN- $\beta$ hierdoor werd aangetast. Uit de resultaten bleek dat de blootstelling aan dit extract de antivirale werking van IFN- $\beta$ inderdaad enigszins verminderde. Gelukkig bleek het overgebleven effect nog ruim voldoende om epitheel cellen te beschermen tegen een daaropvolgende virale infectie. Deze resultaten geven aan dat ook in rokers het beschermende effect van IFN- $\beta$ gehandhaafd blijft.

Nadat we in de hoofdstukken 2-4 de mogelijke toepasbaarheid van exogene IFNs als beschermende therapie tegen virale infecties hebben onderzocht, is in hoofdstuk 5 getracht een beter inzicht te krijgen in de rol die bacteriële infecties kunnen spelen bij een verhoogde gevoeligheid voor virale infecties en/of acute exacerbaties. In het bijzonder is gekeken naar de rol van Haemophilus influenzae ( $\mathrm{HI})$, een bacterie die vaak aangetroffen wordt in de lagere luchtwegen zowel tijdens een exacerbatie als tijdens de stabiele fase bij COPD patiënten, en diverse virussen die vaker in COPD patiënten gevonden worden tijdens acute exacerbaties. Onze data toonden aan dat aan $\mathrm{HI}$ blootgestelde epitheel cellen vooral gevoeliger waren voor infecties met een bepaald type rhinovirus (HRV16), een typisch verkoudsheidsvirus, en minder voor infecties met ander type rhinovirus (HRV1B) of met RSV. Dit verschil is waarschijnlijk te verklaren door de bevinding dat blootstelling aan $\mathrm{HI}$ zorgde voor een versterkte expressie van een receptor die specifiek door HRV16, maar niet door HRV1B of RSV gebruikt wordt om een cel binnen te dringen. Daarnaast bleek de ontstekingsreactie versterkt in $\mathrm{HI}$ blootgestelde cellen na virale infecties. Hieruit kan geconcludeerd worden dat (chronische) infecties met Haemophilus influenzae in combinatie met een virale infectie zorgen voor een verhevigde ontstekingsreactie en mogelijk voor een verhoogd risico op acute exacerbaties. 
Samenvattend kunnen we zeggen dat de resultaten zoals beschreven in dit proefschrift sterke aanwijzingen bieden voor:

- een rol voor zowel type I als type II interferonen in het voorkomen van zowel de virale infectie sec als de daarmee gepaard gaande ontstekingsreactie

- een rol voor antibiotica in COPD patiënten met chronische bacteriële infecties (in het bijzonder met Haemophilus influenzae) van de luchtwegen ter voorkoming van excessieve virale infecties en ontstekingsreacties en de daarmee vaak gepaard gaande acute exacerbaties.

Wel dient opgemerkt te worden dat de in dit proefschrift beschreven experimenten uitgevoerd zijn in modellen gebaseerd op geïsoleerde cellen. In hoeverre de voorgestelde concepten daadwerkelijk toepasbaar zullen zijn in de kliniek zullen toekomstige experimenten en mogelijke klinische studies moete. 


\section{List of abbreviations}

\begin{tabular}{|c|c|}
\hline AEs & Acute Exacerbations \\
\hline AP1 & Activator Protein 1 \\
\hline ARIs & Acute Respiratory tract Infections \\
\hline ASL & Airway Surface Liquid \\
\hline COPD & Chronic Obstructive Pulmonary Disease \\
\hline CPE & Cytopathogenic Effect \\
\hline CRD & Chronic Respiratory Diseases \\
\hline CSE & Cigarette Smoke Extracts \\
\hline ELISA & Enzyme-linked immunosorbent assay \\
\hline FCS & Fetal Calf Serum \\
\hline $\mathrm{Hi}$ & Heat inactivated \\
\hline HRV & Human Rhinovirus \\
\hline ICAM-1 & Intercellular Adhesion Molecule-1 \\
\hline IFN & Interferon \\
\hline IFN- $\alpha$ & Interferon-alpha \\
\hline IFN- $\beta$ & Interferon-beta \\
\hline IFN- $\gamma$ & Interferon-gamma \\
\hline IFN- $\lambda$ & Interferon-lambda \\
\hline IL & Interleukin \\
\hline IL-1RA & Interleukin-1 Receptor Antagonist \\
\hline IRF & Interferon regulatory Factor \\
\hline ISG & Interferon Stimulated Genes \\
\hline LDL & Low Density Lipoprotein \\
\hline LRTIs & Lower Respiratory tract Infections \\
\hline MDA5 & Melanoma Differentiated Associated gene 5 \\
\hline $\mathrm{MOI}$ & Multiplicity Of Infection \\
\hline MTT & Thiazolyl Blue Tetrazolium Bromide \\
\hline MX1 & Myxovirus Resistance 1 \\
\hline NFKB & Nuclear Factor kappa B \\
\hline NTHI & Non-typeable Haemophilus influenzae \\
\hline OASL & 2'-5'-oligoadenylate Synthetase Like \\
\hline PAMPS & Pathogen Associated Molecular Patterns \\
\hline PBEC & Primary Bronchial Epithelial Cells \\
\hline PBMC & Peripheral Blood Mononuclear Cells \\
\hline
\end{tabular}




$\begin{array}{ll}\text { PCR } & \text { Polymerase Chain Reaction } \\ \text { PEG } & \text { Polyethylene Glycol } \\ \text { PKR } & \text { Protein Kinase R } \\ \text { PRRs } & \text { Pattern Recognition Receptors } \\ \text { RIG-1 } & \text { Retinoic acid-inducible Gene 5 } \\ \text { RSV } & \text { Respiratory Syncytial Virus } \\ \text { SEM } & \text { Standard Error of the Mean } \\ \text { TCID50 } & \text { 50\% Tissue Culture Infectivity Dose } \\ \text { TLR } & \text { Toll Like Receptors } \\ \text { URTs } & \text { Upper Respiratory tract Infection } \\ \text { WHO } & \text { World Health Organization }\end{array}$


Acknowledgements 
In the name of Allah, the most beneficent, the most merciful.

"He who does not thank people, does not thank Allah"

(Prophet Muhammad (peace be upon him))

Now, the most important part of the thesis, "ACKNOWLEDGEMENTS". It is an important part to me because it gives me an opportunity to thank everyone including those to whom I never did this in person.

First of all my co-supervisor, Dr. Frank Stassen. Frank, I am in short of words to express my gratitude and appreciation for everything you did for me. During last five years, besides being a wonderful supervisor, you have always been very kind and friendly to me. Even during most depressing situations such as repeated failures of experiments, you always encouraged me and made me feel better. You have been very patient with me and let me do my work in my own way with complete independence. You taught me everything and helped me with everything. You taught me how to think scientifically, logically and strategically. Another thing, about you, that I really admire is your availability. No need for an appointment, everyone just knocks at the door, enters the room and says whatever he/she wants to say. One simply could not wish for a better supervisor. Thanks.

My supervisor, professor Cathrien Bruggeman. First, thank you for giving me the opportunity to pursue my PhD at the department of Medical Microbiology. And secondly, thank you for being considerate and understanding supervisor. You always took a keen interest in my work and gave me your full support. You always understood my problems and did every possible thing in your capacity to facilitate me and to make sure the successful completion of my PhD. I am thankful for everything you did for me.

My paranymfen, teachers and very friendly colleagues, Gert and Erik. I would like to include also Laura and Ellen Boelen in this list. I still remember the first day when Gert took me to the lab and said "we will teach you A, B, C... of everything" and you all literally did. You taught me everything and did that very patiently. Apart from being wonderful teachers and colleagues, you have always been very friendly to me. You were always keen to discuss things about how my life was going in Netherlands and how was my family doing back in Pakistan. And this was the reason that soon after starting my PhD, I started feeling that I had known you all already for long time. Thank you all.

I would also like to say thanks to Ellen Stobberingh. A very nice and kind person, who would help you and support you without promulgating it. Thanks. 
The AIOS and AIO's. The hard workers. The great people. Former and current. Many thanks go to you all, including Guy, Michiel, Vishal, Robin, Elly, Michelle, Christel, Wendy, Ellen, Judith, Marijke, Giel, Chris, Danyta, Sander, Anne and Amita (hope I did not forget anybody's name). During last five years you guys have always been wonderful colleagues and friends. Especially Sander, Marijke, Anne, Michiel, Giel and Amita, thanks for your support.

And "special thanks" to Tanja, Fleur and Raymond. Though it is very hard for me to say something nice about you people but since you also happened to be my colleagues so I have to say something "nice" about you. Don't get wrong ideas, I am not going to apologize for teasing you all the time. But, thanks for being such nice friends to me. With your support, I passed through some difficult times. Tanja, thanks for your concerns and help. In fact, sometimes I felt that you were even more worried about me than I was myself. Thanks. Fleur, it was you I started talking to. Thanks for giving me that confidence. I would miss our coffees and long talks. Raymond, it's pity that we could never execute our plans of "patatje" business, otherwise we would have been billionaires by now. Oh, I remember, it was Fleur who stole our idea and worst thing is that she did not do anything with that. Thanks man. I will definitely miss our long stupid discussions and our stupid experiments. I look forward to seeing you in Pakistan someday.

Among AIO group, last but not the least are my roommates Casper, Carla, Charlotte and Birke. Here I have the same situation as I had in the previous paragraph but, I try to say something nice. My dear roommates, thanks for providing such a friendly and lively environment all the time. I really enjoyed the time we spent together. Casper, the statistician, the discoverer of salutations and the Santa, thanks for your help with statistics. Birke, Charlotte and Carla, though you did not join long ago but it feels like I know you all for long time. I find you all wonderful colleagues who are always ready to help. Thank you all. Carla, I would like to say special thanks to you for your contributions in my manuscripts and for helping me with my experiments.

Other than AIOS and AIO's, I have to say thanks to two wonderful ladies, Resi and Margriet. You both have always been very kind and supportive to me and I really appreciate that. Margriet, unfortunately, it was just one short course that we took together but I really enjoyed it. Thanks to both of you.

In the end I would like to express my sincere gratitude to all the colleagues in the whole department. Each and every one of you have been a great colleague. You have always been very nice, kind, supportive and friendly to me. And this was 
the reason that though being away from my family I had never missed them a lot. I would like to say thanks to the colleagues at voedingsbodem keuken (John and Ans, with always smiling face and ready to help), molecular diagnostics (Selma, Bart, Judith (1 \& 2), Katrien, Anita and Marco), bacteriology research (Christel, Jacqueline (1 \& 2), Mayk and Marie-Louise) and Will Muller. At secretary office, Fia, Angele, Frank and Jose who scanned a lot of documents for me. Angele, it would have been difficult to find convenient date of defense without you. Thanks. Also I would like to say thanks to the staff members including Petra, John, Frank van Tiel, Lieke, Marlies and the head of the department, professor dr. Paul Savelkoul for their help and support.

Now, a little bit about my family and friends from Pakistan. But first I would like to thank Higher Education Commission of Pakistan (HEC) for providing me the support for doing PhD in Nederlands.

Dr. Imran Hassan, dr. Nadeem Ali and dr. Toufeer Mehdi, my best friends. I know that you all know how much I value our friendship and how important all of you are to me. But I never acknowledged it. So I will say few words (ta keh sanand rahey.....). I feel myself really lucky that I have friends like you who have always been there for me. We have come a long way. It was a long journey and without your unconditional support, it would have never been possible. I am proud of calling you my friends and I am really thankful for everything you have done for me.

Now, last but not the least, my loving family. My parents, Abdul Ghanni Cheema and Jamila bibi, my grandmother Taliah bibi, my aunts and uncles especially, Nabi Ahmed Cheema, Ali Muhammad Sahi (late), and Abdul Ghafoor Cheema, my sisters and brother, all of my cousins and rest of the family members, I have no words which can express my feelings for all of you. Also no words can express my gratitude for everything all of you did for me and for everything all of you sacrificed for me. I am in deep debt to all of you. I am really thankful to you all. I would also like to say special thanks to Ali Raza Sahi (late) for being such a wonderful brother and friend. We all will miss you for the rest of our lives. May Allah bless you with jannah (Amen). 


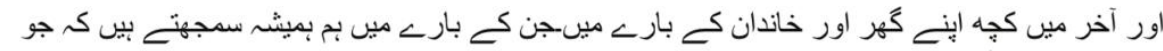

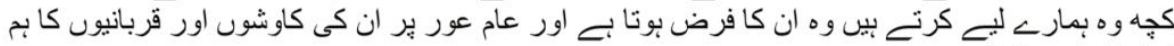

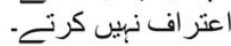

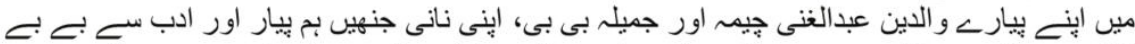

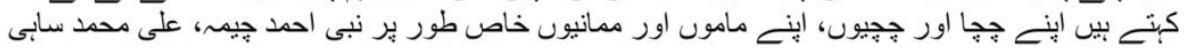

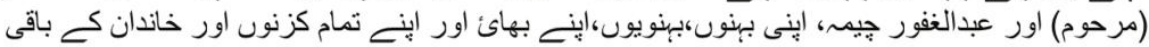

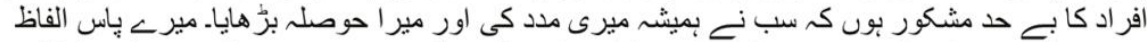

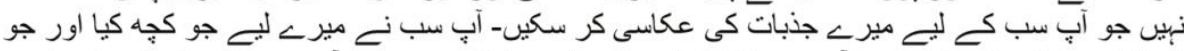

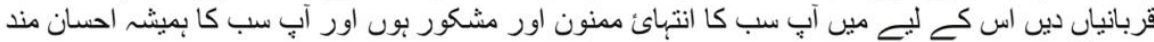
ربوب كا.

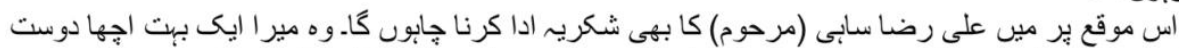

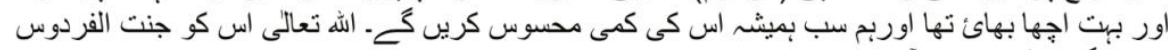

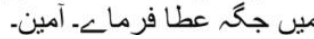




\section{Curriculum vitae}

Fahad Gulraiz was born on 21 February, 1980 in Rahim Yar Khan, Pakistan. In 2000, he started his undergraduate studies in veterinary sciences at the University of Agriculture Faisalabad, Pakistan and obtained his bachelor's degree in 2004. In the same year, he started his Master of Science in Veterinary Microbiology under the supervision of Prof. dr. Muhammad Siddique (late) at the same university and completed it in 2006. Title of his master's research thesis was "Sero-surveillance, isolation and characterization of Avian Influenza virus in commercial layer and broiler flocks in district Rahim Yar Khan". In October 2008, he joined department of Medical Microbiology at Maastricht University, the Netherlands and started his PhD under the supervision of Prof. dr. C.A. Bruggeman and Dr. F. Stassen. Results of his doctoral research are presented in this thesis. 


\section{List of publications}

Gulraiz F, Bellinghausen C, Dentener MA, Reynaert NL, Gaajetaan GR, et al. (2014) Efficacy of IFN-lambda1 to Protect Human Airway Epithelial Cells against Human Rhinovirus 1B Infection. PLoS One 9: e95134.

Gulraiz F, Grauls GE, Beuken EV, Bruggeman CA and Stassen FR. Effect of interferons on the inflammatory and antiviral response of macrophages and A549 in mono- and co-cultures.(under review in Immunology)

Gulraiz F, Bellinghausen C, Grauls GE, Beuken EV, Bruggeman CA and Stassen FR. Haemophilus influenzae increases the susceptibility and inflammatory response of airway epithelial cells to viral infections. (under review in FASEB journal)

Gulraiz F, Bellinghausen C, Beuken EV, Gaajetaan GR, Bruggeman CA and Stassen FR. Exogenous interferon- $\beta$ provides protection against rhinovirus infection even in cigarette smoke extract-exposed airway epithelial cells. (in preparation)

Geelen TH, Gulraiz F, Gaajetaan GR, Grauls GE, Bruggeman CA and Stassen FR. Macrophages enhances epithelial inflammatory responses to non-typeable Haemophilus influenzae via IL-1 signaling. (in preparation)

Bellinghausen C, Gulraiz F, Beuken EV, Rohde GG and Stassen FR. Comparison of use of different methods for the propagation and titration of Human Rhinovirus pools. (in preparation)

Hussain A, Shakoor, Shahid MA, Numan M and Gulraiz F. Clinical and Subclinical Staphylococcus aureus Mastitis in Dairy Buffaloes: Disease Characteristics and Antibiotic Susceptibility Profiles of Isolates. International Journal of Agricultural Research 2(9): 804-811, 2007. 


\section{Abstracts}

Gulraiz, F., Boelen, E., Walbers, S., Bruggeman, C., Steinbusch, H., \& Stassen, F. (2009, October). Production of inflammatory cytokines by murine microglial cells requires the presence of microRNA-155. In GLIA (Vol. 57, No. 13, pp. S146-S146).

F. Gulraiz, E. V. Beuken, G. G. Rohde, F. R. Stassen. Efficacy of IFN-[lambda]1 to protect human airway epithelial cells against rhinovirus 1B infection. Eur Respir J 2013; 42: Suppl. 57, 1884. 